Aus der Klinik für Psychosomatische Medizin und Psychotherapie (Prof. Dr. med. Christoph Herrmann-Lingen) der Medizinischen Fakultät der Universität Göttingen

\title{
Die Bedeutung der Coiled-coil- Domäne für die Inaktivierung des Transkriptionsfaktors STAT1
}

\author{
INAUGURAL-DISSERTATION \\ zur Erlangung des Doktorgrades \\ der Medizinischen Fakultät der \\ Georg-August-Universität zu Göttingen
}

\author{
vorgelegt von \\ Jana Petersen \\ aus \\ Wolfenbüttel
}

Göttingen 2019 
Dekan:

Referent/in

Ko-Referent/in:
Prof. Dr. rer. nat. H.K. Kroemer

Prof. Dr. med. Dr. phil. Dr. rer. nat. Thomas Meyer

Prof. Dr. rer. nat. Susanne Lutz

Datum der mündlichen Prüfung: 26.05 .2020 
Hiermit erkläre ich, die Dissertation mit dem Titel "Die Bedeutung der Coiledcoil-Domäne für die Inaktivierung des Transkriptionsfaktors STAT1" eigenständig angefertigt und keine anderen als die von mir angegebenen Quellen und Hilfsmittel verwendet zu haben.

Göttingen, den

(Unterschrift) 


\section{Inhaltsverzeichnis}

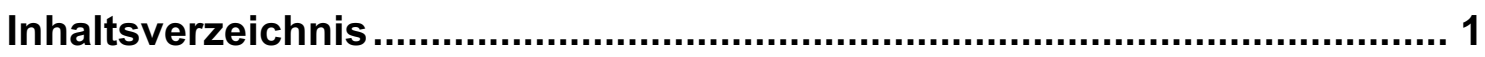

Abkürzungsverzeichnis........................................................................... 3

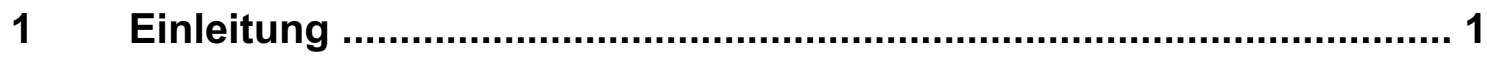

1.1 STAT-Proteine und deren modularer Domänenaufbau........................................1

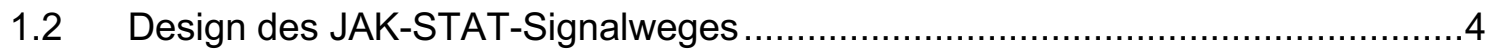

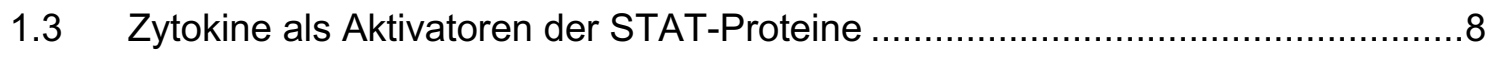

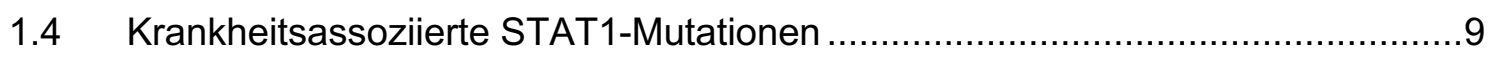

2 Material und Methoden .................................................................. 12

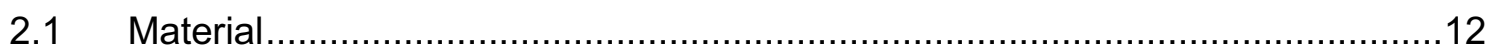

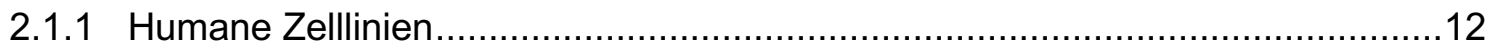

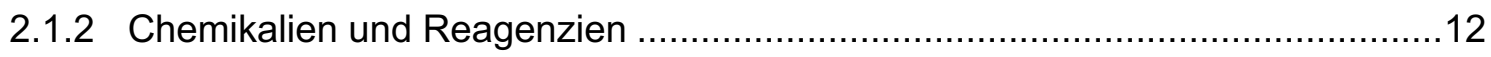

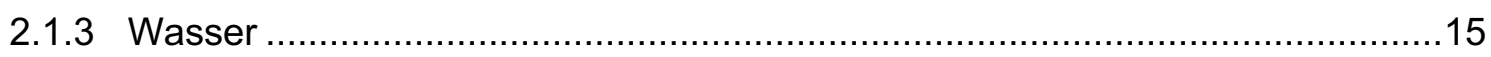

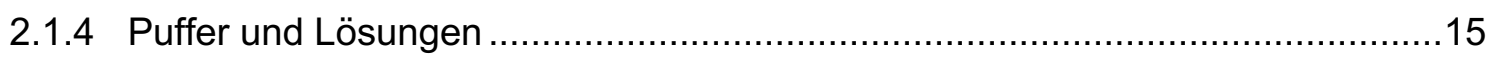

2.1.5 Enzyme, Plasmide und Zytokine ………………...................................18

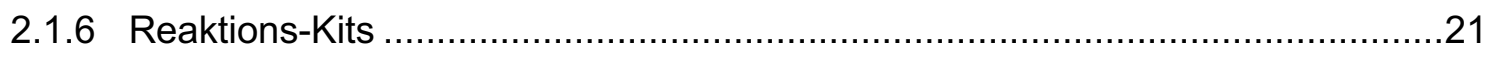

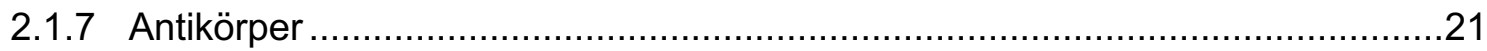

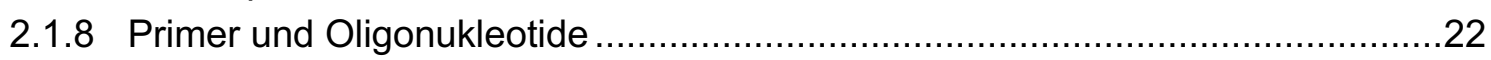

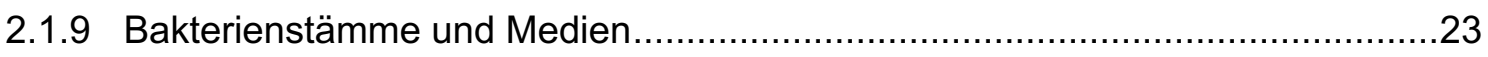

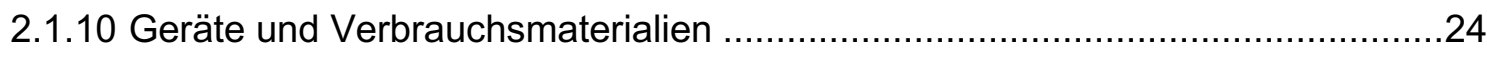

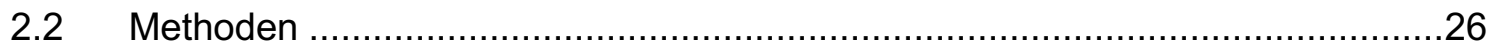

2.2.1 Kristallographische Darstellung des STAT1-Moleküls .....................................26

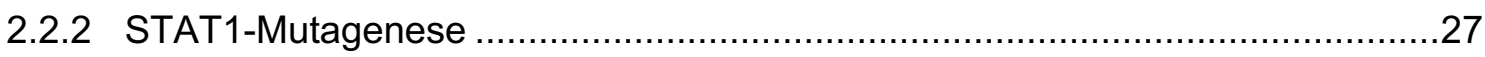

2.2.3 Isolation von Plasmid-DNA und Sequenzierung ……………………............28

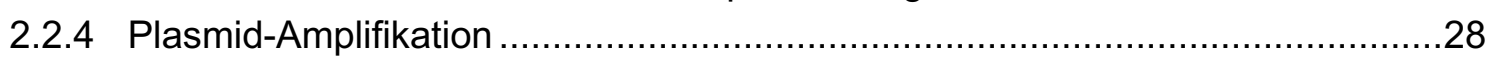

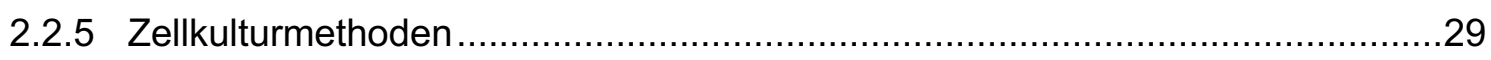

2.2.6 Transfektion von Säugerzellen ................................................................

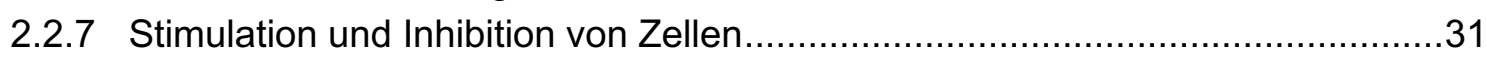

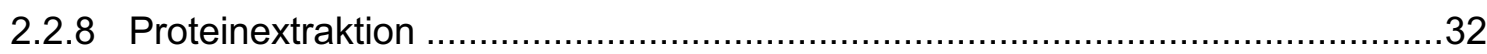

2.2.9 SDS-Polyacrylamid-Gelelektrophorese und Western-Blot-Analyse ...................33

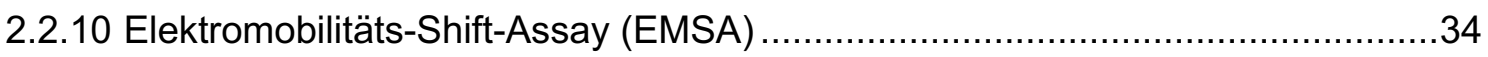

2.2.11 In-vitro-Phosphorylierungs- und Dephosphorylierungs-Assay ...........................35

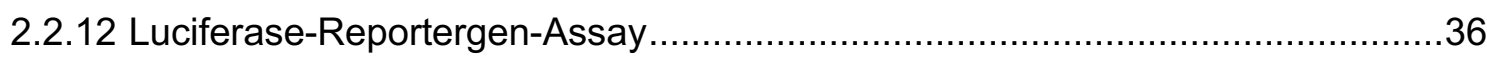

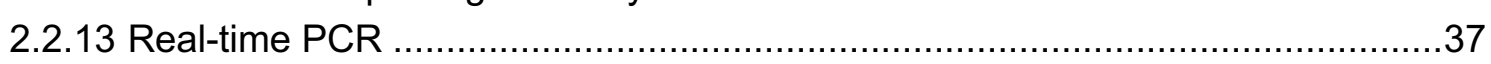

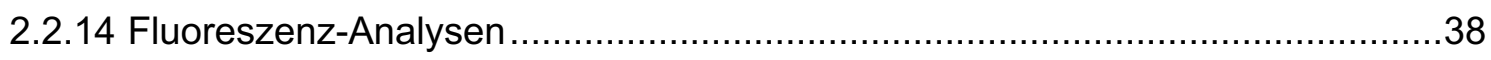

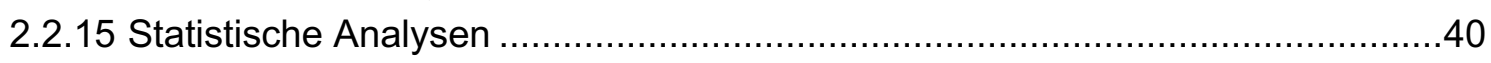


3 Ergebnisse

3.1 Charakterisierung von STAT1-R274, -Q275 und -K278 ..............................42

3.2 Klinische Verbesserung eines CMC-Patienten mit der STAT1-GOFMutation R274Q unter langfristiger Behandlung mit Ruxolitinib....

3.3 Erhöhtes Phosphorylierungsniveau von R274W und Q275A im Vergleich zu STAT1-WT

3.4 STAT1-GOF-Mutationen zeigen eine prolongierte DNA-Bindungsaktivität verglichen mit dem Wildtyp-Molekül

3.5 Verlängerte Kernakkumulation nach IFN $\gamma$-Stimulation der beiden Punktmutanten in der Coiled-coil-Domäne.

3.6 In-vitro-Phosphorylierungs- und Dephosphorylierungskinetik aller generierten STAT1-Varianten entspricht der des WT-Proteins

3.7 Erhöhte Aktivität im Reportergen-Assay von STAT1-R274W, Q275A und K278A.

3.8 STAT1-Punktmutanten im Vier-Helix-Bündel zeigen erhöhte Genexpression von IFN $\gamma$-induzierten Zielgenen.

4 Diskussion.

5 Zusammenfassung.

6 Literaturverzeichnis.

$7 \quad$ Danksagung 


\section{Abkürzungsverzeichnis}

\begin{tabular}{|c|c|}
\hline$A$ & Alanin \\
\hline APS & Ammoniumperoxodisulfat \\
\hline AS & Aminosäure \\
\hline AIRE & Autoimmun-Regulator \\
\hline$\beta-G a l$ & $\beta$-Galaktosidase \\
\hline $\mathrm{Bp}$ & Basenpaare \\
\hline BSA & bovines Serumalbumin \\
\hline CBP & CREB-bindendes Protein \\
\hline CCD & Coiled-coil-Domäne \\
\hline CCL2 & CC-Chemokin-Ligand 2 \\
\hline cDNA & komplementäre DNA \\
\hline CIS & cytokin inducible $\mathrm{SH} 2$-containing protein \\
\hline CREB & cAMP response element-binding protein \\
\hline CRM1 & chromosome region maintenance 1 \\
\hline DBD & DNA-Bindedomäne \\
\hline DMEM & Dulbecco's modifiziertes Eagle-Medium \\
\hline DMSO & Dimethylsulfoxid \\
\hline DNA & Desoxyribonukleinsäure \\
\hline dATP & Desoxyadenosintriphosphat \\
\hline dNTP & Desoxynukleosidtriphosphat \\
\hline DTT & Dithiothreitol \\
\hline$E$ & Glutaminsäure \\
\hline EDTA & Ethylendiamin-N,N,N',N'-tetraessigsäure \\
\hline EGTA & Ethylenglycol-bis-(2-aminoethylether)-N,N,N',N'-tetraessigsäure \\
\hline $\mathrm{EtOH}$ & Ethanol \\
\hline EMSA & Elektrophoretischer Mobilitäts-Shift-Assay \\
\hline $\mathrm{F}$ & Phenylalanin \\
\hline FCS & fetales Kälberserum \\
\hline
\end{tabular}


9

G

Erdbeschleunigung

GAPDH

Glycin

GAS

Glycerinaldehyd-3-phosphat-Dehydrogenase

GBP

Gamma-aktivierte Stelle

GFP

Guanylat-bindendes Protein

GOF

grünfluoreszierendes Protein

GTP

Gain-of-Function

HEPES

Guanosintriphosphat

IFN

$\mathrm{N}$-(2-Hydroxyethyl)-1-piperazino-ethansulfonsäure Interferon

IFNAR

Interferon- $\alpha / \beta$-Rezeptor

IFNGR

Interferon- $\gamma$-Rezeptor

IL

Interleukin

IRF1

IFN-regulatorischer Faktor

ISGF3

IFN-stimulierter Genfaktor 3

ISRE

IFN $\alpha$-stimulated response element

JAK

Janus-Kinase

$\mathrm{K}$

Lysin

$\mathrm{KCl}$

Kaliumchlorid

L

Leucin

LB

Luria-Broth

LD

Linker-Domäne

LOF

Loss-of-Function

$\mathrm{MeOH}$

Methanol

MHC

Haupthistokompatibilitätskomplex

MIG

Monokine induced by IFN $\gamma$

mRNA

messenger RNA (Boten-RNA)

$\mathrm{N}$-Terminus

Aminoterminus

ND

aminoterminale Domäne

NES

nukleäres Exportsignal

NLS

nukleäres Lokalisationssignal 


\begin{tabular}{|c|c|}
\hline NPC & nukleärer Porenkomplex \\
\hline ONPG & ortho-Nitrophenyl- $\beta$-D-Galactopyranosid \\
\hline PAGE & Polyacrylamid-Gelelektrophorese \\
\hline PBS & phosphatgepufferte Salzlösung \\
\hline PCR & $\begin{array}{l}\text { Polymerase-Kettenreaktion } \\
\text { (engl.: polymerase chain reaction) }\end{array}$ \\
\hline PIAS & $\begin{array}{l}\text { Protein-Inhibitor von aktiviertem STAT } \\
\text { (engl.: protein inhibitor of activated STAT) }\end{array}$ \\
\hline Poly-dldC & poly(deoxyinosinic-deoxycytidylic)acid \\
\hline pSTAT1 & STAT1-kodierendes pcDNA3.1-Plasmid \\
\hline pSTAT1-GFP & STAT1-kodierendes pEGFP-N1-Plasmid \\
\hline PTP1B & Protein-Tyrosin-Phosphatase 1B \\
\hline pTyr & Phosphotyrosin \\
\hline PVDF & Polyvinylidenfluorid \\
\hline Q & Glutamin \\
\hline $\mathrm{R}$ & Arginin \\
\hline RNA & Ribonukleinsäure \\
\hline rpm & $\begin{array}{l}\text { Umdrehungen pro Minute } \\
\text { (engl.: revolutions per minute) }\end{array}$ \\
\hline RT & Raumtemperatur \\
\hline RT-PCR & Real-time PCR \\
\hline S & Serin \\
\hline SDS & Natriumlaurylsulfat \\
\hline $\mathrm{SH} 2$ & Src-Homologie-2 \\
\hline SHP-1 & Protein-Tyrosin-Phosphatase 1 mit SH2-Domänen \\
\hline SHP-2 & Protein-Tyrosin-Phosphatase 2 mit SH2-Domänen \\
\hline socs & $\begin{array}{l}\text { Suppressor des Zytokin-Signalwegs } \\
\text { (engl.: suppressor of the cytokine signalling) }\end{array}$ \\
\hline STAT & Signaltransduktor und Aktivator der Transkription \\
\hline Stauro & Staurosporin \\
\hline $\mathrm{T}$ & Threonin \\
\hline T-Zelle & T-Lymphozyt \\
\hline TAD & Transaktivierungsdomäne \\
\hline
\end{tabular}




$\begin{array}{ll}\text { TBE } & \text { Tris-Borsäure-EDTA } \\ \text { TBS-T } & \text { Tris-gepufferte Salzlösung mit 0,05\% Tween } \\ \text { TC-PTP/TC45 } & \text { T-Zell-Protein-Tyrosin-Phosphatase } \\ \text { TEMED } & \text { N,N,N',N',-Tetramethylethylendiamin } \\ \text { Tris } & \text { Tris-(Hydroxymethyl)-Aminomethan } \\ \text { U } & \text { Einheiten } \\ \text { UV } & \text { ultraviolett } \\ \text { W } & \text { Tryptophan } \\ \text { WT } & \text { Wildtyp } \\ \text { Y } & \text { Tyrosin }\end{array}$




\section{$1 \quad$ Einleitung}

\subsection{STAT-Proteine und deren modularer Domänenaufbau}

STAT-Proteine (Signaltransduktoren und Aktivatoren der Transkription) sind eine Gruppe von Transkriptionsfaktoren, welche entscheidenden Einfluss auf immunologische, proliferative und zahlreiche weitere zelluläre Prozesse nehmen (Levy und Darnell 2002). Die präferentiell im Zytoplasma lokalisierten und einer kontinuierlichen nukleozytoplasmatischen Translokation unterworfenen STAT-Proteine werden durch Zytokinstimulation von Zellen aktiviert. Nach Bindung von Zytokinen an ihre Rezeptoren wird eine Reihe von posttranslationalen Proteinmodifikationen in Gang gesetzt, welche von Janus-Kinasen katalysiert werden und zu einer singulären Tyrosin-Phosphorylierung in STAT-Molekülen führen (Schindler und Darnell 1995; Levy und Darnell 2002). Zu den Mitgliedern der humanen STAT-Familie zählen STAT1, STAT2, STAT3, STAT4, STAT5a, STAT5b und STAT6. Sie haben jeweils eine Länge von 750-850 Aminosäuren mit einem Molekulargewicht von 80-113 kDa (Levy und Darnell 2002). Erstmals entdeckt wurde diese Proteinfamilie in den 1990er Jahren bei der Untersuchung der intrazellulären Signalkette von Interferonen (Schindler et al. 1992b; Levy und Darnell 2002). Seitdem wurden Komponenten im JAK-STAT-Signalweg in verschiedenen Organismen, wie Nematoden, Drosophila, dem Schleimpilz Dictyostelium sowie Vertebraten, charakterisiert (Yan et al. 1996; Kawata et al. 1997; Barillas-Mury et al. 1999; Liu et al. 1999; Oates et al. 1999; Pascal et al. 2001; Sung et al. 2003).

Transkriptionell aktive STAT-Proteine, wie das gut untersuchte STAT1-Molekül, bestehen aus einer aminoterminalen Domäne (ND), einem im Domänenaufbau konservierten Kernfragment und einer carboxyterminalen Transaktivierungsdomäne (TAD). Zum Kernfragment zählen eine DNA-Bindedomäne (DBD) gefolgt von einer Linker- (LD), einer Src-Homologie-2- (SH2D) und einer Coiled-coilDomäne (CCD), die auch als 4-Helix-Bündel bezeichnet wird (Darnell 1997; Levy und Darnell 2002). 
Die aminoterminale Domäne von STAT1 ist, wie auch bei den anderen Mitgliedern der STAT-Familie, vom Rest des Moleküls proteolytisch abspaltbar. Ihre Hauptaufgabe liegt in der Vermittlung von Protein-Protein-Interaktionen zwischen STAT1-Proteinen unter Ausbildung von Tetrameren. Eine stabile, kooperative DNA-Bindung ist durch Oligomerisierung von Tyrosin-phosphorylierten STAT1-Molekülen möglich (John et al. 1999). Durch den Austausch eines konservierten Phenylalanin-Rests an Position 77 nach Alanin kann das mutierte STAT1 zwar noch an DNA binden, die transkriptionelle Aktivität ist jedoch in Interferon- $\gamma($ IFN $\gamma$ )-stimulierten Zellen vermindert (Begitt et al. 2008; Meyer et al. 2004). Weiterhin ist die aminoterminale Domäne an der Stabilisierung einer antiparallelen Konformation beteiligt (Chen et al. 2003; Meyer et al. 2004; Mao et al. 2005; Mertens et al. 2006).

Die aus gut 100 Aminosäuren bestehende SH2-Domäne ist die am stärksten konservierte Domäne der STAT-Proteine. Sie vermittelt die Bindung der Moleküle an phosphorylierte membranständige Rezeptoren oder intrazellulär gelegene Tyrosin-Kinasen (Shuai et al. 1994). Weiterhin spielt sie eine wichtige Rolle für die Interaktion zweier STAT-Monomere. Stabilisiert durch reziproke Phosphotyrosin-Wechselwirkungen, können nach IFN-Stimulation sowohl Homo- als auch Heterodimere gebildet werden (Chen et al. 1998; Shuai et al. 1993b; Shuai et al. 1994). IFN $\gamma$-Stimulation resultiert beim STAT1-Molekül in der Ausbildung stabiler Homodimere (Darnell et al. 1994; Wenta et al. 2008). Hierbei erkennt ein Argininrest in Position 602 der SH2-Domäne des einen STAT1Monomers den Phosphotyrosinrest des kontralateralen Monomers in Position 701 (Chen et al. 1998; Shuai et al. 1994). Im Unterschied dazu kommt es nach Stimulation mit IFN $\alpha$ neben STAT1-Homodimeren zur Bildung von STAT1/2Heterodimeren. Zusammen mit p48 bildet sich hierbei ein hetero-trimerer Komplex, genannt ISGF3 (IFN-stimulierter Genfaktor 3) (Darnell et al. 1994).

Die DNA-Bindedomäne eines STAT1-Moleküls besteht aus 172 Aminosäuren. Der Aufbau aus mehreren ß-Faltblättern und Schleifen ähnelt dem von Immunglobulinen, wobei die Struktur besondere Ähnlichkeiten zu der DBD des Transkriptionsfaktor NF-kB und des Tumorsuppressorproteins p53 aufweist (Bork et al. 1994; Chen et al. 1998). Über einen konservierten Bereich innerhalb der Aminosäurereste 400-500 ist eine präzise Bindung an palindromische DNASequenzen möglich, wobei die spezifischen Aminosäurereste eines jeden Pro- 
tomers eine halbe palindromische GAS-Bindestelle (Gamma-aktivierte Stelle) mit der Sequenz 5'-TTC(N) 3-4GAA-3' kontaktieren (Decker et al. 1997; Chen et al. 1998). Eine Mutation an Position 460 führt zu reduzierter DNA-Affinität (Horvath et al. 1995; Darnell 1997; Yang et al. 2002). Das Karyopherin Importin$\alpha 5$ bindet an das nukleäre Lokalisationssignal in der DNA-Bindedomäne und transportiert im Komplex mit weiteren Importfaktoren phosphorylierte STAT1Dimere in den Zellkern (Fagerlund et al. 2002; McBride 2002; Meyer et al. 2002). Damit das Signal für das Importin- $\alpha 5$-Molekül zugänglich ist, müssen die beiden STAT1-Protomere in paralleler Konfiguration zueinander vorliegen (Zhong et al. 2005). Der Begriff parallel bezieht sich hierbei auf die Ausrichtung der SH2-Domänen zweier interagierenden Protomere, welche in die gleiche Richtung zeigen und über reziproke Wechselwirkungen mit dem Phosphotyrosinrest des Partnerprotomers die parallele STAT1-Dimer-konfiguration stabilisieren (Shuai et al. 1994).

Die Linker-Domäne schafft eine Verbindung zwischen der DNA-Bindedomäne und der SH2-Domäne (Chen et al. 1998). Die Funktionen der Linker-Domäne sind zu Teilen noch unbekannt, doch wird ihr eine Einflussnahme auf die DNABindung und transkriptionelle Aktivität von STAT1-Proteinen zugeschrieben (Yang et al. 1999; Yang et al. 2002; Hüntelmann et al. 2014).

Wie auch die aminoterminale Domäne ist die carboxyterminale Transaktivierungsdomäne an Protein-Protein-Interaktionen beteiligt. Über diese Domäne ist eine Bindung an transkriptionelle Co-Aktivatoren wie das CREB-bindende Protein/p300 (Zhang et al. 1996) sowie an das Tumorsuppressorprotein BRCA1 (Ouchi et al. 2000), das in der DNA-Replikation involvierte MCM5-Protein (Zhang et al. 1998) und, im Falle des STAT6-Moleküls, an NCoA1 möglich (Litterst und Pfitzner 2001). Im STAT1-Molekül befindet sich darüber hinaus an Position 701 in dieser Domäne ein kritischer Tyrosinrest, welcher durch JanusKinasen phosphoryliert werden kann und für die transkriptionelle Aktivität des Proteins eine entscheidende Rolle spielt (Schindler et al. 1992a; Shuai et al. 1992). Ein weiterer, für die maximale transkriptionelle Aktivität wichtiger Serinrest befindet sich an Position 727. Durch alternatives Spleißen entstehen zwei Isoformen von STAT1, nämlich STAT1- $\alpha$ und STAT1- $\beta$. Die höher-molekulare Isoform STAT1- $\alpha$ wird durch Kinasen an Position 727 phosphoryliert und erlangt somit die maximale transkriptionelle Aktivität (Wen et al. 1995; Darnell 
1997). Der transkriptionell inaktiven $\beta$-Form fehlt dieser Rest (Darnell et al. 1994; Darnell 1997) und wie Experimente an B-Lymphozyten bestätigen, kann die inaktive Form als Inhibitor der $\alpha$-Form agieren (Walter et al. 1997; BaranMarszak 2004).

Die Coiled-coil-Domäne von STAT1 besteht aus vier antiparallelen $\alpha$-Helices (Levy und Darnell 2002). Biochemische Experimente aus dem Darnell-Labor konnten Hinweise auf eine physiologische Bedeutung einer antiparallelen Dimer-Konformation von STAT1 erbringen (Zhong et al. 2005; Mertens et al. 2006). Im Unterschied zu der parallelen Konformation zeigen in der KristallStruktur des antiparallelen Konformers die SH2-Domänen in entgegengesetzte Richtungen, wobei eine Interaktionsfläche zwischen der Coiled-coil-Domäne des einen Protomers und der DNA-Bindedomäne des Partnerprotomers entsteht, die zur Stabilisierung dieses Komplexes beiträgt. In dieser Konformation kann das STAT1-Dimer durch eine spezifische nukleäre Phosphatase dephosphoryliert und anschließend aus dem Zellkern ins Zytoplasma exportiert werden (Mao et al. 2005; Zhong et al. 2005; Mertens et al., 2006; Wenta et al. 2008). Darüber hinaus befindet sich in dem 4-Helix-Bündel ein leucinreiches nukleäres Exportsignal (NES) (Begitt et al. 2000).

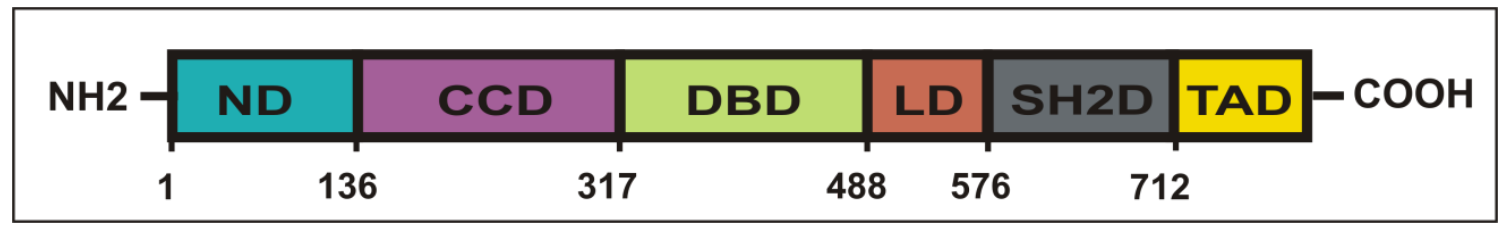

Abb. 1: Domänenstruktur des Transkriptionsfaktors STAT1. Die sechs funktionellen Domänen setzen sich aus einem aus vier Domänen bestehenden Kernfragment mit der Coiled-coilDomäne (CCD), DNA-Bindedomäne (DBD), Linker-Domäne (LD) und Src-Homologie-2Domäne (SH2) sowie aus zwei terminalen Domänen zusammen, bestehend aus der aminoterminalen Domäne (ND) und der carboxyterminalen Transaktivierungsdomäne (TAD).

\subsection{Design des JAK-STAT-Signalweges}

Die Aktivierung der STAT-Proteine erfolgt über den JAK-STAT-Signalweg, welcher zu den am besten untersuchtesten Transduktionswegen zählt (Darnell et al. 1994). Extrazellulär sezernierte Zytokine binden an ihren jeweiligen Transmembranrezeptor, wodurch Untereinheiten des Rezeptors dimerisieren und nicht-kovalent assoziierte Janus-Kinasen autophosphoryliert werden (Darnell et 
al. 1994; Schindler und Darnell 1995). Die Zytokinrezeptoren, wie beispielsweise der IFN $\gamma$-Rezeptor, bestehen aus einer ligandenbindenden extrazellulären, einer transmembranösen und einer intrazellulär gelegenen carboxyterminalen Domäne (Bach et al. 1997). Die phosphorylierten und somit aktivierten JanusKinasen führen zu einer Phosphorylierung von Tyrosinresten im intrazellulären Teil des Rezeptors, wodurch Andockstellen für STAT-Proteine entstehen. Die Janus-Kinasen sind ein essentieller Bestandteil dieser Kaskade, da der Zytokinrezeptor keine intrinsische Tyrosin-Kinaseaktivität besitzt. Die Rekrutierung der STAT-Moleküle mit Bindung an die phosphorylierten Andockstellen im Rezeptorschwanz erfolgt über deren SH2-Domäne (Darnell et al. 1994; Greenlund et al. 1995). Daraufhin erfolgt die Phosphorylierung der STATs durch JanusKinasen an einem invariablen und hochkonservierten Tyrosinrest in der carboxyterminalen Transaktivierungsdomäne (Shuai et al. 1993a). Beim STAT1Protein führt diese Phosphorylierung an Position Y701 nach Stimulation der Zelle mit IFN $\gamma$ zur Ausbildung von parallel angeordneten Homodimeren, die innerhalb kurzer Zeit in den Nukleus transloziert werden (Schindler et al. 1992a; Shuai et al. 1992; Shuai et al. 1993a; Shuai et al. 1994). Dort induziert der Transkriptionsfaktor die Expression von IFN $\gamma$-abhängigen Zielgenen über die Bindung an GAS-Stellen (Shuai et al. 1992; Darnell et al. 1994;). IFNo-Stimulation führt nach Ausbildung des ISFG3-Komplex und Translokation in den Zellkern ebenfalls zur Bindung an spezifische DNA-Sequenzen, jedoch in diesem Fall an ISRE-Stellen (IFN $\alpha$-stimulated response element) (Darnell 1997; Horvath 2000). 


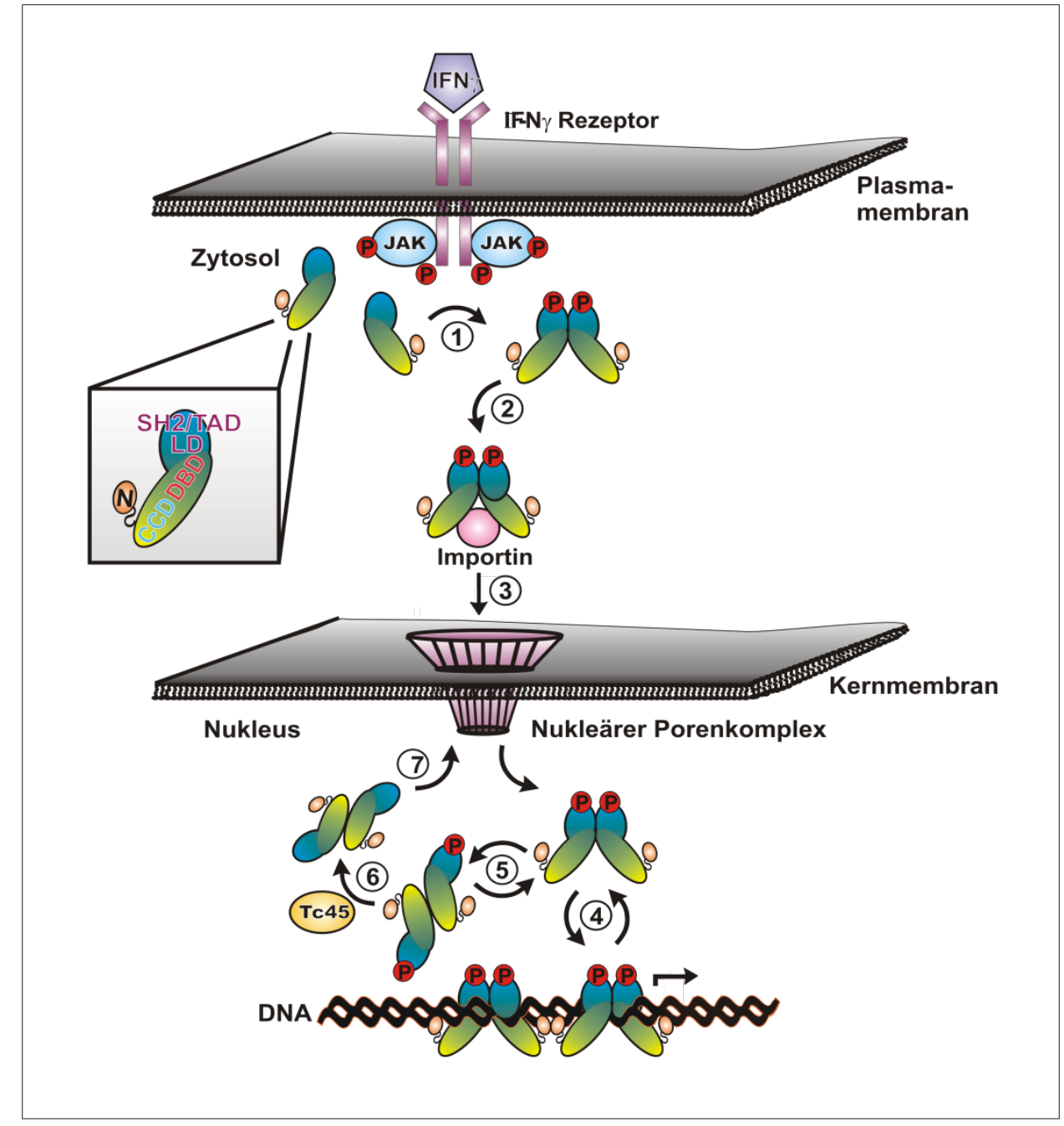

Abb. 2: Aktivierungs- und Inaktivierungszyklus von STAT1. Darstellung des JAK-STATSignalwegs nach IFN $\gamma$-Stimulation. Das Zytokin bindet an seinen Rezeptor und setzt die intrazelluläre Dimerisierung zweier Rezeptoruntereinheiten in Gang. Tyrosin-Phosphorylierung von STAT1 durch aktivierte JAK-Kinasen (1) und Ausbildung eines phosphorylierten, parallelen STAT1-Dimers (2), Importin- $\alpha 5$ bindet an das in der DBD gelegene NLS und es kommt zur Translokation von dimerisiertem STAT1 in den Zellkern (3), transkriptionell aktives STAT1 bindet an palindrome DNA-Sequenzen unter Ausbildung von Tetrameren (4), Shift von parallel zu antiparallel Konformation nach DNA-Dissoziation (5), TC45-katalysierte Dephosphorylierung (6) und nukleärer Export des dephosphorylierten STAT1 (7)

Der JAK-STAT-Signalweg spielt eine Rolle für die Induktion zellulärer Antworten nach Stimulation durch Interferone, Interleukine und Wachstumsfaktoren (Darnell et al. 1994; Williams 1999; Levy und Darnell 2002). Mittels Negativregulation wird eine dauerhafte Zielgenaktivierung oder Fehlregulationen verhindert. Eine hierfür wichtige zytoplasmatische Protein-Familie sind die aus sieben Mitgliedern bestehenden SOCS-Proteine (suppressors of cytokine signaling), welche eine STAT-Aktivierung durch Inhibition der katalytischen Region von 
JAKs oder über die Bindung an phosphorylierte Zytokinrezeptoren verhindern, wobei letzteres über die zu dieser Proteinfamilie gehörenden CIS-Proteine (cytokine-inducible SH2-domain-containing protein) geschieht (Starr und Hilton 1999; Levy und Darnell 2002; Rawlings et al. 2004). SOCS1 und SOCS3 hemmen die aktivierten JAKs über ihre $\mathrm{N}$-terminale Domäne, indem sie als Pseudosubstrat der katalytischen Region der JAKs fungieren und somit deren Aktivität herabsetzen (Starr und Hilton 1999; Krebs und Hilton 2001). Des Weiteren kommen im Zytoplasma die Tyrosin-Phosphatasen SHP-1 (SH2-containing phosphatase), SHP-2 und PTP1B (protein tyrosine phosphatase 1B) als Inhibitoren zum Einsatz. Sie erleichtern die Dephosphorylierung von Janus-Kinasen oder aktivierten Zytokinrezeptoren (Levy und Darnell 2002; Rawlings et al. 2004). Im Zellkern spielen nukleäre Phosphatasen und mehrere PIAS-Proteine (protein inhibitor of activated STAT) eine entscheidende Rolle für die STATNegativregulierung (Haspel und Darnell 1999; Starr und Hilton 1999). Nach Dissoziation von der DNA werden STAT1-Dimere durch die für dieses Molekül spezifische T-Zell-Protein-Tyrosin-Phosphatase 45 (TC45) dephosphoryliert und somit inaktiviert (Haspel et al. 1996; Haspel und Darnell 1999; ten Hoeve et al. 2002; Meyer et al. 2003). Nach Entfernung des Phosphotyrosinrests führt die Bindung des in der CCD-lokalisiertem Exportsignals an CRM-1 (chromosome region maintanance) und anschließende Kontaktaufnahme mit einem nukleären Porenkomplex (NPC) zur Ausschleusung des STAT1-Dimers (Mattaj und Englmeier 1998; Begitt et al. 2000; Meyer et al. 2003). Die nötige Energie für diesen Prozess wird durch eine Ran-abhängige GTPase bereitgestellt (Fornerod et al. 1997; Mattaj und Englmeier 1998; Kudo et al. 1999).

Genau wie der CRM1-vermittelte Export ist auch der Transport von phosphorylierten STAT1-Dimeren in den Nukleus energieabhängig, da parallel angeordneten Protomere mit einem Molekulargewicht von 180kDA zu groß sind, um die Kernmembran über freie Diffusion passieren zu können (Mattaj und Englmeier 1998; Weis 1998; Meyer und Vinkemeier 2004). In einem ersten Schritt binden die phosphorylierten Dimere an Importin- $\alpha 5$ (Sekimoto et al. 1997; Fagerlund et al. 2002; McBride et al. 2002; Nardozzi et al. 2010b), ein zur Gruppe der Karyopherine gehörender Transportadapter, bestehend aus $\alpha$-Helices, den sogenannten Armadillo-Repeats (Nardozzi et al. 2010). Importin- $\alpha 5$ liegt im Komplex mit Importin- $\beta$ vor, wobei Importin- $\beta$ mit einer energieliefernden Ran- 
abhängigen GTPase und Nukleoporinen in der Zellmembran interagiert. Anschließend gelangt das Dimer über einen aktiven Transportmechanismus in den Nukleus (Mattaj und Englmeier 1998; Görlich und Kutay 1999). Unphosphoryliertes STAT1 liegt im Zytoplasma als Monomer oder antiparalleles Dimer vor. Es gelangt auch ohne vorherige Zytokinstimulation durch einen energieunabhängigen Prozess stetig in den Zellkern und wieder hinaus (Meyer et al. 2002; Marg et al. 2004).

\subsection{Zytokine als Aktivatoren der STAT-Proteine}

Bei Zytokinen handelt es sich um extrazellulär gelegene Glykoproteine mit einer Länge von 100-200 Aminosäuren. Wachstumsfaktoren, Interleukine (IL), Chemokine und Interferone gehören zur Familie dieser Botenstoffe (Schooltink und Rose-John 2002). Interferone spielen eine wichtige Rolle in immunmodulatorischen und antiproliferativen Prozessen. Unterschieden werden Typ-I- (IFN $\alpha$, IFN $\beta$, IFN $\varepsilon$, IFN $\kappa$, IFN $\omega$ ) und Typ-II-Interferone (IFN $\gamma$ ) (Platanias 2005). Die Typ-II-Interferone, zu denen lediglich IFN $\gamma$ zählt, besitzen eine breite antimikrobielle Wirkungsweise (Dupuis 2001; Chapgier et al. 2006a). Sie sind auf Chromosom 12 lokalisiert und binden an ihren eigenen IFN $\gamma$-Rezeptor (IFNGR). Der Rezeptor besteht aus den zwei Untereinheiten IFNGR1/IFNGR2, wobei IFNGR1 mit JAK1 und IFNGR2 mit JAK2 interagiert. Er wird an der Oberfläche sämtlicher kernhaltiger Zellen, ausgenommen den Erythrozyten, exprimiert (Langer und Pestka 1988). Da die Bindung von IFN $\gamma$ an seinen Rezeptor zur Aktivierung des JAK-STAT-Signalwegs und Translokation von STAT1 in den Zellkern mit anschließender Transkription von Zielgenen führt, können Mutationen im STAT1-Molekül zu einer überschießenden oder gehemmten Immunantwort mit Folgen für den Organismus führen (Boisson-Dupuis et al. 2012). Die Transkription des Zytokins selbst erfolgt in aktivierten T-Zellen und natürlichen Killerzellen. Über IFN $\gamma$ werden verschiedene Aspekte des Immunsystems reguliert, einschließlich der Stimulation von Phagozyten und antigenpräsentierenden Zellen über den Major-Histokompatibilitätskomplex I und II (MHC I und MHC II) (Boehm et al. 1997)

Mitglieder der Typ-I-Interferone werden durch natürliche Killerzellen aktiviert und besitzen antivirale Eigenschaften. Sämtliche kernhaltige Zellen exprimieren 
auf ihrer Oberfläche einen gemeinsamen Typ-I-Zytokinrezeptor, welcher wie schon im Falle von IFN $\gamma$ aus zwei, jedoch anderen Untereinheiten besteht: IFNAR1 und IFNAR2. Die Transkription erfolgt in virusinfizierten Leukozyten und Fibroblasten (Chang et al. 1992; Platanias 2005). Typ I und II Interferone sind in der Lage die Genexpression des MHC-I-Komplexes über einen von IRF-1 (Interferon-regulierter Faktor 1) abhängigen Mechanismus einzuleiten (Chang et al. 1992).

\subsection{Krankheitsassoziierte STAT1-Mutationen}

STAT1 spielt als Transkriptionsfaktor eine entscheidende Rolle im Signalweg von IFN $\alpha / \beta$ und IFN $\gamma$, um die Expression von Zielgenen zu ermöglichen. Mutationen im STAT1-Protein führen zu unterschiedlichen Krankheitsentitäten, die entweder autosomal rezessiv oder autosomal dominant vererbt werden (Boisson-Dupuis et al. 2012). Autosomal rezessiv vererbte Loss-of-FunctionMutationen (LOF) im STAT1-Protein mit Defekten im STAT1-Signalweg führen bei betroffenen Patienten zu erhöhten Prävalenzen und verstärkten Reaktionen auf Infektionen mit Herpes-Viren und Mykobakterien. Das vermehrte Auftreten von mykobakteriellen Infektionen lässt sich durch eine fehlerhafte IFN $\gamma$-Antwort erklären, die Anfälligkeit für Herpes-Infektionen durch eine eingeschränkte IFN $\alpha / \beta$-Antwort (Dupuis et al. 2003; Chapgier et al. 2009; Kong et al. 2010; Kristensen et al. 2011). Neben einem autosomal rezessiven Erbgang gibt es LOF-Mutationen, die autosomal dominant vererbt werden und bei den Betroffenen gehäuft zu mykobakteriellen Infektionen führen. Diese können bereits durch schwach virulente Erreger ausgelöst werden. Das seltene Immundefizienzsyndrom Mendelian Susceptibility to Mycobacterial Disease kann bei den Patienten beispielsweise bereits durch eine BCG-Impfung oder nichttuberkulöse Mykobakterien (environmental mycobacteria) hervorgerufen werden (Dupuis 2001; Casanova und Abel 2002; Chapgier et al. 2006b).

Autosomal-dominant vererbbare heterozygote Gain-of-Function(GOF)-Mutationen im Stat1-Gen führen bei Betroffenen vermehrt zu bakteriellen Infektionen, hauptsächlich ausgelöst durch Staphylococcus aureus. Weiterhin kann es zu Autoimmunkrankheiten und zum Krankheitsbild der invasiv oder chronisch mukokutanen Candidose (CMC) kommen (Liu et al. 2011; van de Veerdonk et 
al. 2011; Depner et al. 2016; Toubiana et al. 2016). CMC-Patienten leiden unter schwerem Candida-albicans-Befall, wobei der Pilz Schleimhäute wie die Mundhöhle und Genitalien befällt. Darüber hinaus können Nägel und Haut betroffen sein (Spellberg et al. 2006; Puel et al. 2010b). Neben Aminosäureaustauschen im STAT1-Molekül gelten Mutationen im STAT3-Gen (Minegishi et al. 2007; de Beaucoudrey et al. 2008; Ma et al. 2008; Milner et al. 2008; Renner et al. 2008), IL-12B, IL12RB1 (de Beaucoudrey et al. 2008) oder AIRE (AutoimmunRegulator) (Kisand et al. 2010; Puel et al. 2010a) als Auslöser dieses Krankheitsbildes. Ebenfalls zum Ausbruch von CMC kann es bei dem polyendokrinen Autoimmunsyndrom (PAS) Typ 1 kommen, bei dem betroffene Patienten hohe Titer an neutralisierenden Autoantikörpern gegen IL-17A, IL-17F und IL-22 (Kisand et al. 2010; Puel et al. 2010b) aufweisen, oder dem Hyper-lgESyndrom, bei dem dominant-negative Mutationen im STAT3-Protein zu einer gestörten Entwicklung von IL-17 produzierenden T-Zellen führen (Minegishi et al. 2007; de Beaucoudrey et al. 2008; Ma et al. 2008; Milner et al. 2008; Renner et al. 2008; Hiller et al. 2018).

Das Vorliegen einer GOF-Mutation im Transkriptionsfaktor STAT1 führt zu einer gesteigerten Expression von IFN $\alpha / \beta$ und IFN $\gamma$-stimulierten Zielgenen (Liu et al. 2011; Takezaki et al. 2012; Soltész et al. 2013). Dadurch wird Einfluss auf die Differenzierung von T-Helfer (TH) 17-Zellen (Liu et al. 2011; Takezaki et al. 2012; Soltész et al. 2013) und TH-22-Zellen (Hiller et al. 2018) genommen, wodurch die Konzentration von IL-17 vermindert und die Anfälligkeit für Candida-albicans-Infektionen gesteigert wird (Puel et al. 2010a; Puel et al. 2010b; Puel et al. 2012). Im Jahr 2011 wurden bei 47 CMC-Patienten heterozygote GOF-Mutationen durch Exonsequenzierung beschrieben (Liu et al. 2011). In den folgenden Jahren fanden bei weiteren betroffenen Patienten Mutationsanalysen im STAT1-Protein statt. In einer aktuellen Studie von Depner und Kollegen wurden insgesamt acht bereits als CMC-Auslöser bekannte STAT1Mutationen im Genom der Patienten identifiziert (M202V, A267V, R274W, R274Q, T385M und K388E, N397D und F404Y) und fünf weitere, bis dahin unbekannte Mutationen entdeckt (F172L, Y287D, P293S, T385K und S466R). Bemerkenswerterweise sind die meisten der genannten Mutationen in der Coiled-coil-Domäne und einige in der DNA-Bindedomäne des STAT1-Moleküls lokalisiert (Depner et al. 2016). Diese zwei Domänen stabilisieren im nicht- 
mutierten Protein die Formierung und Stabilität der antiparallelen DimerKonformation (Mao et al. 2005).

Ein an der Universitätsmedizin Göttingen behandelter Patient leidet unter CMC mit den klassischen Symptomen wie Schluckstörungen durch ulzerierende Mukositis. Nach genetischem Screening wurde die Substitutionsmutante R274Q in der STAT1-Coiled-coil-Domäne bei dem Patienten identifiziert (Mössner et al. 2016). Vor Kurzem konnte durch Fujiki und Kollegen gezeigt werden, dass diese krankheitsassoziierte Mutation in einer erhöhten Tyrosin-Phosphorylierung und gesteigerten transkriptionellen Aktivität resultiert, das Repertoire an Zielgenen durch diese Punktmutation jedoch nicht verändert wird (Fujiki et al. 2017). Der genaue molekulare und pathogenetisch bedeutsame Mechanismus der Mutante R274Q ist dennoch nicht ausreichend entschlüsselt. Es ist unklar, ob die Hyperphosphorylierung der Punktmutante möglicherweise durch eine veränderte Phosphorylierungskinetik der JAK-Kinase hervorgerufen wird oder ob der Prozess der Inaktivierung durch verminderte Interaktion mit der TC45Phosphatase gestört ist. Darüber hinaus ist nicht bekannt, ob die Kernakkumulation von STAT1 nach Austausch des Argininrestes an Position 274 beeinflusst wird. Staab und Kollegen haben bereits die in der DBD-lokalisierten und ebenfalls hyperphosphorylierten Substitutionsmutanten T385A und F364A genauer charakterisiert und zeigen können, dass die Stabilität des antiparallelen STAT1Dimers nach Austausch der Aminosäuren an den Positionen 385 und 364 durch Alanin herabgesetzt ist. Dies führt zu einer partiellen Resistenz gegenüber der Inaktivierung durch die TC45-Phosphatase (Staab et al. 2013b; Staab et al. 2013a).

In dieser Arbeit soll eine gezielte Charakterisierung der GOF-Mutante R274W und zweier benachbarten Punktmutanten in der Coiled-coil-Domäne im Hinblick auf Kernakkumulation, DNA-Bindung, Interaktion mit der nukleären TC45Phosphatase und Rezeptoraktivierung erfolgen, um den molekularen Mechanismus dieser krankheitsassoziierten Mutationen genauer zu entschlüsseln. 


\section{Material und Methoden}

\subsection{Material}

\subsubsection{Humane Zelllinien}

In dieser Arbeit wurden zwei Zelllinien verwendet, bereitgestellt von Prof. Dr. Uwe Vinkemeier, Universität Nottingham. HeLa-S3-Zellen bezeichnen humane Epithelzellen eines Zervix-Adenokarzinoms. Bei der zweiten Zelllinie handelt es sich um STAT1-defiziente Zellen, entstanden aus der humanen FibrosarkomZelllinie $2 \mathrm{fTHG}$.

\subsubsection{Chemikalien und Reagenzien}

\begin{tabular}{l|l}
\hline $\begin{array}{l}\left.{ }^{33} \mathrm{P}\right] \text {-Desoxyadenosintriphosphat } \\
(\mathrm{dATP})\end{array}$ & Hartmann Analytic, Braunschweig \\
\hline 10x Eco-Pol-Puffer & New England Biolabs, Ipswich, UK \\
\hline Agar & Carl Roth, Karlsruhe \\
\hline Ammoniumperoxiddisulfat (APS) & Carl Roth \\
\hline Ampicillin & Sigma-Aldrich, Taufkirchen \\
\hline Borsäure & Amersham Pharmacia Biotech, Frei- \\
\hline Bovines Serumalbumin (BSA) & burg \\
\hline Bromphenol-Blau & Carl Roth \\
\hline Buraton 10 F & Sigma-Aldrich \\
\hline Complete-Mini-Protease-Inhibitoren & Roche, Rotkreuz, Schweiz \\
\hline Dimethylsulfoxid (DMSO) & Carl Roth \\
\hline di-Natriumhydrogenphosphat- & Carl Roth \\
\hline Dihydrat & \\
\hline
\end{tabular}




\begin{tabular}{|c|c|}
\hline Dithiothreitol (DTT) & AppliChem, Darmstadt \\
\hline Ethanol & Carl Roth \\
\hline $\begin{array}{l}\text { Ethylendiamin-N,N,N',N'- } \\
\text { tetraessigsäure (EDTA) }\end{array}$ & Sigma-Aldrich \\
\hline $\begin{array}{l}\text { Ethylenglycol-bis-(2- } \\
\text { aminoethylether)- }\end{array}$ & Carl Roth \\
\hline$N, N, N^{\prime}, N^{\prime}$-tetraessigsäure (EGTA) & \\
\hline Fetales Kälberserum & Biochrom, Berlin \\
\hline Ficoll-Paque Plus & Amersham Bioscience, Freiburg \\
\hline Fluoromount G & SouthernBiotech, Birmingham, USA \\
\hline Formaldehyd $37 \%$ in $\mathrm{H}_{2} \mathrm{O}$ & Carl Roth \\
\hline Glukose & Carl Roth \\
\hline Glycin & Carl Roth \\
\hline Glycerin & Carl Roth \\
\hline Glycylglycin & Sigma-Aldrich \\
\hline $\begin{array}{l}\text { N-(2-Hydroxyethyl)-1-piperazino- } \\
\text { ethansulfonsäure (HEPES) }\end{array}$ & Carl Roth \\
\hline Hefeextrakt & Carl Roth \\
\hline Hoechst 33258 & Sigma-Aldrich \\
\hline IGEPAL-CA-360 & Sigma-Aldrich \\
\hline Isopropanol & Carl Roth \\
\hline Kaliumchlorid & Merck Millipore, Darmstadt \\
\hline Kaliumdihydrogenphosphat & Carl Roth \\
\hline Kaliumhydroxid & Carl Roth \\
\hline Kanamycin & Sigma-Aldrich \\
\hline Magnesiumchlorid-6-hydrat & Sigma-Aldrich \\
\hline Magnesiumsulfat & Carl Roth \\
\hline MegaTran 1.0 & Origene, Rockville, USA \\
\hline
\end{tabular}




\begin{tabular}{|c|c|}
\hline ß-Mercaptoethanol & Sigma-Aldrich \\
\hline Methanol & Carl Roth \\
\hline Natriumcarbonat & Carl Roth \\
\hline Natriumchlorid & Carl Roth \\
\hline Natriumdihydrogenphosphat & Merck Millipore \\
\hline Natriumlaurylsulfat (SDS) & Carl Roth \\
\hline $\begin{array}{l}\text { Natriumlaurylsulfat Polyacrylamid- } \\
\text { Gelelektrophorese-Laufpuffer (SDS- } \\
\text { Laufpuffer) }\end{array}$ & Carl Roth \\
\hline Natriumorthovanadat & ACROS Organics, New Jersey, USA \\
\hline $\begin{array}{l}\text { Ortho-Nitrophenyl-ß-D- } \\
\text { Galactopyranosid (ONPG) }\end{array}$ & Sigma-Aldrich \\
\hline Pefabloc (SC) & Carl Roth \\
\hline $\begin{array}{l}\text { Penicillin }(5000 \mathrm{U} / \mathrm{ml}) \text { - Streptomycin } \\
(5000 \mathrm{U} / \mathrm{ml})\end{array}$ & Life Technologies, Carlsbad, USA \\
\hline $\begin{array}{l}\text { Phosphat-gepufferte Salzlösung } \\
\text { (PBS) }\end{array}$ & Life Technologies \\
\hline $\begin{array}{l}\text { Polydeoxylnosin-deoxycytosin Säure } \\
\text { (Poly-dldC) }\end{array}$ & Sigma-Aldrich \\
\hline 2-Propanol & Carl Roth \\
\hline Puromycin & Sigma-Aldrich \\
\hline Rinder-Serumalbumin (BSA) & Carl Roth \\
\hline Rotiphorese Gel 30, -Gel 40 & Carl Roth \\
\hline Salzsäure & Carl Roth \\
\hline Staurosporin & Sigma-Aldrich \\
\hline $\begin{array}{l}\mathrm{N}, \mathrm{N}, \mathrm{N}^{`}, \mathrm{~N}^{\prime},- \text { Tetramethylethylendiamin } \\
(\mathrm{TEMED})\end{array}$ & Carl Roth \\
\hline Tris-Hydrochlorid (Tris-HCl) & Carl Roth \\
\hline $\begin{array}{l}\text { Tris-(hydroxymethyl)-aminomethan } \\
\text { (Tris-Base) }\end{array}$ & Carl Roth \\
\hline
\end{tabular}




\begin{tabular}{l|l}
\hline Triton $\mathrm{X}-100$ & Sigma-Aldrich \\
\hline Trypton & Carl Roth \\
\hline Tween-20 & Sigma-Aldrich \\
\hline Wasserstoffperoxid $\left(\mathrm{H}_{2} \mathrm{O}_{2}\right)$ & Carl Roth \\
\hline
\end{tabular}

\subsubsection{Wasser}

Zur Herstellung von Puffern, Lösungen und Medien wurde doppelt-destilliertes Wasser $\left(\mathrm{ddH}_{2} \mathrm{O}\right)$ mit einem spezifischen Widerstand von $18.2 \mathrm{M} \Omega \mathrm{cm}$ verwendet. Aufbereitet wurde das Wasser mit Hilfe der Anlage Arium pro (Sartorius, Göttingen). Kam es zur Anwendung von DNAse-, RNase- oder proteinfreiem Wasser, wurde Molecular Biological Grade Water (5 Prime, Hilden, Deutschland) verwendet.

\subsubsection{Puffer und Lösungen}

\begin{tabular}{|c|c|}
\hline Name & Zusammensetzung \\
\hline $5 \times$ Shift-Puffer, pH 7,9 & $\begin{array}{l}100 \mathrm{mM} \text { HEPES } \\
200 \mathrm{mM} \mathrm{KCl} \\
5 \mathrm{ml} \mathrm{MgCl}_{2} \\
2,5 \mathrm{mM} \text { EDTA } \\
0,5 \mathrm{mM} \text { EGTA } \\
20 \% \text { Ficoll }\end{array}$ \\
\hline $5 \times$ TBE-Laufpuffer, pH 8,0 & $\begin{array}{l}445 \mathrm{mM} \text { TRIS } \\
445 \mathrm{mM} \mathrm{H}_{3} \mathrm{BO}_{3} \\
10 \mathrm{mM} \text { EDTA }\end{array}$ \\
\hline $6 \times$ SDS-Puffer & $\begin{array}{l}350 \text { mM TRIS-HCL } \\
8 \% \text { SDS } \\
30 \% \text { Glycerol } \\
10 \% \beta \text {-Mercaptoethanol } \\
0,04 \% \text { Bromophenol }\end{array}$ \\
\hline 100x Magnesium-Lösung & $100 \mathrm{mM} \mathrm{MgCl}{ }_{2} \times 6 \mathrm{H}_{2} \mathrm{O}$ \\
\hline
\end{tabular}




\begin{tabular}{|c|c|}
\hline & 4,5 mM $\beta$-Mercaptoethanol \\
\hline Ablösepuffer, pH 6,8 & $\begin{array}{l}62,5 \mathrm{mM} \text { Tris-HC } \\
2 \% \text { SDS } \\
0,7 \% \beta \text {-Mercaptoethanol }\end{array}$ \\
\hline$\beta$-Galactosidase-Puffer & $\begin{array}{l}\text { 23,5\% ONPG-Puffer } \\
\text { 1,07\% 100x Magnesium-Lösung } \\
\text { + Natriumphosphatpuffer }\end{array}$ \\
\hline Complete-Lösung & Complete-Mini-Protease-Inhibitoren \\
\hline Einfriermedium & $\begin{array}{l}90 \% \text { FCS } \\
10 \% \text { DMSO }\end{array}$ \\
\hline Luciferase-Puffer & $\begin{array}{l}0,3 \% \text { DTT }(1 \mathrm{M}) \\
0,1 \% \text { Pefabloc (100 mg/ml) } \\
1 \% \text { Complete Lösung } \\
\text { in Triton-Glycylglycin-Lyse-Puffer }\end{array}$ \\
\hline Natriumphosphat-Puffer, $\mathrm{pH} 7,2$ & $\begin{array}{l}23,4 \mathrm{mM} \mathrm{NaH}_{2} \mathrm{PO}_{4} \times \mathrm{H}_{2} \mathrm{O} \\
76,6 \mathrm{mM} \mathrm{Na}_{2} \mathrm{HPO}_{4} \times 7 \mathrm{H}_{2} \mathrm{O}\end{array}$ \\
\hline Nukleärer Extraktionspuffer, pH 7.4 & $\begin{array}{l}420 \mathrm{mM} \mathrm{KCl} \\
1 \mathrm{mM} \mathrm{EDTA} \\
0,1 \mathrm{mM} \mathrm{Na}_{3} \mathrm{VO}_{4} \\
20 \mathrm{mM} \mathrm{HEPES} \\
20 \%(\mathrm{v} / \mathrm{v}) \text { Glycerin }\end{array}$ \\
\hline Oligo-Puffer, pH 7,5 & $\begin{array}{l}10 \mathrm{mM} \mathrm{MgCl}_{2} \\
50 \mathrm{mM} \mathrm{KCl} \\
20 \mathrm{mM} \text { TRIS-HCl }\end{array}$ \\
\hline ONPG- Puffer & $\begin{array}{l}\text { 13,3 mM ONPG } \\
100 \text { mM Natriumphosphat-Puffer }\end{array}$ \\
\hline PBS, $\mathrm{pH} 7,4$ & $\begin{array}{l}136 \mathrm{mM} \mathrm{NaCl} \\
2,7 \mathrm{mM} \mathrm{KCl} \\
8,2 \mathrm{mM} \mathrm{Na}_{2} \mathrm{HPO}_{4} \times 2 \mathrm{H}_{2} \mathrm{O}\end{array}$ \\
\hline
\end{tabular}




\begin{tabular}{|c|c|}
\hline & $1,5 \mathrm{mM} \mathrm{KH}_{2} \mathrm{PO}_{4}$ \\
\hline Sammelgelpuffer, pH 6,8 & $\begin{array}{l}0,5 \mathrm{M} \text { TRIS-HCI } \\
0,4 \% \text { SDS }\end{array}$ \\
\hline Trenngelpuffer, pH 8,8 & $\begin{array}{l}1,5 \mathrm{M} \text { TRIS-HCl } \\
0,4 \% \text { SDS }\end{array}$ \\
\hline TBS, pH 7,4 & $\begin{array}{l}137 \mathrm{mM} \mathrm{NaCl} \\
10 \mathrm{mM} \text { Tris- } \mathrm{HCl}\end{array}$ \\
\hline Transferpuffer, pH 8,0 & $\begin{array}{l}25 \text { mM Tris-Base } \\
150 \text { mM Glycin } \\
\text { 10\% Methanol }\end{array}$ \\
\hline Triton-Glycylglycin-Lysepuffer, $\mathrm{pH} 7,8$ & $\begin{array}{l}25 \text { mM Glycylglycin } \\
15 \mathrm{mM} \mathrm{MgSO}_{4} \\
4 \text { mM EGTA } \\
1 \% \text { Triton X-100 }\end{array}$ \\
\hline $\begin{array}{l}\text { Zellkulturmedium HeLa-Zellen, Voll- } \\
\text { medium }\end{array}$ & $\begin{array}{l}1 \% \text { or } 10 \% \text { FCS } \\
1 \% \text { Penicillin/Streptomycin } \\
1 \% \text { L-Glutamin } \\
85 \text { nM Puromycin } \\
\text { in Roswell Park Memorial Institute } \\
\text { Medium } 1640 \text { (RPMI) }\end{array}$ \\
\hline $\begin{array}{l}\text { Zellkulturmedium U3A-Zellen, Voll- } \\
\text { medium }\end{array}$ & $\begin{array}{l}1 \% \text { oder } 10 \% \text { FCS } \\
1 \% \text { Penicillin/Streptomycin } \\
1 \% \text { L-Glutamin } \\
85 \text { nM Puromycin } \\
\text { in Dulbecco's-modifiziertem Eagle- } \\
\text { Medium (DMEM) }\end{array}$ \\
\hline $\begin{array}{l}\text { Zytoplasmatischer Extraktionspuffer, } \\
\mathrm{pH} 7,4\end{array}$ & $\begin{array}{l}10 \mathrm{mM} \mathrm{KCl} \\
1 \mathrm{mM} \text { EDTA } \\
0,1 \mathrm{mM} \mathrm{Na}_{3} \mathrm{VO}_{4} \\
20 \mathrm{mM} \text { Hepes }\end{array}$ \\
\hline
\end{tabular}




\subsubsection{Enzyme, Plasmide und Zytokine}

2.1.5.1 Enzyme

\begin{tabular}{l|l}
\hline AmpliTaq-Gold-DNA-Polymerase & Applied Biosystems, Darmstadt \\
\hline DNA-Polymerase I (Klenow-Enzym) & New England Biolabs, Schwalbach \\
\hline Dpnl-Endonuklease & Stratagene, La Jolla, USA \\
\hline Jak2 & $\begin{array}{l}\text { Enzo Life Sciences Inc., Farmingdale, } \\
\text { USA }\end{array}$ \\
\hline PfuTurbo-DNA-Polymerase & Stratagene, La Jolla, USA \\
\hline peqGold-DNase I & PEQLAB Biotechnologie GmbH, Er- \\
langen \\
$\begin{array}{l}\text { T-Zell-Protein-Tyrosin-Phosphatase } \\
\text { (human, rekombinant, C-terminale 11 } \\
\text { kDa-Deletion (TCAC11, Reste 1- } \\
\text { 317), exprimiert in E. coli) }\end{array}$ & Biomol-International, Plymouth, USA \\
\hline \begin{tabular}{l} 
Trypsin/EDTA \\
\hline
\end{tabular} & PAA, Pasching, Österreich \\
\hline
\end{tabular}

2.1.5.2 STAT1-Plasmide

\begin{tabular}{l|l|l}
\hline pcDNA3.1 & $\begin{array}{l}\text { Eukaryontischer Ex- } \\
\text { pressionsvektor mit ei- } \\
\text { ner Länge von 5,4 kb }\end{array}$ & $\begin{array}{l}\text { Invitrogen Carlsbad, } \\
\text { USA }\end{array}$ \\
\hline pcDNA3.1-STAT1 $\alpha$ & $\begin{array}{l}\text { Humane STAT1 } \alpha \text {-cDNA } \\
\text { kloniert in pcDNA3.1 } \\
\text { von Thermo Fisher }\end{array}$ & (Begitt et al. 2000) \\
\hline pcDNA3.1-STAT1 $\alpha$ & $\begin{array}{l}\text { Derivat von pcDNA3.1, } \\
\text { eingeführt nach Aus- }\end{array}$ & Diese Arbeit \\
\hline
\end{tabular}




\begin{tabular}{|c|c|c|}
\hline (R274W) & $\begin{array}{l}\text { tausch von Tryptophan } \\
\text { für Arginin mit dem Pri- } \\
\text { merpaar R274WF/ } \\
\text { R274WR }\end{array}$ & \\
\hline $\begin{array}{l}\text { pcDNA3.1- STAT1 } \alpha \\
(Q 275 A)\end{array}$ & $\begin{array}{l}\text { Derivat von pcDNA3.1, } \\
\text { eingeführt nach Aus- } \\
\text { tausch von Glutamin für } \\
\text { Alanin mit dem Primer- } \\
\text { paar Q275AF/ Q275AR }\end{array}$ & Diese Arbeit \\
\hline $\begin{array}{l}\text { pcDNA3.1-STAT1 } \alpha \\
(\mathrm{K} 278 \mathrm{~A})\end{array}$ & $\begin{array}{l}\text { Derivat von pcDNA3.1 } \\
\text { eingeführt nach Aus- } \\
\text { tausch von Lysin mit } \\
\text { Alanin mit dem Primer- } \\
\text { paar K278AF/K278AR }\end{array}$ & Diese Arbeit \\
\hline pEGFP-N1 & $\begin{array}{l}\text { Vektor zur Expression } \\
\text { von N-terminalen GFP- } \\
\text { Fusionsplasmiden in } \\
\text { Säugerzellen }\end{array}$ & $\begin{array}{l}\text { Clontech, Mountain } \\
\text { View, USA }\end{array}$ \\
\hline pSTAT $1 \alpha-G F P$ & $\begin{array}{l}\text { Rekombinantes huma- } \\
\text { nes pSTAT1 } \alpha \text { Protein } \\
\text { (AS 1-747), fusioniert } \\
\text { mit grünfluoreszieren- } \\
\text { dem Protein (GFP) am } \\
\text { carboxyterminalen Ende } \\
\text { und kloniert in pEGFP- } \\
\text { N1 }\end{array}$ & (Begitt et al. 2000) \\
\hline pSTAT1 $\alpha(\mathrm{R} 274 \mathrm{~W})-\mathrm{GFP}$ & $\begin{array}{l}\text { Derivat von pEGFP-N1, } \\
\text { eingeführt nach Aus- } \\
\text { tausch von Tryptophan } \\
\text { für Arginin mit dem Pri- } \\
\text { merpaar R274WF/ } \\
\text { R274WR }\end{array}$ & Diese Arbeit \\
\hline
\end{tabular}




\begin{tabular}{l|l|l}
\hline pSTAT1 $\alpha(Q 275 A)-G F P$ & $\begin{array}{l}\text { Derivat von pEGFP-N1, } \\
\text { eingeführt nach Aus- } \\
\text { tausch von Glutamin für } \\
\text { Alanin mit dem Primer- } \\
\text { paar Q275AF/ Q275AR }\end{array}$ & Diese Arbeit \\
\hline pSTAT1 $\alpha($ K278A)-GFP & $\begin{array}{l}\text { Derivat von pEGFP-N1 } \\
\text { eingeführt nach Aus- } \\
\text { tausch von Lysin mit } \\
\text { Alanin mit dem Primer- } \\
\text { paar K278AF/K278AR }\end{array}$ & Diese Arbeit \\
\hline
\end{tabular}

2.1.5.3 Plasmide für Reportergen-Assays

\begin{tabular}{l|l|l}
\hline pßGal & $\begin{array}{l}\text { Plasmid, welches als } \\
\text { Expressionsvektor der } \\
\text { ß-Galaktosidase fungiert }\end{array}$ & $\begin{array}{l}\text { Stratagene, La Jolla, } \\
\text { USA }\end{array}$ \\
\hline pGAS3xLy6E & $\begin{array}{l}\text { IFN } \gamma \text {-abhängiger Re- } \\
\text { portergenvektor mit drei } \\
\text { GAS-Bindestellen }\end{array}$ & (Wen et al. 1995) \\
\hline pIC-339 & $\begin{array}{l}\text { Reportergenkonstrukt, } \\
\text { welches einen trunkier- } \\
\text { ten Promotor des hu- } \\
\text { manen ICAM-1-Gens } \\
\text { mit singulärer GAS- } \\
\text { Bindestelle enthält }\end{array}$ & $\begin{array}{l}\text { Saag, Utrecht, Nieder- } \\
\text { lande }\end{array}$ \\
\hline
\end{tabular}

Die in dieser Arbeit verwendeten Plasmide kodieren für STAT1 $\alpha$. pSTAT1 $\alpha$ GFP kodiert für die $\alpha$-Spliceform von STAT1 und wird hier als pSTAT1-GFP bezeichnet; pcDNA3.1-STAT1 $\alpha$ erhält als Abkürzung die Bezeichnung pSTAT1. 


\subsubsection{Zytokine}

In dieser Arbeit wurde ausschließlich IFN $\gamma$ der Firma Biomol (Hamburg) zur Zellstimulation verwendet. Falls nicht anders angegeben wurde IFN $\gamma$ mit dem jeweiligen Zellkulturmedium auf eine Konzentration von 1:2000 verdünnt und anschließend direkt auf die Zellen pipettiert.

\subsubsection{Reaktions-Kits}

\begin{tabular}{l|l}
\hline $\begin{array}{l}\text { Absolute-Blue-QPCR-SYBR-Green- } \\
\text { Mix }\end{array}$ & $\begin{array}{l}\text { Thermo Fisher Scientific, Waltham, } \\
\text { USA }\end{array}$ \\
\hline Luciferase-Assay-System & Promega, Mannheim \\
\hline peqGold Plasmid Miniprep Kit I & PEQLAB Biotechnologie, Erlangen \\
\hline peqGold Total RNA Kit & PEQLAB Biotechnologie \\
\hline QIAGEN Plasmid Maxi Kit & QIAGEN, Hilden \\
\hline QuikChange II Site-Directed Muta- & Stratagene, La Jolla, USA \\
genesis Kit & \\
\hline Verso cDNA Kit & Thermo Fisher Scientific \\
\hline
\end{tabular}

2.1.7 Antikörper

\begin{tabular}{l|l}
\hline $\begin{array}{l}\text { STAT1 } \alpha \text { p84/p91 (E-23): sc-346 (Ka- } \\
\text { ninchen) }\end{array}$ & Santa Cruz Biotechnology \\
\hline $\begin{array}{l}\text { STAT1 } \alpha \text { p91 (M-23): sc-591 (Kanin- } \\
\text { chen) }\end{array}$ & Santa Cruz Biotechnology \\
\hline $\begin{array}{l}\text { STAT3 p92 (H-190): sc-7179 (Kanin- } \\
\text { chen) }\end{array}$ & Santa Cruz Biotechnology \\
\hline $\begin{array}{l}\text { IRDye 800 CW Anti-Kaninchen IgG } \\
\text { aus der Ziege }\end{array}$ & LI-COR Biosciences, Bad Homburg \\
\hline $\begin{array}{l}\text { Cy3 AffiniPure Anti-Kaninchen IgG } \\
\text { aus der Ziege }\end{array}$ & Dianovo, Hamburg \\
\hline \begin{tabular}{l} 
Phospho-STAT1 (Tyr701) \\
\hline
\end{tabular}
\end{tabular}




\subsubsection{Primer und Oligonukleotide}

2.1.8.1 Mutageneseprimer (nur Vorwärtsprimer abgebildet)

\begin{tabular}{l|l}
\hline Gen & Sequenz \\
\hline R274W F & 5'gagagtctgcagcaagttgggcagcagcttaaaaagttg' \\
\hline Q275A F & 5'gtctgcagcaagttcgggcgcagcttaaaaagttggagg' \\
\hline K278A F & 5'caagttcggcagcagcttgcaaagttggaggaattggaac3' \\
\hline R602A F & 5'cagccggggaccttcctgctggcgttcagtgagagctcc3' \\
\hline Y701F F & 5'ggccctaaaggaactggatttatcaagactgagttg3' \\
\hline
\end{tabular}

Sequenzierungsprimer

\begin{tabular}{l|l}
\hline $335 \mathrm{R}$ & $5^{\prime}$-tgaactggacccctgtcttc-3' \\
\hline
\end{tabular}

2.1.8.2 Primer für RT-PCR (qPCR)

\begin{tabular}{l|l}
\hline Gen & Sequenz \\
\hline hSTAT1 F & $5^{\prime}$-ccgtttcatgacctcctgt-3' \\
hSTAT1 R & $5^{\prime}$ 'tgaatattccccgactgagc-3' \\
\hline hMIG1 F & $5^{\prime}$-ccaccgagatccttatcgaa-3' \\
hMIG1 R & $5^{\prime}$-ctaaccgacttggctgcttc-3' \\
\hline hIRF-1 F & $5^{\prime}$-agctcagctgtgcgagtgta-3' \\
hIRF-1 R & $5^{\prime}$-tagctgctgtggtcatcagg-3' \\
\hline hMCP1 F & $5^{\prime}$-ccagtcacctgctgttatacc-3' \\
hMCP1 R & $5^{\prime}$-tggaatcctgaacccacttct-3' \\
\hline hCXCL10 F & $5^{\prime}$-attctgagctacagcagag-3' \\
\hline
\end{tabular}




\begin{tabular}{l|l}
\hline hCXCL10 R & $5^{\prime}$-gcttgcaggaataattcaa-3' \\
\hline hGAPDH F & $5^{\prime}$-gaaggtgaaggtcggagtc-3' \\
hGAPDH R & $5^{\prime}$-gaagatggtgatgggatttc-3' \\
\hline
\end{tabular}

2.1.8.3 Oligonukleotid-Sonden für EMSA

\begin{tabular}{|c|c|}
\hline $\begin{array}{l}\text { 2xGAS F } \\
2 \times G A S R\end{array}$ & $\begin{array}{l}5 \text { 'ttttcgtttccccgaaattgacggatttccccgaaac3' } \\
5^{\prime} \text { 'tttgtttcggggaaatccgtcaatttcggggaaacg3' }\end{array}$ \\
\hline GAS-nonGAS F & $5^{\prime}$-ttttcgtttccccgaaattgacggatttccccgaac-3' \\
\hline GAS-nonGAS R & $5^{\prime}$-ttttgttggggtaaatccgtcaatttcggggaaacg3' \\
\hline 2xnonGAS F & $5^{\prime}$-ttttcgtttaccccaaattgacggatttaccccaac-3' \\
\hline 2xnonGAS R & $5^{\prime}$-ttttgttggggtaaatccgtcaatttggggtaaacg-3' \\
\hline M67 F & $5^{\prime}$-ttttcgacatttcccgtaaatctg-3' \\
\hline M67 R & $5^{\prime}$-ttttcagatttacgggaaatgtcg-3' \\
\hline
\end{tabular}

\subsubsection{Bakterienstämme und Medien}

\begin{tabular}{l|l} 
Bakterienstamm & Herkunft \\
\hline E. coli DH5 $\alpha$-Zellen & $\begin{array}{l}\text { AG Molekulare Psycho- } \\
\text { kardiologie, Göttingen }\end{array}$ \\
\hline E.coli XL1-Blue & $\begin{array}{l}\text { Agilent Technologies, } \\
\text { Santa Clara, USA }\end{array}$ \\
\hline
\end{tabular}

2.1.9.1 Zellkulturmedien zur Anzucht von Bakterien

\begin{tabular}{l|l|l|l}
\hline Name & Zusammensetzung & $\mathrm{pH}$-Wert & Herkunft \\
\hline LB-Medium & $\begin{array}{l}1 \% \text { Trypton } \\
0,5 \% \text { Hefeextrakt }\end{array}$ & 7,0 & Carl Roth \\
& $1 \% \mathrm{NaCl}$ & & \\
\hline SOC-Medium & $2 \%$ Trypton & 7,5 & \\
\hline
\end{tabular}




\begin{tabular}{l|l|l|l}
\hline & $0,5 \%$ Hefeextrakt & & \\
$10 \mathrm{mM} \mathrm{NaCl}$ & & \\
$2,5 \mathrm{mM} \mathrm{KCl}$ & & \\
$10 \mathrm{mM} \mathrm{MgCl}_{2}$ & & \\
\hline LB-Agar-Medium & $\begin{array}{l}10 \mathrm{mM} \mathrm{MgSO}_{4} \\
1 \% \text { Trypton }\end{array}$ & 7,0 & Carl Roth \\
& $\begin{array}{l}0,5 \% \text { Hefeextrakt } \\
1 \% \mathrm{NaCl}\end{array}$ & & \\
& $1,5 \%$ Agar-Agar & & \\
\hline
\end{tabular}

Sowohl das LB-Medium als auch das LB-Agar-Medium wurden $30 \mathrm{~min}$ autoklaviert und je nachdem, welches Plasmid verwendet wurde, wahlweise mit Kanamycin $(50 \mu \mathrm{g} / \mathrm{ml})$ oder Ampicillin $(100 \mu \mathrm{g} / \mathrm{ml})$ als Selektionsmarker beimpft. Die Einstellung des $\mathrm{pH}$-Wertes erfolgte mit $\mathrm{NaOH}$.

Das SOC-Medium wurde nach Einstellung des $\mathrm{pH}-$ Wertes mit $\mathrm{NaOH}$ für 20 min bei $121^{\circ} \mathrm{C}$ und 1,5 bar autoklaviert. Anschließend wurde steril filtrierte Glukose hinzugefügt.

2.1.9.2 Medien zur Herstellung von Vollmedien

\begin{tabular}{l|l} 
Name & Herkunft \\
\hline $\begin{array}{l}\text { Dulbecco's modifiziertes } \\
\text { Eagle-Medium (DMEM) }\end{array}$ & Biochrom, Berlin \\
\hline $\begin{array}{l}\text { Rosewell Park Memorial } \\
\text { Institut (RPMI) Medium }\end{array}$ & $\begin{array}{l}\text { Lonza, Basel, Switzer- } \\
\text { land }\end{array}$ \\
\hline
\end{tabular}

2.1.10 Geräte und Verbrauchsmaterialien

2.1.10.1 Geräte

\begin{tabular}{l|l}
\hline BioPhotometer Plus & Eppendorf AG, Hamburg \\
\hline Elektrophorese System Minigel-Twin & Biometra, Göttingen, Deutschland \\
\hline Eppendorf-Cycler & Eppendorf AG \\
\hline
\end{tabular}




\begin{tabular}{|c|c|}
\hline Fluoreszenzmikroskop Axiovert 200M & Zeiss, Oberkochen \\
\hline Inkubator B $5061 \mathrm{EC}-\mathrm{CO}_{2}$ & Heraeus, Hanau \\
\hline Laser Scanner FLA-5100 & Fuji, Düsseldorf \\
\hline Lesegerät Infinite M200Pro & Tecan, Männedorf, Schweiz \\
\hline Luminometer Centro XS ${ }^{3}$ LB 960 & Berthold Technologies, Bad Wildbad \\
\hline Mikrozentrifuge 5415 R & Eppendorf AG \\
\hline Mikrozentrifuge MiniSpin Plus & Eppendorf AG \\
\hline Odyssey Sa Imaging System & LI-COR Biosciences, Bad Homburg \\
\hline Orbitalschüttler & VWR Life Science, Erlangen \\
\hline $\begin{array}{l}\text { Pipetten (P1000, P200, P100, P10, } \\
\text { P2,5) }\end{array}$ & Eppendorf AG \\
\hline Schüttelinkubator, Innova 42 & Eppendorf AG \\
\hline Schüttler, Heidolph Duomax 1030 & Heidolph, Schwabach \\
\hline Semi-Dry Transfer-Apparatur & PEQLAB Biotechnologie $\mathrm{GmbH}$ \\
\hline Sicherheitsbank HERAsafe KS9 & Thermo Fisher Scientific, Dreieich \\
\hline Wasserbad & Schuett Biotec, Göttingen \\
\hline Zentrifuge $5804 \mathrm{R}$ & Eppendorf AG \\
\hline
\end{tabular}

2.1.10.2 Verbrauchsmaterialien

\begin{tabular}{l|l}
\hline 96-Lochplatte & Nunc, Roskilde, Dänemark \\
\hline 8-Kammer-Objektträger & Sarstedt, Nümbrecht \\
\hline Atemschutzmaske, 1873+ Aura FFP3 & 3M, Berkshire, UK \\
\hline Deckglas & Thermo Fisher Scientific \\
\hline Illustra MicroSpin G-25 Säulen & GE Healthcare, Little Chalfont, UK \\
\hline Injektionsnadeln & B. Braun, Melsungen \\
\hline Lochplatten (8-Loch, 48-Loch) & Sarstedt \\
\hline
\end{tabular}




\begin{tabular}{|c|c|}
\hline Objektträger & Thermo Fisher Scientific \\
\hline Parafilm & Merz, Frankfurt am Main \\
\hline Pipettenspitzen (P10, P100, P1000) & Sarstedt / Eppendorf \\
\hline Polyvinylidenfuorid (PVDF)-Membran & Merck Millipore, Darmstadt \\
\hline Purple Nitrile-Xtra Handschuh & Halyard Health, Alpharetta, USA \\
\hline $\begin{array}{l}\text { Reaktionsgefäße }(0,2 \mathrm{ml}, 1,5 \mathrm{ml}, 2 \\
\mathrm{ml})\end{array}$ & Eppendorf \\
\hline Rundboden-Röhrchen (14 ml) & BD, Heidelberg \\
\hline Serologische Pipetten ( $5 \mathrm{ml}, 10 \mathrm{ml})$ & Sarstedt \\
\hline Spritze (10 ml, $20 \mathrm{ml})$ & BD, Heidelberg \\
\hline $\begin{array}{l}\text { Schutzfolie MicroAmp Optical Adhe- } \\
\text { sive Film }\end{array}$ & Thermo Fisher Scientific \\
\hline ThermoFast 96-Lochplatte, weiß & Thermo Fisher \\
\hline UV-Küvette $(70 \mu \mathrm{l})$ & Brand, Wertheim \\
\hline Vasco Nitril Handschuh & B. Braun, Melsungen, Deutschland \\
\hline Whatman-Papier & GE Healthcare \\
\hline Zellkulturflasche (T75) & Sarstedt \\
\hline Zellschaber $(25 \mathrm{~cm})$ & Sarstedt \\
\hline Zentrifugenröhrchen (15 ml, $50 \mathrm{ml})$ & Sarstedt \\
\hline
\end{tabular}

\subsection{Methoden}

\subsubsection{Kristallographische Darstellung des STAT1-Moleküls}

Die kristallographische Darstellung eines Tyrosin-phosphorylierten STAT1Dimers sowie die Darstellung eines nicht-phosphorylierten Dimers in antiparalleler Konformation gelang mit Hilfe des Software Programms PyMol (DeLano Scientific, San Francisco, USA). Verwendet wurden hierfür Strukturdaten aus der Proteindatenbank (PBD) mit dem Link 1BF5 für die parallele und 1YVL 
(Mao et al. 2005) für die antiparallele Anordnung der STAT1-Protomere. Anhand des zuletzt genannten PDB-Links konnten Aminosäurereste mit vermutetem Einfluss auf die Stabilität der antiparallen Konformation in der CCD und DBD des STAT1-Dimers markiert werden.

\subsubsection{STAT1-Mutagenese}

Zunächst wurden drei STAT1-GOF-Mutationen in der Coiled-coil-Domäne des Moleküls zur genaueren Charakterisierung ausgewählt. Anschließend wurden die spezifischen Primer bestellt und mit Hilfe des QuickChange Site-DirectedMutagenesis-Kits die entsprechenden Punktmutationen in das STAT1-Plasmid eingefügt. Verwendung als Plasmid fanden die zwei Expressionsvektoren pcDNA3.1-STAT1 und pEGFP-N1-STAT1. Die Mutagenesereaktion wurde durch die Zugabe von 0,5 $\mu$ l Mutagenese-Primer (125 ng/ $\mu$ l) zu 1,25 $\mu$ I STAT1-Plasmid (10 ng/l) gestartet und anschließend 19,75 $\mu \mathrm{l} \mathrm{H}_{2} \mathrm{O}, 2,5 \mu \mathrm{l} 10 \times$ Reaktionspuffer, 0,5 $\mu$ l PfuTurbo-DNA-Polymerase (2,5 U/ $\mu \mathrm{l}$ ) und 0,5 $\mu \mathrm{l}$ dNTP (Desoxynukleosidtriphosphat)-Mix vervollständigt. Nach Herstellung des Mutageneseansatzes erfolgte eine Polymerase-Kettenreaktion (PCR) bestehend aus insgesamt 30 Zyklen. Die Zyklen wurden im Thermocycler (Biometra, Göttingen) wie folgt durchlaufen:

\begin{tabular}{l|l}
\hline Schritt 1 & Denaturierung, $30 \mathrm{sec}, 95^{\circ} \mathrm{C}$ \\
\hline Schritt 2 & Denaturierung, $30 \mathrm{sec}, 95^{\circ} \mathrm{C}$ \\
\hline Schritt 3 & Hybridisierung, $60 \mathrm{sec}, 55^{\circ} \mathrm{C}$ \\
\hline Schritt 4 & Synthese, $14 \mathrm{~min}, 68^{\circ} \mathrm{C}$ \\
\hline
\end{tabular}

Abschließend erfolgte ein einstündiger Verdau mit 0,5 $\mu$ des Restriktionsenzy-

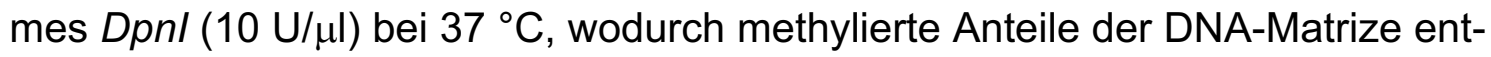
fernt wurden.

In einem nächsten Schritt wurden $2 \mu$ der Plasmid-DNA in superkompetente

XL1-blue E.coli-Zellen überführt. Da die Lagerungstemperatur der Zellen $-80^{\circ} \mathrm{C}$ betrug, wurden sie zunächst auf Eis aufgetaut und anschließend ein Reaktionsansatz bestehend aus $50 \mu$ l Bakterien-Zellen und $2 \mu$ Plasmid-DNA hergestellt. Einer 30-minütigen Inkubationsperiode auf Eis schloss sich ein 45-sekündiger 
Hitzeschock in einem $42{ }^{\circ} \mathrm{C}$ warmen Wasserbad an. Nachdem die Zellen erneut für 2 min auf Eis gelagert wurden, erfolgte die Übertragung in 0,5 ml vorgewärmtes SOC-Medium, woraufhin sich eine einstündige Inkubationsperiode bei $37{ }^{\circ} \mathrm{C}$ und $225 \mathrm{rpm}$ im Schüttelinkubator anschloss. Daraufhin wurden $250 \mu \mathrm{l}$ der Zellsuspension auf eine LB-Agar Platte übertragen, wobei je nach verwendetem Plasmid spezifische Antibiotika $(50 \mu \mathrm{g} / \mathrm{ml})$ enthalten waren. Anschließend wurden die Bakterienzellen über Nacht bei $37{ }^{\circ} \mathrm{C}$ kultiviert. Wurde pEGFP-N1-STAT1 als Plasmid verwendet, diente Kanamycin als Selektionsmarker, bei pcDNA3.1 hingegen Ampicillin.

\subsubsection{Isolation von Plasmid-DNA und Sequenzierung}

Um amplifizierte STAT1-Plasmid-DNA aus den transformierten XL1-blue Zellen isolieren zu können, wurde zunächst eine Bakterienkolonie von der Agar Platte gepickt und in 5ml Antibiotika-haltiges LB-Medium überführt. Anschließend erfolgte unter Schütteln eine über Nacht andauernde Inkubationsperiode bei $37^{\circ} \mathrm{C}$ und $225 \mathrm{rpm}$. Am nächsten Tag kam das peqGOLD Plasmid Miniprep Kit I zum Einsatz, um eine kleine Menge Plasmid-DNA nach Herstellangaben zu isolieren. Anschließend wurden $6 \mu$ des isolierten DNA-Produktes mit $1 \mu$ Sequen-zierprimer und $8 \mu \mathrm{l} \mathrm{H} 2 \mathrm{O}$ gemischt. Der Ansatz wurde zur Sequenzierung an SEQLAB Sequence Laboratories (Göttingen) gesendet. Lieferten die Sequenzierungsergebnisse am folgenden Tag die gewünschten Mutationen, konnte mit der Produktion von größeren Plasmid-Mengen begonnen werden.

\subsubsection{Plasmid-Amplifikation}

Die Produktion von größeren Mengen Plasmid-DNA erforderte in einem ersten Schritt die Transformation der DNA in DH5 $\alpha$-kompetente Zellen. Wie auch bei den zuvor verwendeten XL-1-blue-Zellen handelte es sich um $E$.coli-Zellen, welche bei $-80^{\circ} \mathrm{C}$ gelagert wurden. $100 \mu$ Bakterienzellen wurden zunächst auf Eis aufgetaut und anschließend $2 \mu$ Plasmid-DNA hinzugefügt. Danach folgten zwei Inkubationsperioden auf Eis, eine 30-minütige und eine 2-minütige. Zwischen den beiden Inkubationszeiten durchliefen die Zellen bei $42{ }^{\circ} \mathrm{C}$ einen Hitzeschock für $30 \mathrm{sec}$. 
Bevor $250 \mu \mathrm{l}$ der Zellsuspension auf eine LB-Agarplatte mit dem passenden Antibiotikum $(50 \mu \mathrm{l} / \mathrm{ml})$ gegeben wurden, erfolgte der Transfer der Zellen in $1 \mathrm{ml}$ SOC-Medium und eine Inkubationsperiode im Schüttler von einer Stunde bei $37^{\circ} \mathrm{C}$ und $225 \mathrm{rpm}$. Zur Kultivierung wurden die Agarplatten über Nacht bei $37^{\circ} \mathrm{C}$ gelagert.

Am nächsten Tag wurde eine Kolonie von der Agar-Platte gepickt und zusammen mit $50 \mu \mathrm{g} / \mathrm{ml}$ des entsprechenden Antibiotikums in 5ml LB-Medium transferiert. Es folgte eine 6-stündige Inkubationsperiode bei $37{ }^{\circ} \mathrm{C}$ und $225 \mathrm{rpm}$. Die Suspension wurde in $100 \mathrm{ml}$ antibiotikahaltiges Medium $(50 \mu \mathrm{l} / \mathrm{ml})$ überführt und über Nacht erneut unter Schütteln bei $37^{\circ} \mathrm{C}$ inkubiert. Am nächsten Tag wurde die Suspension nach Herstellerangaben mit dem Quiagen Plasmid Maxi Kit behandelt. Schlussendlich erfolgte die Resuspendierung der extrahierten DNA in $50 \mu \mathrm{l}$ DNAse-, RNAse-freiem und proteinfreiem Wasser. Nach Bestimmung der Konzentration der Plasmid-DNA mit Hilfe eines Photometers bei einer Wellenlänge von $260 \mathrm{~nm}$ in einer $70 \mu \mathrm{l}-U V$-Küvette und anschließender Adjustierung auf eine Konzentration von $1 \mu \mathrm{g} / \mu \mathrm{l}$, konnten die Proben bei $-20{ }^{\circ} \mathrm{C}$ eingefroren werden. Vor der Adjustierung wurde sichergestellt, dass die DNA nicht verunreinigt vorlag. Hierfür wurde die Absorption bei einer Wellenlänge von $280 \mathrm{~nm}$ gemessen und der Quotient $\mathrm{A}_{260} / \mathrm{A}_{280}$ gebildet. Lag der Wert bei 1,8 wurde von einer reinen Probe ausgegangen. Die Formel zur Berechnung der DNAKonzentration lautete:

DNA-Konzentration $[\mu \mathrm{g} / \mathrm{ml}]=A_{260} \times 50 \times$ Verdünnungsfaktor

\subsubsection{Zellkulturmethoden}

Auftauvorgang und Kultivierung von humanen Zellen

Das sterile Arbeiten unter mikrobiologischen Sicherheitsbänken war Voraussetzung für die erfolgreiche Kultivierung von Zellen. Die in der vorliegenden Arbeit verwendeten Zellen wurden in dem für die jeweilige Zelllinie spezifischem Medium kultiviert. STAT1-defiziente U3A-Zellen wurden in DMEM versetzt mit 10\% FCS, $1 \%$ Penicillin/Streptomycin und 0,04 $\mu \mathrm{g} / \mathrm{ml}$ Puromycin kultiviert und HeLaZellen in Quantum 101 HeLa-Medium, welches mit 1\% Penicillin/Streptomycin supplementiert war. Nachdem die bei $-80^{\circ} \mathrm{C}$ gelagerten Zellen im Wasserbad aufgetaut vorlagen, wurden sie zunächst in dem vorgewärmten Medium resus- 
pendiert. Anschließend erfolgte die Überführung in $10 \mathrm{ml}$ des gleichen Mediums und die Zentrifugation bei $1000 \mathrm{rpm}$ für $5 \mathrm{~min}$ und $20^{\circ} \mathrm{C}$. Der Zellüberstand wurde verworfen und das Pellet in Vollmedium erneut resuspendiert. Nun erfolgte die Kultivierung bei $37^{\circ} \mathrm{C}$ im Brutschrank in einer mit Wasserdampf gesättigten $5 \%$-igen $\mathrm{CO}_{2}$-Atmosphäre. Aufbewahrt wurden die Zellen in $75 \mathrm{~cm}^{2}$ großen Zellkulturflaschen.

\section{Einfriervorgang}

Für den Einfriervorgang wurde ein spezielles Medium verwendet, das $90 \%$ FCS und 10\% DMSO enthielt. Die nötige Lagerungstemperatur der Zellen von $-80{ }^{\circ} \mathrm{C}$ wurde langsam mit Hilfe von DMSO, welches als Gefrierschutzmittel fungierte, erreicht. Bevor die Zellen eingefroren wurden, erfolgte deren Vorbereitung bei einer Konfluenz von ungefähr $70 \%$, wofür das Zellmedium zunächst entfernt und die Zellen einmalig mit PBS gewaschen wurden. Daraufhin folgte die Gabe von Trypsin, wodurch die Zellen gelöst wurden. Nachdem die TrypsinAktivität durch Zugabe von frischem Medium gestoppt wurde, schloss sich deren Resuspendierung und ein 5-minütiger Zentrifugationsvorgang bei 1000 rpm und $20^{\circ} \mathrm{C}$ an. Das entstandene Zellpellet wurde in der nötigen Menge Einfriermedium resuspendiert und konnte anschließend über Nacht in einer Gefrierbox (Nalgene, Heidelberg) gelagert werden.

Zellpassage

Die Vereinzelung und Umsetzung der Zellen erfolgte alle zwei bis drei Tage bei einer Konfluenz von ungefähr 100\%. Die Zellen mussten zunächst mit PBS gewaschen werden, wofür der Überstand der adhärenten Zellen entfernt und PBS hinzugefügt wurde. Nach der Waschung erfolgte die Inkubation mit Trypsin/EDTA-Lösung (0,05\% Trypsin, 0,2 g/l EDTA; Biochrom) für etwa 2-3 min bei $37{ }^{\circ} \mathrm{C}$ im Brutschrank. Vor der Benutzung wurden PBS, Trypsin/EDTA und das im Anschluss verwendete Zellkulturmedium auf $37^{\circ} \mathrm{C}$ vorgewärmt. Für die Ausplattierung mussten die adhärenten Zellen als Suspension vorliegen und die Trypsin/EDTA-Aktivität gestoppt werden, was durch die Zugabe von passendem Vollmedium (10\% FCS) erreicht wurde. Je nachdem welche Verdünnung gewünscht war, konnte die Suspension in eine neue Zellkulturflasche mit frischem Vollmedium (10\% FCS) überführt werden, wobei die Zellen typischerweise in einer Verdünnung von 1:4 bis 1:6 ausplattiert wurden. 


\subsubsection{Transfektion von Säugerzellen}

Zur Analyse der verschiedenen STAT1-Mutationen fand die Transfektion von mutationsspezifischer Plasmid-DNA bei einer Zellkonfluenz von $50-70 \%$ statt. Für die Transfektion standen je nach Experiment Lochplatten oder Objektträger zur Verfügung und abhängig davon wurden folgende Transfektionsansätze hergestellt:

6-Lochplatte, je Loch:

3,2 $\mu \mathrm{g}$ Plasmid-DNA $(1 \mu \mathrm{g} / \mu \mathrm{l}), 160 \mu \mathrm{l} \mathrm{NaCl}(150 \mathrm{mM}), 4,8 \mu \mathrm{l}$ MegaTran 1.0 48-Lochplatte, je Loch:

$0,5 \mu$ l Plasmid-DNA, $50 \mu \mathrm{l} \mathrm{NaCl}(150 \mathrm{mM}), 1,56 \mu \mathrm{l}$ MegaTran 1.0

8-Kammer-Objektträger, je Kammer:

0,4 $\mu \mathrm{g}$ Plasmid-DNA $(1 \mu \mathrm{g} / \mu \mathrm{l}), 20 \mu \mathrm{l} \mathrm{NaCl}(150 \mathrm{mM}), 0,6 \mu \mathrm{l}$ MegaTran 1.0

Nach Herstellung wurde der Ansatz für $10 \mathrm{sec}$ gevortext und bei Raumtemperatur (RT) für 10 min inkubiert. Anschließend erfolgte die Transfektion, wofür der Ansatz direkt auf die Zellen pipettiert wurde. Nach ungefähr $24 \mathrm{~h}$ konnten die Zellen für Experimente verwendet werden. Die Effizienz der Transfektion von GFP-Konstrukten konnte durch Verwendung eines Fluoreszenzmikroskops vor Beginn des Experiments beurteilt werden.

\subsubsection{Stimulation und Inhibition von Zellen}

Die Stimulation der Zellen erfolgte nach verschiedenen Protokollen. In dieser Arbeit kam ausschließlich rekombinantes IFN $\gamma$ zum Einsatz, welches zuvor mit vorgewärmtem Medium auf eine Konzentration von $50 \mathrm{ng} / \mathrm{ml}$ eingestellt und anschließend zur Stimulation auf die Zellen pipettiert wurde. Zur Inhibition wurde der Protein-Kinase-Inhibitor Staurosporin in einer Konzentration von $1 \mu \mathrm{M}$ verwendet. 6-Lochplatten wurden mit $1 \mathrm{ml} \mathrm{IFN} \gamma$ - oder Staurosporin-haltigem Medium stimuliert, 48-Lochplatten mit $500 \mu \mathrm{l}$ und 8-Kammer-Objektträger mit $200 \mu \mathrm{l}$ der entsprechenden Lösung. Sollte auf die Stimulationsphase mit IFN $\gamma$ eine Inhibitionsphase mit Staurosporin folgen, so wurden die Kammern bzw. Objektträger zuvor mit PBS gewaschen. 


\subsubsection{Proteinextraktion}

Für Western-Blot-Analysen, Gelshift-Assays und Dephosphorylierungs-Experimente wurden Proteinextrakte aus zuvor transfizierten und stimulierten U3Aoder HeLa-Zellen gewonnen. Die Transfektion erfolgte in 6-Lochplatten mit pEGFP-N1-STAT1 oder pcDNA3.1-Konstrukten, die Stimulation mit IFN $\gamma$ (50 $\mathrm{ng} / \mathrm{ml})$ und je nach Versuch zusätzlich mit Staurosporin $(1 \mu \mathrm{M})$. Nach der Stimulation wurden die Zellen mit PBS gewaschen und anschließend lysiert. Für die Lysierung wurde pro Loch $60 \mu \mathrm{l}$ frisch angefertigter zytoplasmatischer Extraktionspuffer auf die Zellen gegeben. Dem Puffer wurden kurz vor Verwendung 1\% Complete-Mini-Protease-Inhibitoren, $3 \mathrm{mM}$ DTT, 0,4 mM Pefabloc und 0,1\% IGEPAL-CA-630 hinzugefügt. Dieser Schritt fand bereits auf Eis statt. Auch im Weiteren wurden die Zellen stets auf Eis gelagert. Nach einer Einwirkzeit von 5 min wurden die Lysate mit Hilfe eines Zellschabers von der Platte entfernt und in ein Reaktionsgefäß $(1,5 \mathrm{ml})$ überführt. Daraufhin folgte bei $4{ }^{\circ} \mathrm{C}$ und $16.100 \mathrm{~g}$ ein 15-sekündiger Zentrifugationsvorgang. Hierbei bildete sich ein Zellpellet und ein Überstand, welcher in ein neues Reaktionsgefäß gegeben und erneut für 5 min bei $4{ }^{\circ} \mathrm{C}$ und $16.100 \mathrm{~g}$ zentrifugiert wurde. $40 \mu \mathrm{l}$ des hierbei entstandenen Überstandes wurde als zytosolischer Proteinextrakt gesammelt.

Die aus dem ersten Zentrifugationsvorgang entstandenen pelletierten Zellkerne wurden mit $60 \mu \mathrm{l}$ frischem nukleärem Extraktionspuffer resuspendiert. Ähnlich wie der zytoplasmatische Extraktionspuffer wurde auch der nukleäre Puffer unmittelbar vor Verwendung mit 1\%-igem Complete-Mini-Protease-Inhibitor Cocktail, $3 \mathrm{mM}$ DTT und 0,4 mM Pefabloc versetzt. Nach einer Inkubationszeit von $30 \mathrm{~min}$ wurden die Lysate für $15 \mathrm{~min}$ bei $4{ }^{\circ} \mathrm{C}$ und $16.100 \mathrm{~g}$ zentrifugiert. Es wurden $40 \mu \mathrm{l}$ des Überstands als nukleärer Extrakt entnommen und mit den zuvor hergestellten zytoplasmatischen Extrakten vereint. Anschließend wurden die fertigen Proben bei $-80{ }^{\circ} \mathrm{C}$ tiefgefroren. Sollten die Extrakte weder für EMSA-Experimente noch für Dephosphorylierungs-Assays dienen, sondern in Western-Blot-Analysen Verwendung finden, wurde vor dem Einfrieren jeweils $80 \mu \mathrm{l}$ Proteinextrakt mit 14,4 $\mu \mathrm{l} 6$ x SDS-Probenpuffer komplementiert und für 3 min bei $95^{\circ} \mathrm{C}$ gekocht. Anschließend wurden die Proben bei $-20{ }^{\circ} \mathrm{C}$ gelagert. 


\subsubsection{SDS-Polyacrylamid-Gelelektrophorese und Western-Blot-Analyse}

Die SDS-Polyacrylamid-Gelelektrophorese wurde in dieser Studie verwendet, um Proteine anhand ihres molekularen Gewichts aufzutrennen. Um STAT1Proteine aus den zuvor gewonnenen Extrakten zu separieren, wurde ein diskontinuierliches Zwei-Phasen-Gel verwendet bestehend aus Gelen unterschiedlicher Zusammensetzung. Das im oberen Teil verwendete Sammelgel bestand zu 25\% aus Sammelgelpuffer, 16\% Rotipherese Gel 30, 0,06\% APS, 0,2\% TEMED. Für den unteren Teil wurde ein Trenngel hergestellt bestehend aus 25\% Trenngelpuffer, 33,1\% Rotipherese Gel 30, 0,03\% APS und 0,16\% TEMED. Bis zur Polymerisation wurde das Trenngel 20 min stehen gelassen und mit Isopropanol bedeckt, um einen möglichst geraden Anschluss des Trenngels zu gewährleisten. Auf die Herstellung des Trenngels, folgte die des Sammelgels, wobei dieses direkt auf das Trenngel gegossen wurde. Auch diesmal dauerte die Polymerisation ungefähr $20 \mathrm{~min}$, wobei hierbei zur nachfolgenden Proteinbeladung mit Hilfe eines Plastikkammes Geltaschen konstruiert wurden. Diese wurden anschließend mit 12-18 $\mu \mathrm{l}$ Gesamtzellextrakte beladen, welche zuvor bei $95^{\circ} \mathrm{C}$ für 3 min erhitzt wurden. Die Auftrennung der Proteine erfolgte bei einer konstanten Stromstärke bei $11 \mathrm{~mA}$ in SDS-Laufpuffer. Sobald die Blaufärbung des SDS-Proben-Puffers das Trenngel durchlaufen hatte, wurde die Elektrophorese gestoppt und die aufgetrennten Proteine in einem nächsten Schritt nach der Semi-Dry-Methode auf eine zuvor in Methanol hydro-philisierte Polyvinylidenfluorid (PVDF)-Membran übertragen. Dieser Vorgang dauerte pro Gel 90 min bei einer Stromstärke von $80 \mathrm{~mA}$. Anschließend wurde die Membran für $1 \mathrm{~h}$ bei RT mit 4\%igem Rinderserumalbumin (BSA) gelöst in Tris-gepufferte Salzlösung (TBS) und 0,05\%-igem Tween-20 (TBS-T) Zusatz geblockt. Über Nacht erfolgte die Inkubation der Membran bei $4{ }^{\circ} \mathrm{C}$ mit einem Phospho-STAT1 (Tyr 701) Antikörper, welcher zuvor auf eine Konzentration von 1:1000 in 4\% BSA in TBS-T verdünnt wurde.

Um Aufschluss über die Menge an pSTAT1 in den unterschiedlichen STAT1Derivaten zu erlangen, wurden am darauffolgenden Tag die Proteinbanden immunologisch detektiert. Hierfür wurde der Blot fünfmal in TBS-T gewaschen und anschließend ein an IRDye-gekoppelter Sekundärantikörper in einer Verdünnung 1:10000 in 4\% BSA in TBS-T hinzugefügt. Die Inkubation dauerte unter Schütteln $1 \mathrm{~h}$ im abgedunkelten Raum. Danach wurde der Blot erneut fünfmal 
für je $5 \mathrm{~min}$ in TBS-T gewaschen und war anschließend soweit vorbereitet, dass die Proteinbanden mit Hilfe des LI-COR Odyssey Sa Imaging System detektiert werden konnten.

Da neben der Menge an phosphoryliertem STAT1 auch die Menge an unphosphoryliertem STAT1 sichtbar gemacht werden sollte, wurde die PSTAT1 Immunreaktivität nach der Detektion entfernt. Hierfür wurde die Membran mit Ablösepuffer für $1 \mathrm{~h}$ bei $60{ }^{\circ} \mathrm{C}$ inkubiert. Um den Ablösepuffer anschließend vollständig von der Membran zu entfernen, folgte auf die Inkubationsperiode im Wasserbad eine viermalige Waschung in TBS-T je 15 min. Daraufhin wurden unspezifische Bindestellen für $1 \mathrm{~h}$ in $4 \%$ BSA in TBS-T blockiert und die PVDFMembran anschließend mit einem STAT1-spezifischem p84/p91 (E-23) Primärantikörper inkubiert. Die Proteinbanden wurden erneut unter Verwendung des Sekundärantikörpers und LI-COR Odyssey Sa Imaging Systems dargestellt.

\subsubsection{Elektromobilitäts-Shift-Assay (EMSA)}

Anhand von EMSA-Versuchen wurde an DNA-gebundenes STAT1 mit Hilfe radioaktiv markierter $\left[{ }^{33} \mathrm{P}\right]$-DNA-Sonden unter Verwendung von PhosphoImager-Platten autoradiographisch detektiert. Zur erfolgreichen Durchführung der EMSA-Versuche wurden zuvor hybridisierte, doppelsträngige Oligonukleotid-Sonden an ihren überhängenden Enden mit Hilfe eines Klenow-Fragmentes der E. coli DNA- Polymerase mit [ $\left.{ }^{33} \mathrm{P}\right]-\mathrm{dATP}$ Nukleotiden radioaktiv markiert, wobei verschiedene Sonden zum Einsatz kamen: M67 mit einer hoch-affinen GAS-Sequenz, 2 x GAS mit zwei kanonischen GAS-Sequenzen, GAS-nonGAS mit einer kanonischen und einer degenerierten GAS-Sequenz und zuletzt 2xnonGAS, die zwei degenerierte GAS-Sequenzen enthält.

Der genaue Vorgang der Oligonukleotid-Hybridisierung umfasste die Zugabe von Oligo-Puffer (50 pM) zu 100 pM komplementären Oligonukleotiden und einen anschließenden 5 -minütigen Kochvorgang bei $95{ }^{\circ} \mathrm{C}$. Für die radioaktive Markierung wurden 0,1 ng Oligonukleotide mit 0,8 $\mu \mathrm{l}\left[{ }^{33} \mathrm{P}\right]-\mathrm{dATP}$ und $5 \cup \mathrm{En}$ zym in $5 \mu \mathrm{l} 10 \times$ Eco-Pol-Puffer gemischt. Freie Nukleotide wurden anschlieBend durch Zentrifugation mit Illustra MicroSpin-G-25-Säulen bei $700 \mathrm{x} \mathrm{g}$ und 
RT entfernt. Bis zur Verwendung in EMSA-Experimenten wurden die radioaktiv markierten Proben bei $4{ }^{\circ} \mathrm{C}$ gelagert.

Um die Proteinbanden von DNA-gebundenem STAT1 mittels Elektrophorese am Ende des Versuches autoradiographisch von ungebundenem Protein unterscheiden zu können, wurde ein TBE-Polyacrylamidgel benötigt. Das Gel enthielt folgende Komponenten: 0,1\% TEMED, 12\% Rotiphorese-Gel 40, 4,8\% 5 x TBE und $0,2 \%$ APS. Nach Herstellung des Gels erfolgte eine 2-stündige Prääquilibrierung bei $400 \mathrm{~V}$.

Zu Beginn des EMSA-Experiments wurden 4,5 $\mu$ l der zuvor gewonnenen Proteinextrakte ohne SDS-Puffer mit 8,5 $\mu$ l Master Mix (0,5 $\mu$ l Poly-dldC (2 $\mu \mathrm{g} / \mu \mathrm{l}), 2,5$ $\mu l 5 \times$ Shift Puffer, 1,3 $\mu$ I DTT (100 mM), 0,2 $\mu$ l DNA Probe, $\left.4 \mu \mathrm{ddH}_{2} 0\right)$ gemischt und für 15 min bei RT inkubiert. Je nachdem welcher Versuch geplant war, folgten anschließend verschiedene Vorgehensweisen: Bei Kompetitionsexperimenten wurde den Proben eine nicht-radioaktiv markierte M67-Probe in 750-fachem molaren Überschuss für die angegebenen Zeiten hinzugefügt. Bei Super-Shift-Experimenten wurden die Reaktionsansätze mit $2 \mu l$ STAT1spezifischem Antikörper E-23 oder unspezifischem STAT3-Antikörper H-190 für 40 min inkubiert. Anschließend wurde das Polyacrylamidgel mit den fertigen Proben beladen und die insgesamt 2,5 h andauernde Elektrophorese bei $400 \mathrm{~V}$ und 10-15 mA pro Gel in 0,25 x TBE-Puffer gestartet. Nach beendeter elektrophoretischer Auftrennung erfolgte die Übertragung des Gels auf ein WhatmanPapier, welches daraufhin vollständig vakuumgetrocknet wurde. Während einer mehrtätigen Inkubationsperiode wurden in einem letzten Schritt die radioaktiven Signale auf eine Phospho-Imager-Platte übertragen und der Film mit dem Typhoon FLA 9500 Scanner und der Software TINA v. 2.0 ausgelesen.

\subsubsection{In-vitro-Phosphorylierungs- und Dephosphorylierungs-Assay}

Zu Beginn des In-vitro-Dephosphorylierungs-Assay erfolgte die Herstellung eines Dephosphorylierungspuffers (50 mM KCl, $25 \mathrm{mM}$ Tris- $\mathrm{HCl}, \mathrm{pH} \mathrm{7,5,} \mathrm{0,5}$ $\mathrm{mg} / \mathrm{ml}$ BSA, $5 \mathrm{mM}$ EDTA), welcher durch die Zugabe von Complete-MiniProtease-Inhibitoren, $20 \mathrm{mM}$ DTT und $2 \mathrm{U}$ STAT1-spezifischer TC45Phosphatase vervollständigt wurde. Anschließend wurden $10 \mu \mathrm{l}$ des Puffergemisches zu der gleichen Menge Gesamtzellextrakt aus rekonstituierten und mit 
IFN $\gamma$-stimulierten STAT1-U3A-Zellen hinzugefügt. Die Proben wurden 0 min, 30 min oder $60 \mathrm{~min}$ bei $30{ }^{\circ} \mathrm{C}$ inkubiert. Je nach Versuchsprotokoll enthielt die Phosphatase-Reaktion keine DNA-Sonde oder doppelsträngige Oligonukleotide mit ein- oder zwei GAS-Bindestellen (25 nM) in Tandem-Orientierung.

Für den Phosphorylierungs-Assay wurden $10 \mu$ Kinase-Puffer ( $3 \mathrm{mM} \mathrm{MnCl}_{2}, 3$ $\mu \mathrm{M} \mathrm{Na}_{3} \mathrm{VO}_{4}, 0,1 \mathrm{mM}$ ATP, 50 mM Hepes, $\mathrm{pH}$ 7,4, $3 \mathrm{mM} \mathrm{MgCl}_{2}$ ) und $10 \mu \mathrm{l}$ Proteinextrakt aus unstimulierten, STAT1-rekonstituierten U3A-Zellen vereint. Der Kinase-Puffer wurde kurz vor Versuchsbeginn mit $4 \mu \mathrm{g} / \mathrm{ml}$ rekombinanter JAK2Kinase und $10 \mathrm{mM}$ DTT versetzt. Die Proben wurden bei $30^{\circ} \mathrm{C}$ für die angegebenen Zeiten inkubiert.

Der Reaktionsabbruch erfolgte in beiden beschriebenen Assays durch Zugabe von 6x SDS-Probenpuffer für 3 min bei $95^{\circ} \mathrm{C}$. Das Ausmaß der Phosphorylierung sowie die Menge an Gesamt-STAT1 je Probe wurden mittels Polyacrylamid-Gelelektrophorese und anschließendem immunologischen Nachweis mit spezifischem Antikörper in Western-Blot-Experimenten analysiert.

\subsubsection{Luciferase-Reportergen-Assay}

Mit Hilfe von Luciferase-Reportergen-Assays konnte die transkriptionelle Aktivität der verschiedenen STAT1-Mutanten und des Wildtyp-Moleküls unter Verwendung IFN $\gamma$-sensitiver Reportergenkonstrukte bestimmt werden. Hierbei kamen zwei verschiedene Luciferase-kodierende Konstrukte zum Einsatz, wobei pIC-339 ein Promotorfragment des humanen ICAM-1-Gens mit einer singulären GAS-Sequenz enthält und 3xLy6E drei STAT1-Bindestellen in seiner Promotorregion aufweist (Wen et al. 1995). Gemeinsam mit einem für ß-Galaktosidase kodierendem Plasmid (200 ng) und pSTAT1-WT bzw. mutiertem Plasmid (250 ng) wurden die genannten Konstrukte (70 ng) in U3A-Zellen transfiziert, welche zuvor in 48-Lochplatten kultiviert worden sind. Am nächsten Tag wurden die Zellen entweder für $6 \mathrm{~h}$ mit IFN $\gamma(50 \mathrm{ng} / \mathrm{ml})$ stimuliert oder unbehandelt gelassen. Anschließend wurde das Zellmedium entfernt, die Zellen einmalig mit PBS gewaschen und für 15 min in $100 \mu \mathrm{l}$ frisch angesetztem Luciferase-Puffer bei RT lysiert. In einem nächsten Schritt erfolgte die Überführung der Lysate in 1,5 $\mathrm{ml}$ Reaktionsgefäße. Nach einem 15-minütigen Zentrifugationsvorgang bei $4{ }^{\circ} \mathrm{C}$ und maximaler Geschwindigkeit wurde $20 \mu \mathrm{l}$ des Überstandes in eine 96- 
Lochplatte (Nunc, Roskilde, Dänemark) pipettiert. Die Luciferase-Aktivität konnte mit Hilfe eines Luminometer Centro XS ${ }^{3}$ LB 960 nach Zugabe von $50 \mu$ Substratlösung gemessen werden. Die Auswertung der Ergebnisse erfolgte mit dem Software Programm MikroWin Version 4.41, wobei pro STAT1-Konstrukt und Stimulationszeitraum sechs unabhängige Transfektionsansätze getestet wurden.

Die Luciferase-Aktivität wurde auf die Expression der kotransfizierten ßGalaktosidase normalisiert. Hierfür wurden $20 \mu$ l der zuvor zentrifugierten Lysate in ein neues 1,5-ml-Reaktionsgefäß überführt und mit $280 \mu \mathrm{l}$ ßGalaktosidasepuffer versetzt. Farbloses ortho-Nitrophenyl-ß-D-Galaktopyransid (ONPG) hat sich hierbei nach ungefähr 20 min in gelbes ortho-Nitrophenol umgewandelt. Nach Farbumschlag wurde die Reaktion durch Zugabe von $500 \mu \mathrm{l}$ Natriumcarbonat-Lösung $\left(0,5 \mathrm{M} \mathrm{Na}_{2} \mathrm{CO}_{3}\right)$ gestoppt. Daraufhin erfolgte die photometrische Bestimmung der ß-Galaktosidaseaktivität durch das Lesegerät Infinite 200 PRO bei einer Wellenlänge von $420 \mathrm{~nm}$. Um eine standardisierte Messung zu gewährleisten, wurde am Ende der Quotient aus Luciferase- und Galaktosidase-Aktivität gebildet.

\subsubsection{Real-time PCR}

RNA-Extraktion und reverse Transkription in cDNA

Damit die Expression von STAT1-Zielgenen anhand der Real-time PCR gemessen werden konnte, wurde zunächst RNA mit Hilfe eines PeqGold Total RNA Kits aus pcDNA3.1-Plasmid transfizierten U3A-Zellen nach Herstellerangaben extrahiert. Die Zellen wurden zuvor in Hungermedium (1\% FCS) kultiviert, für $6 \mathrm{~h}$ mit IFN $\gamma$ in der Konzentration von $50 \mathrm{ng} / \mathrm{ml}$ stimuliert und vor Verwendung des RNA-Kits mit PBS gewaschen. Nach erfolgreicher Isolation wurde in einem nächsten Schritt die gewonnene RNA entweder bei $-80{ }^{\circ} \mathrm{C}$ eingefroren oder mit Hilfe des Verso cDNA Kits von Thermo Fisher Scientific in komplementäre DNA (cDNA) umgeschrieben. Die Herstellung erfolgte hierbei in einer 30minütigen Synthesephase bei $42{ }^{\circ} \mathrm{C}$, gefolgt von 2-minütigem Kochen bei $95{ }^{\circ} \mathrm{C}$. Der nach Herstellerangaben verwendete Reaktionsansatz beinhaltete 8 $\mu \mathrm{l}$ RNA in einem Volumen von $20 \mu \mathrm{l}$. Nach Abschluss der reversen Transkripti- 
on wurde die cDNA bis zur Verwendung in der Real-time PCR bei $-20^{\circ} \mathrm{C}$ gelagert.

\section{Real-time PCR}

Zu Beginn der Real-time PCR wurden auf eine weiße 96-Lochplatte $19 \mu$ Master- Mix zusammen mit $1 \mu \mathrm{l}$ cDNA gegeben. Der Master-Mix beinhaltete $10 \mu \mathrm{l}$ Absolute-Blue-QPCR-SYBR-Green-Mix, 8,4 $\mu \mathrm{lddH_{2 }}$ o und $0,28 \mu$ leines spezifischen Primer-Paares $(5 \mu \mathrm{M})$. Die Platte wurde anschließend fest mit adhäsivem Film verschlossen. Als komplementäre Primer-Paare wurden STAT1, IRF1, MIG1, CXCL1 und MCPI1 verwendet und anschließend das Genexpressionslevel dieser typischen STAT1-Zielgene bestimmt. Als Referenzgen diente hierbei GAPDH. Pro Reaktionsansatz erfolgten drei unabhängige Messungen. Die Reaktion beinhaltete folgende Schritte:

\begin{tabular}{l|l}
\hline Schritt 1 & Denaturierung, $15 \mathrm{~min}, 95{ }^{\circ} \mathrm{C}$ \\
\hline Schritt 2 & $\begin{array}{l}\text { Denaturierung, } 15 \mathrm{sec}, 95{ }^{\circ} \mathrm{C}(45 \\
\text { Zyklen der Schritte } 2 \mathrm{bis} 4)\end{array}$ \\
\hline Schritt 3 & Primer-Hybridisierung, $30 \mathrm{sec}, 55^{\circ} \mathrm{C}$ \\
\hline Schritt 4 & Synthese, $30 \mathrm{sec}, 72{ }^{\circ} \mathrm{C}$ \\
\hline
\end{tabular}

Die relativen Expressionslevel der verschiedenen Gene wurden anschließend quantifiziert und mit Hilfe der Formel $2^{-(\Delta \Delta C t \text { Ziel - } \Delta C t \text { Referenzprobe) }}$ miteinander verglichen.

\subsubsection{Fluoreszenz-Analysen}

Flowzytometrie

T-regulatorische Zellen wurden als $\mathrm{CD}^{+}{ }_{-}, \mathrm{CD}^{+}-$, CD25 $5^{\text {high }}-$, CD127 $7^{\text {low-positive }}$ periphere Blutzellen aus dem Blut eines Patienten mit der GOF-Mutation und einer gesunden Kontrollperson zu Vergleichszwecken mittels Flow-Zytometrie nach Standardmethoden detektiert. 
Mikroskopische Analysen

Direkte Fluoreszenzmikroskopie

Mittels Fluoreszenzmikroskopie und unter Verwendung von blau-fluoreszierendem Hoechst 33258 konnte der Zellkern detektiert werden und somit Aussagen bezüglich des nukleären Akkumulationsverhaltens getroffen werden. Hierfür wurde das Fluoreszenzmikroskop Axiovert 200M mit verschiedenen Fluoreszenzfiltern verwendet, wobei Fluoreszenzsignale der Hoechst-gefärbten Zellkerne bei einer Wellenlänge von $280 \mathrm{~nm}$ und die GFP-markierten STAT1Emissionen bei einer Wellenlänge von $480 \mathrm{~nm}$ aufgenommen wurden. Auf 8Kammer-Objektträgern kultivierte HeLa-Zellen wurden mit pEGFP-N1-STAT1WT oder mutiertem Plasmid transfiziert und am nächsten Tag zu den angegebenen Zeiten mit IFN $\gamma(50 \mathrm{ng} / \mathrm{ml})$ stimuliert, unbehandelt gelassen oder nach IFN $\gamma$-Stimulation zusätzlich mit $1 \mu \mathrm{M}$ Staurosporin behandelt. Die stimulierten Zellen wurden anschließend mit PBS gewaschen und mit $300 \mu$ 4\% Paraformaldehyd in PBS pro Kammer für 15 min fixiert. Daraufhin erfolgte eine Waschung mit PBS und $d_{d d H_{2}} \mathrm{O}$. Als nächstes wurden $300 \mu$ lichtempfindliche Hoechst-Lösung (1:5000 in FCS PBS) pro Kammer hinzugefügt. Für eine erfolgreiche Färbung wurde der Objektträger 10 min lang bei RT im Dunkeln und unter Schütteln inkubiert, gefolgt von einer zweifachen Behandlung mit PBS und einmaligen Waschung mit $\mathrm{ddH}_{2} \mathrm{O}$. Die Kammer wurde vom Objektträger entfernt und die Zellen mit Flouromount G Eindeckmedium bedeckt. Zur Aushärtung des Mediums erfolgte die Lagerung des Objektträgers lichtgeschützt für mindestens eine Nacht bei $4{ }^{\circ} \mathrm{C}$.

Immunfärbung

Anhand immunzytochemischer Färbungen wurde die zytokininduzierte Kernakkumulation von unmarkiertem, rekombinanten STAT1 detektiert. Unter Verwendung des Fluoreszenzmikroskops wurden Aufnahmen eines Cy3-gekoppelten Sekundärantikörpers bei einer Wellenlänge von $550 \mathrm{~nm}$ angefertigt. U3A-Zellen wurden mit STAT1-exprimierenden pcDNA3.1-Konstrukten transfiziert und in 8Kammer-Objekträgern kultiviert. Am nächsten Tag erfolgte die Stimulation mit 
IFN $\gamma$ zu den angegebenen Zeiten oder die Zellen wurden unbehandelt gelassen. Je nach Versuchsprotokoll schloss sich der Zytokinstimulation eine Behandlung mit $1 \mu \mathrm{M}$ Staurosporin für verschiedene Zeiten an. Daraufhin wurden die Zellen einmal mit PBS gewaschen und anschließend zur Fixierung in jede Kammer $300 \mu$ leiskaltes Methanol gegeben. Das Methanol wurde nach 15 min Einwirkzeit entfernt und die Zellen erneut einmal mit PBS gewaschen. Damit der Antikörper im nächsten Schritt in die fixierten Zellen eindringen konnte, wurden sie zunächst 20 min mit 1,0\% Triton X-100 permeabilisiert. Als nächstes erfolgten zwei Waschschritte mit PBS und eine 45-minütige Inkubationsperiode mit $300 \mu \mathrm{l} 25 \%$ FCS in PBS bei RT auf dem Schüttler, um unspezifische Bindungsstellen zu blockieren. In einem nächsten Schritt wurden die Zellen für 45 min mit $300 \mu \mathrm{l}$ STAT1-spezifischem Primärantikörper E-23 (1:1000 mit 25\% FCS verdünnt in PBS) inkubiert und anschließend dreimal mit PBS gewaschen.

Im Anschluss erfolgte die Gabe des rotfluoreszierenden, Cy3-gekoppelten Sekundärantikörpers (3 $\mu \mathrm{g} / \mathrm{ml}$ in 25\% FCS in PBS). Da dieser sensibel auf Licht reagiert, fand die 45-minütige Inkubationsperiode im Dunkeln statt. Im Anschluss daran wurden die Zellen zweimal mit PBS gewaschen und die Zellkerne mit der bereits beschriebenen Hoechst-Färbung gefärbt. Schlussendlich wurden die Zellen auf dem Objektträger mit Fluoromount-Eindeckmedium fixiert.

Aufnahmen der immunzytochemischen und fluoreszenzmikroskopischen Zellpräparate erfolgten mit einer CCD-Kamera. Anschließend wurde das Verhältnis der Fluoreszenzintensitäten von Cytoplasma und Zellkern gebildet. Zur Bearbeitung der Aufnahmen kamen das Software-Programm Image-Pro MDA 5.1 und Coral Draw zum Einsatz. Mittelwerte und Standardabweichungen von mindestens 10-20 zufällig ausgewählten Zellen pro Stimulationszeitpunkt aus drei unabhängigen Experimenten wurden berechnet und graphisch dargestellt.

\subsubsection{Statistische Analysen}

Die Auswertung digital aufgenommener Bilder erfolgte mit dem SoftwareProgramm Image J. Für STAT1-WT und die generierten Punktmutanten wurden für die verschiedenen Stimulationszeitpunkte, Standardabweichungen und Mittelwerte berechnet. Unterschiede zwischen dem Wildtyp-Molekül und den STAT1-Mutanten wurden mit Hilfe des Student-t-Tests und Wilcoxon-Mann- 
Whitney-Tests ermittelt. Die Analyse der Daten erfolgte mit dem SoftwareProgramm SigmaStat (Systat Software, Erkrath) und Microsoft Excel (Microsoft Deutschland, Unterschleißheim), wobei in allen Tests ein $p$-Wert $\leq 0,05$ als statistisch signifikant angesehen wurde. 


\section{Ergebnisse}

\subsection{Charakterisierung von STAT1-R274, -Q275 und -K278}

Mit dem Ziel, den molekularen Mechanismus von CMC verursachenden Gainof-Function-Mutationen im Transkriptionsfaktor STAT1 genauer zu untersuchen, wurde zunächst die Struktur eines DNA-gebundenen STAT1-Dimers kristallographisch dargestellt und anschließend verschiedene Aminosäurereste in der häufig involvierten Coiled-coil-Domäne betrachtet. An Position 274 befindet sich ein Argininrest, wobei die Seitenkette der Aminosäure zur Innenfläche des parallelen Dimers gerichtet ist. Dies galt auch für den benachbarten Glutaminrest an Position 275 und einen Lysinrest an Position 278. Nach Sequenzvergleich der sieben STAT-Proteine konnte gezeigt werden, dass diese drei Aminosäuren zu einem stark konservierten Sequenzmotiv mit der Struktur R/Q-Q/R-Q/L/E- $\Psi$ $\mathrm{K} / \mathrm{E} / \mathrm{R} / \mathrm{G}$ gehören, wobei $\Psi$ für einen hydrophoben Aminosäurerest steht. Das Motiv innerhalb der $\alpha$-Helix enthält, mit Ausnahme von STAT6 (Q239), in allen STAT-Proteinen an erster Stelle ein Arginin, an zweiter Position ein Glutamin, ausgenommen STAT4 (R275), und an vierter Position hydrophobe Aminosäuren wie Leucin, Isoleucin oder Valin.

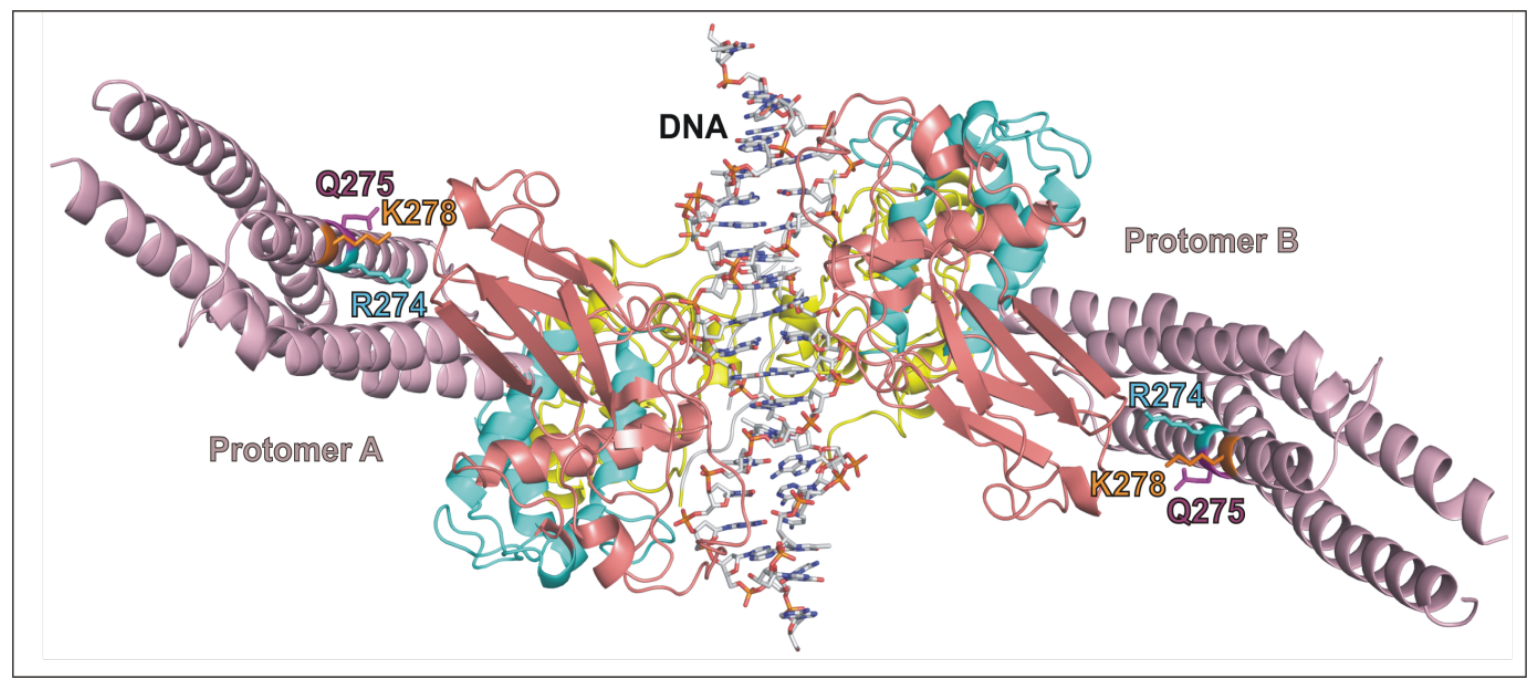

Abb. 3: Kristallstruktur des Tyrosin-phosphorylierten und DNA-gebundenen STAT1Dimers mit Darstellung von drei Aminosäureresten in der Coiled-coil-Domäne. Die Abbildung zeigt die Kristallstruktur eines an DNA gebundenen STAT1-Dimers in paralleler Konformation. Besonders hervorgehoben sind die Aminosäurereste an Position 274 (hellblau), 275 (vio- 
lett) und 278 (orange) in der helllila gekennzeichneten Coiled-coil-Domäne. Des Weiteren sind die anderen zum Kernfragment zählenden Domänen abgebildet, wobei die SH2-Domäne in gelb, die Linker-Domäne in hellblau und die DNA-Bindedomäne in lachs dargestellt werden.

Auf die kristallographische Darstellung eines parallelen STAT1-Dimers erfolgte in einem zweiten Schritt die Darstellung in antiparalleler Konformation (Abb.4). Hierbei fiel auf, dass zwei verschiedene Bindungsflächen zwischen den STAT1Protomeren bestehen. Im Innern der Dimer-Schnittstelle bilden die Aminosäurereste R274, Q275 und K278 des einen Monomers eine fingerartige Brücke, wodurch zwei benachbarten Protomere miteinander in Verbindung treten. Im äußeren Bereich besteht eine zweite Interaktionsfläche, die hauptsächlich durch eine Verbindung zwischen den Aminosäureresten F172 und T385 stabilisiert wird.

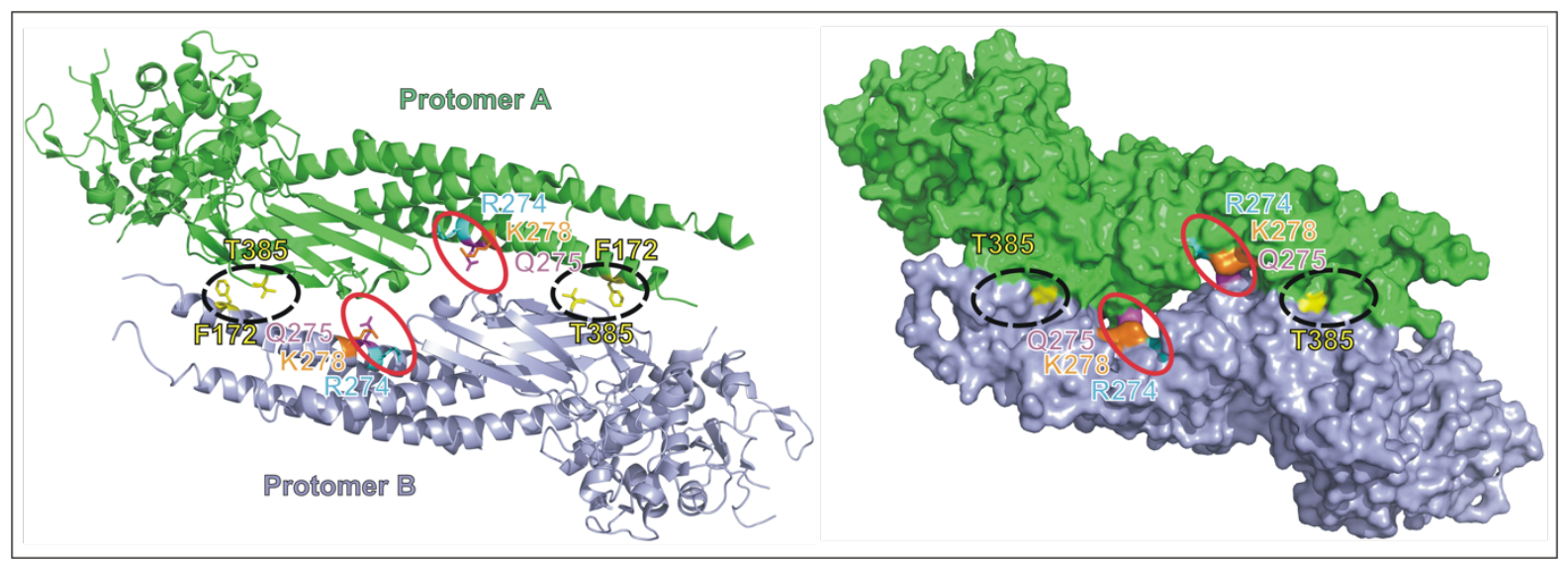

Abb. 4: Kristallographische Darstellung eines in antiparalleler Konformation vorliegenden STAT1-Dimers. In der Ribbon-Darstellung im linken Bildteil ist ein nicht an DNA gebundenes STAT1-Dimer gezeigt, im rechten Bildteil wird das gleiche Dimer als Oberflächendarstellung dargestellt. Zu sehen sind zwei deutlich voneinander unterscheidbare Interaktionsflächen zwischen den STAT1-Protomeren, welche mit schwarzen und roten Kreisen markiert sind. Die im äußeren Bereich lokalisierten Aminosäurereste F172 und T385 sind gelb hervorgehoben, die im Inneren gelegenen Aminosäurereste in den in Abb.3 genannten Farben.

\subsection{Klinische Verbesserung eines CMC-Patienten mit der STAT1-GOF-Mutation R274Q unter langfristiger Behandlung mit Ruxolitinib}

Wie bereits von Mössner und Kollegen veröffentlicht, litt ein von CMC betroffener Patient unter den für dieses Krankheitsbild typischen Symptomen wie ulzerativer Mukositis und obstruktiven Strikturen im Ösophagus, was zu starkem 
Schluckstörungen mit Gewichtsverlust führte. Anhand genetischen Screenings wurde die STAT1-GOF-Mutation R274Q bei dem Patienten identifiziert. Eine bereits seit über 25 Jahren bestehende antimykotische Therapie erbrachte nur noch geringen Erfolg. Die daraufhin eingeleitete sechsmonatige Behandlung mit dem oralen Janus-Kinase-Inhibitor Ruxolitinib führte zu einer deutlichen Verbesserung der Symptomatik mit Gewichtszunahme (Mössner et al. 2016). Die Fortsetzung der Behandlung für weitere 38 Monate verbesserte den Gesundheitszustand kontinuierlich, führte jedoch nicht zur vollständigen Remission der Erkrankung.

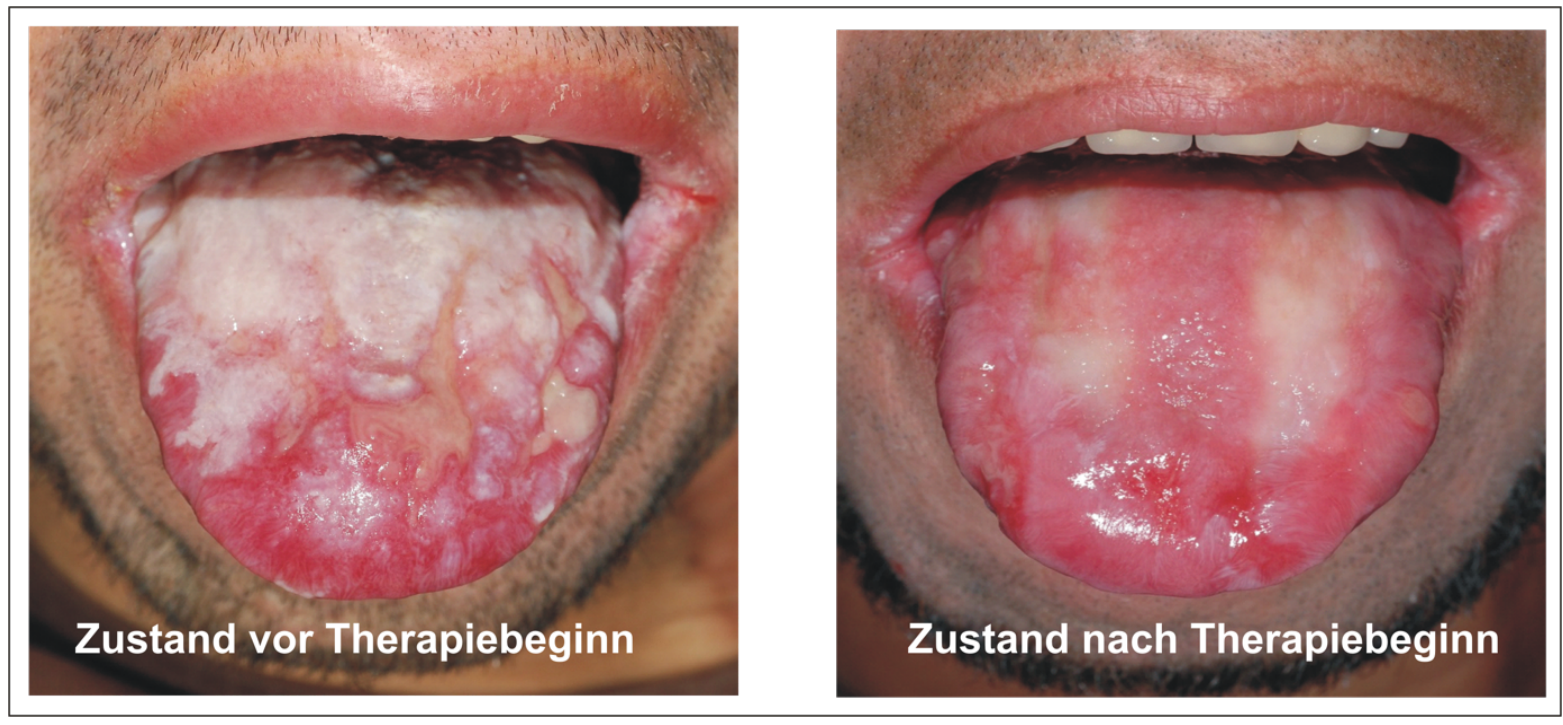

Abb. 5: Patient mit CMC vor und nach Therapiebeginn mit dem Tyrosin-Kinase-Inhibitor Ruxolitinib. Die Behandlung mit dem potenten JAK-Inhibitor Ruxolitinib führte bei einem Patienten mit der heterozygoten STAT1-GOF-Mutation R274Q zu einer deutlichen Verbesserung oraler Schmerzen und der Nahrungspassage. Abgebildet ist der Zustand vor und nach einer 38 Monate dauernden Therapie mit Ruxolitinib.

Die zunächst durchgeführte sechsmonatige Behandlung mit Ruxolitinib erbrachte eine Erhöhung der Gesamt-Anzahl an CD4+- und CD8+-positiven T-Lymphozyten sowie von B-Zellen im Blut des Patienten. Die daraufhin fortgeführte Therapie mit dem Tyrosin-Kinase-Inhibitor konnte zwar eine deutliche klinische Verbesserung, jedoch keine Erhöhung von regulatorischen T-Zellen erbringen, wie das Ergebnis einer Durchflusszytometrie in Abb.6 zeigt. 


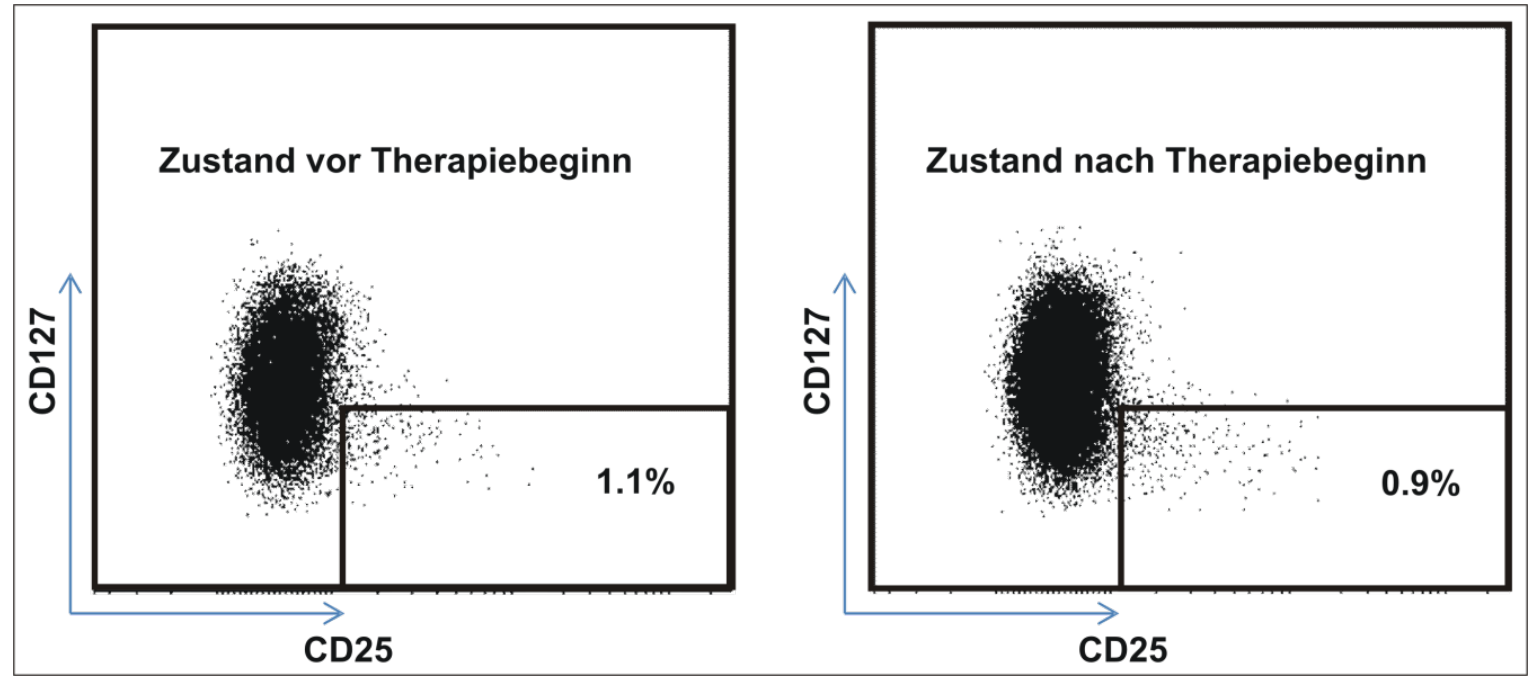

Abb. 6: Ergebnis einer Durchflusszytometrie zur Bestimmung der regulatorischen TZellen vor und nach Therapiebeginn. Die FACS-Analyse zeigt, dass der Patient nach einer 38-monatigen Behandlung mit Ruxolitinib keine Erhöhung an T-regulatorischen Zellen, gemessen an $\mathrm{CD}^{+}, \mathrm{CD}^{+}, \mathrm{CD}^{2} 5^{\text {high }}$ und $\mathrm{CD} 27^{\text {low }}$ peripheren Blutzellen, aufweist.

Aufgrund der gegebenen Homologie und der klinischen Relevanz des Sequenzmotivs erfolgte die Einführung von Punktmutationen in der Coiled-coilDomäne von STAT1 mit Hilfe sequenzspezifischer Mutagenese. An Position 274 wurde der Aminosäurerest Arginin gegen Tryptophan, an Position 275 Glutamin gegen Alanin und an der Stelle 278 Lysin gegen Alanin ersetzt. Anschließend wurden Experimente zur genauen Charakterisierung dieser drei Substitutionsmutanten durchgeführt.

\subsection{Erhöhtes Phosphorylierungsniveau von R274W und Q275A im Vergleich zu STAT1-WT}

Um die Effekte der generierten Punktmutanten auf zellulärer Ebene genauer untersuchen zu können, erfolgte in STAT1-defizienten U3A-Zellen die Transfektion von Expressionsvektoren, die für unmarkierte oder GFP-fusionierte STAT1-Varianten kodierten. Die mit dem Wildtyp-Molekül oder eines seiner Derivate transfizierten Zellen wurden anschließend für 45 min mit rekombinantem IFN $\gamma(50 \mathrm{ng} / \mathrm{ml})$ stimuliert, wodurch erwartungsgemäß über eine Aktivierung des JAK-STAT-Signalweges und Phosphorylierung an Position 701 das STAT1Dimer in den Zellkern transloziert wurde. Daraufhin erfolgte die Inkubation mit dem potenten Kinase-Inhibitor Staurosporin. Gesamtzellextrakten wurden hergestellt und die mittels SDS-Gelelektrophorese separierten Proteinbanden im 
elektrischen Feld auf eine PVDF-Membran übertragen. Die Abnahme des Phosphorylierungsniveaus in den verschiedenen STAT1-Punktmutanten wurde in Western-Blot-Experimenten unter Verwendung eines Phosphotyrosinspezifischen STAT1-Antikörpers ermittelt und anschließend mit der Kinetik des Wildtyp-Moleküls verglichen. Nach Verwendung des Ablösepuffers und Inkubation mit dem pan-STAT1-spezifischem Antikörper E-23 wurde am nächsten Tag die Gesamt-STAT1-Menge bestimmt.

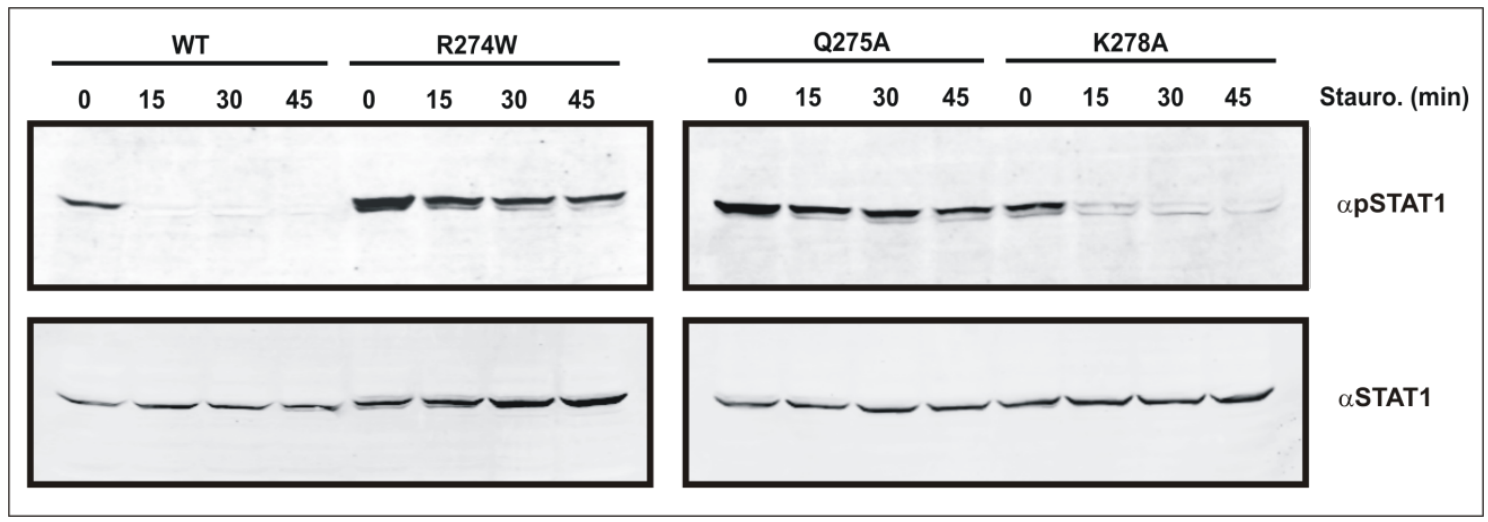

Abb. 7: Erhöhtes Ausmaß der Tyrosin-Phosphorylierung von STAT1-R274W und STAT1Q275A im Vergleich zu STAT1-WT in pcDNA3.1-STAT1-transfizierten U3A-Zellen. STAT1defiziente U3A-Zellen wurden mit unmarkiertem STAT-WT-Plasmid transfiziert oder mit einem strukturgleichen Expressionsvektor, der für die angegebenen STAT1-Punktmutanten kodiert, und am Folgetag für 45 min mit IFN $\gamma$ stimuliert. Anschließend erfolgte die Zugabe von $1 \mu \mathrm{M}$ Staurosporin. Der obere Blot zeigt das jeweilige Phosphorylierungsniveau der verschiedenen Mutanten und dem STAT1-WT-Molekül, detektiert mit Hilfe eines Phospho-STAT1-spezifischen Antikörpers. Der untere Blot zeigt die detektierte Menge an Gesamt-STAT1 in den verwendeten Proteinextrakten und verdeutlicht die vergleichbaren Ausgangskonzentrationen.

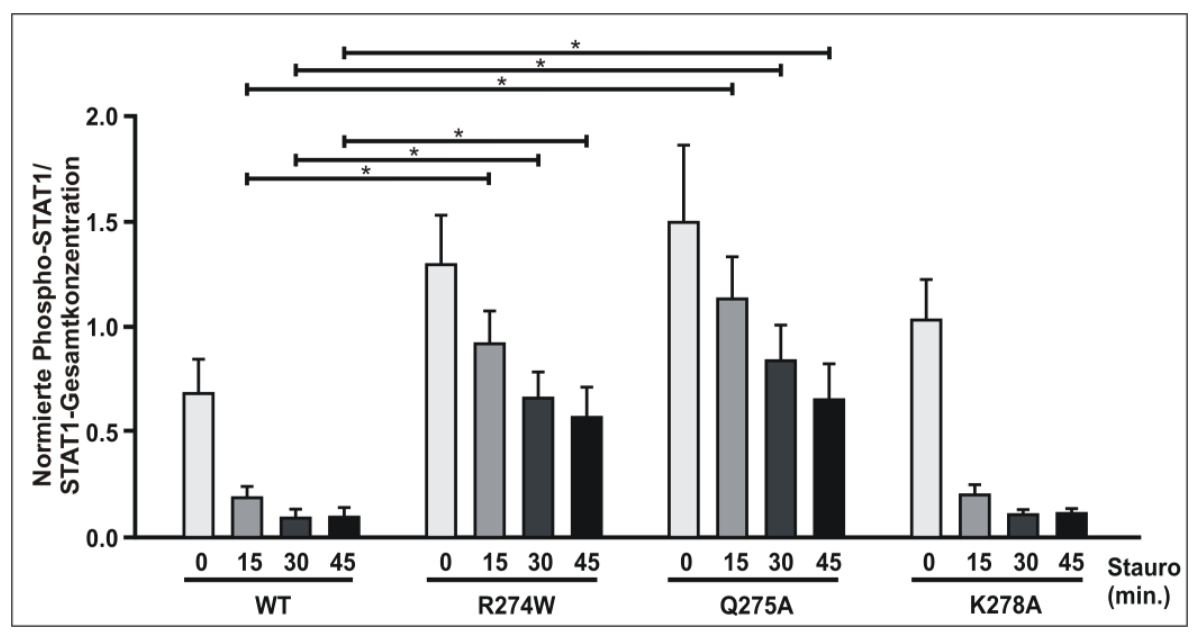

Abb. 8: Quantifizierung der Western-Blot-Analysen bestätigt die Hyperphosphorylierung der zwei Mutanten R274W und Q275A in IFN $\gamma$-vorbehandelten und Staurosporin- 
exponierten U3A-Zellen. Drei unabhängige Western-Blot-Experimente wurden statistisch ausgewertet und die Ergebnisse als Säulendiagramm dargestellt, wobei statistisch signifikante Resultate mit Balken und Sternchen $\left(^{*}\right)$ gekennzeichnet sind.

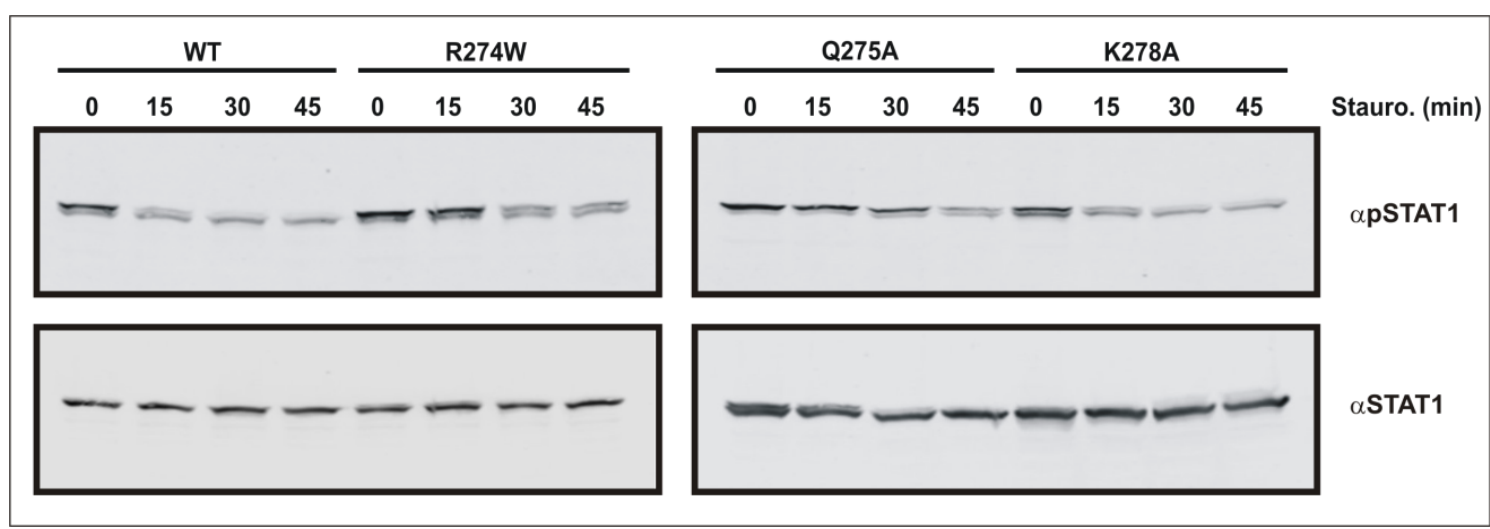

Abb. 9: Verminderte In-vivo-Dephosphorylierung von STAT1-R274W-GFP und Q275AGFP verglichen mit STAT1-WT-GFP nach Stimulation mit IFN $\gamma$ und anschließender Staurosporin-Behandlung. STAT1-negative U3A-Zellen wurden mit pEGFP-N1-STAT1-WT oder pEGFP-N1-mutierten Plasmiden transfiziert und am nächsten Tag für 45 min mit IFN $\gamma$ stimuliert. Nach anschließender Staurosporin-Inkubation für die angegebenen Zeiträume wurden Proteinextrakte gewonnen und die dargestellten Proteinbanden durch Verwendung eines Phosphotyrosin-spezifischen Antikörpers ( $\alpha$ SSTAT1) und Reexposition derselben Membranen mit einem pan-STAT1-Antikörper ( $\alpha$ STAT1) in Western-Blot-Analysen ermittelt.

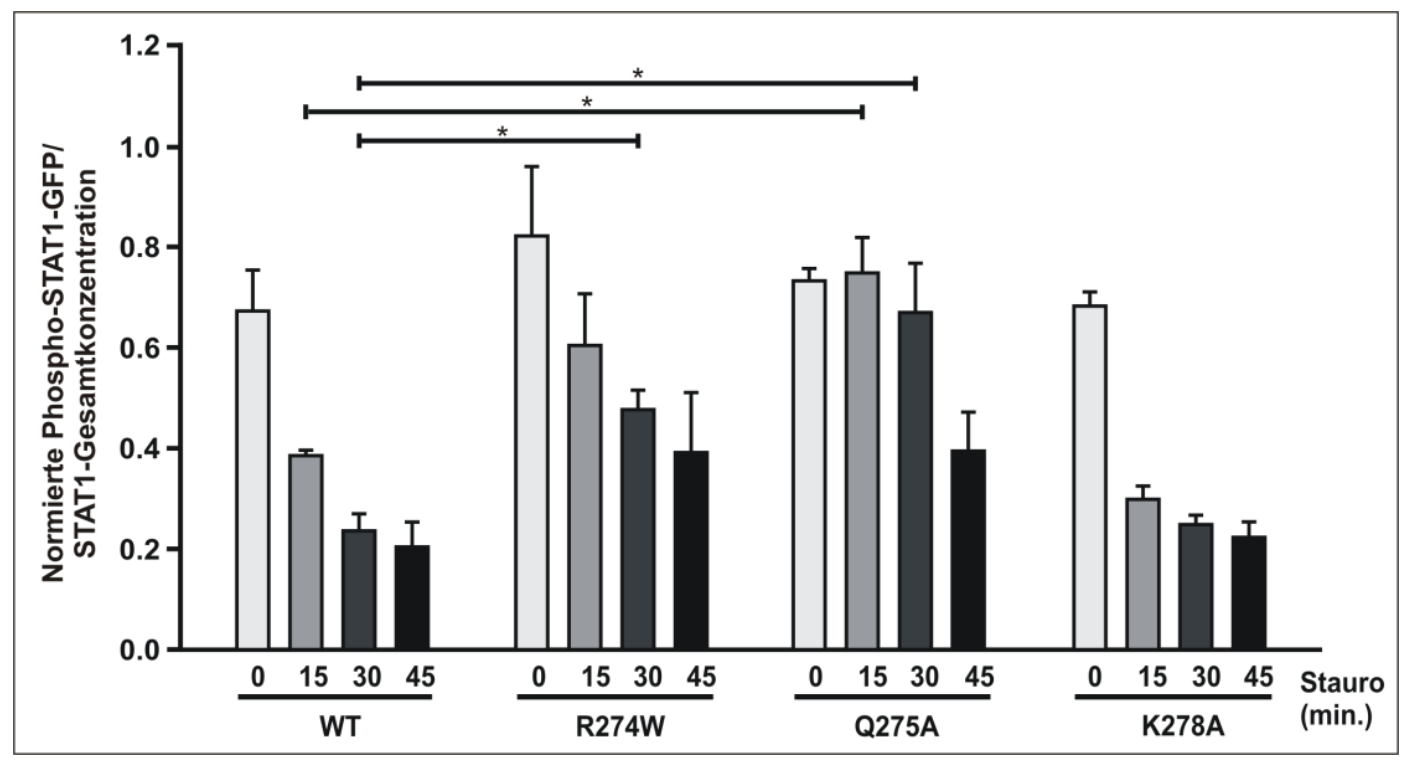

Abb. 10: Die Quantifizierung von IFN $\gamma$-stimulierten, STAT1-rekonstituierten U3A-Zellen zeigt die Hyperphosphorylierung von Fusionsproteinen mit grünfluoreszierendem Protein bei den beiden Mutanten R274W und Q275A bezogen auf das Wildtyp-Molekül. Für die Quantifizierung wurden Lysate aus drei unabhängigen Transfektionsansätzen verwendet und die entsprechenden Western-Blot-Assays wie in Abb. 9 durchgeführt. 
Die Western-Blot-Analysen zeigten, dass das Phosphorylierungsniveau aus den Gesamtzellextrakten von U3A-Zellen transfiziert mit pcDNA3.1STAT1-Konstrukten bzw. STAT1-GFP-kodierenden Plasmiden bei den Mutanten R274W und Q275A nach Zytokinstimulation der rekonstituierten Zellen erhöht ist. Nach 15-minütiger Staurosporin-Inkubation ist bei dem STAT1-WT-Molekül bereits eine deutliche Abnahme der TyrosinPhosphorylierung zu beobachten (Abb.7 und Abb.9). Bei beiden generierten Mutanten liegt zu gleichen Zeitpunkten eine Hyperphosphorylierung vor. Je länger die Inhibition mit Staurosporin anhält, desto schwächer erscheint das Phosphorylierungssignal im STAT1-WT-Protein. Eine Abnahme ist auch in den beiden generierten Punktmutanten sichtbar, jedoch in einem geringen Maße. Die Signifikanz dieser Ergebnisse wurde durch statistische Auswertung und anschließende Darstellung im Säulendiagramm bestätigt (Abb. 8 und Abb. 10). Vergleicht man die Proteinbanden der dritten generierte Punktmutante K278A in Abb. 7 und Abb. 9 hinsichtlich der in-vivo-Dephosphorylierungsrate mit dem Wildtyp-Molekül, so ergeben sich keine erkennbaren Unterschiede.

\subsection{STAT1-GOF-Mutationen zeigen eine prolongierte DNA- Bindungsaktivität verglichen mit dem Wildtyp-Molekül}

Um Aussagen über die DNA-Bindungsaktivität der generierten STAT1 Punktmutanten treffen zu können, wurden elektrophoretische MobilitätsShift-Assays (EMSA) durchgeführt. Für die unterschiedlichen Versuche und Reaktionsansätze wurde stets die gleiche Menge an Proteinextrakten verwendet. In einem ersten Experiment wurden Gesamtzellextrakte für 15 min mit einer $\left[\mathrm{P}^{33}\right]$-radioaktiv markierten M67-Probe mit enthaltener singulärer GAS-Sequenz inkubiert. Die Herstellung der Extrakte erfolgte aus transient transfizierten U3A-Zellen, welche zuvor für 45 min mit IFN $\gamma$ stimuliert und anschließend mit $1 \mu \mathrm{M}$ Staurosporin für $0,15,30$ oder 45 min inhibiert wurden. Für die Rekonstitution der STAT1-Expression wurden mutierte oder wildtypische pcDNA3.1-STAT1-Expressionsplasmide verwendet. Im Anschluss an die elektrophoretische Auftrennung der phosphorylierten STAT1-Proteine mit Hilfe eines nicht-denaturierenden Polyacrylamidgels konnte die DNA-Bindung an die $\left[\mathrm{P}^{33}\right]$-radioaktiv markierte 
hoch-affine DNA-Sonde unter Verwendung einer Phospho-Imager-Platte detektiert werden. Die Ergebnisse bestätigen die der Western-BlotAnalysen, da auch in diesem Experiment das Phosphorylierungssignal des nach Tryptophan mutierten Argininrests 274 und des nach Alanin mutierten Glutaminrests 275 über die Bindung an M67 indirekt bestimmt wurde und verglichen mit dem WT-Protein deutlich erhöht war. Die Mutante K278A zeigte keine Unterschiede im Tyrosin-Phosphorylierungsniveau im Vergleich zum Wildtyp-Protein. Um die STAT1-spezifische Bindung an die hoch-affine DNA-Sonde M67 nachzuweisen, wurden Supershift-Experimente mit spezifischen STAT1- oder unspezifischen STAT3-Antikörpern vorgenommen.

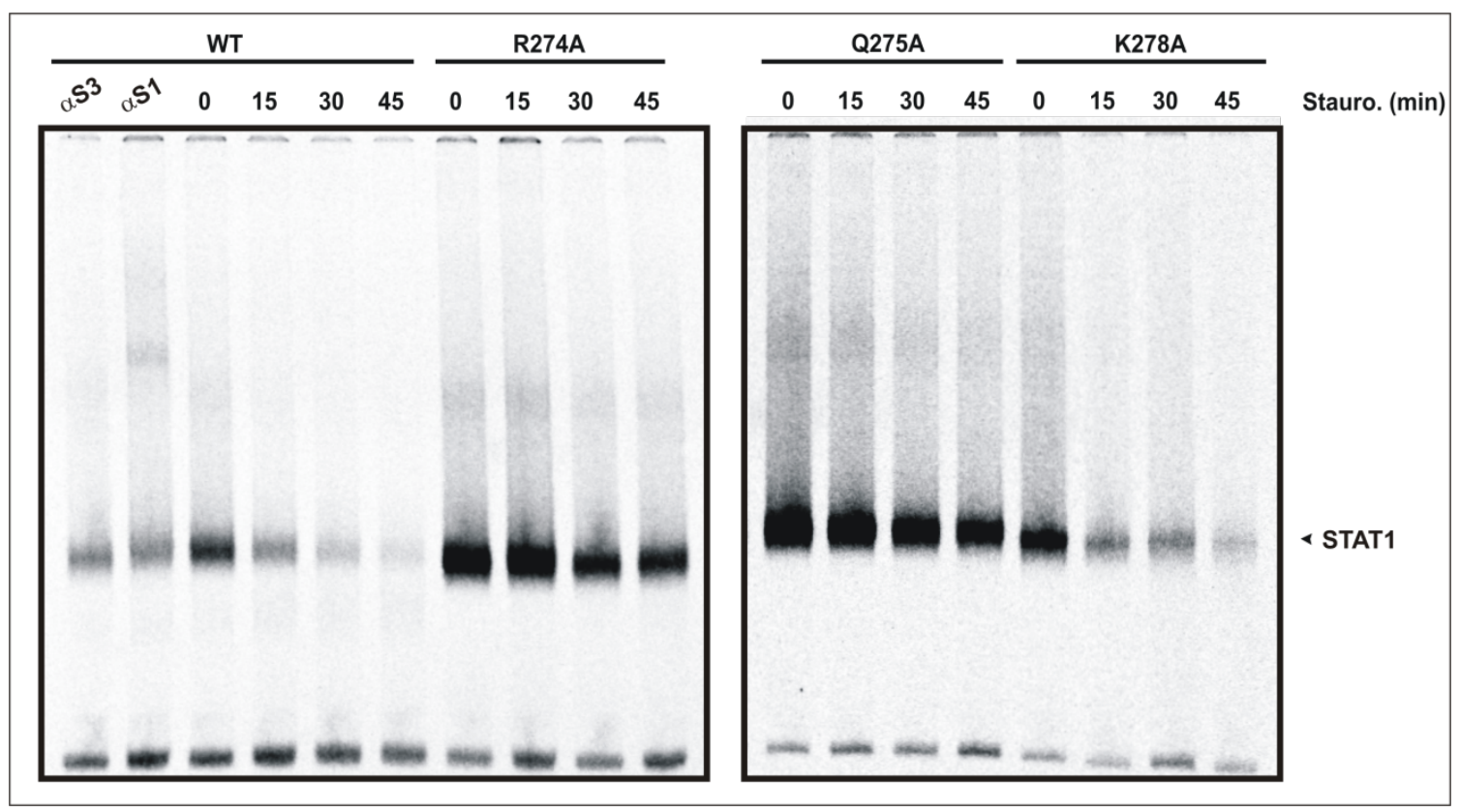

Abb. 11: Erhöhte Bindung der STAT1-Punktmutanten R274W und Q275A an radioaktiv markierte GAS-Sonde. Gelretardierungsexperiment mit $\left[\mathrm{P}^{33}\right]$-radioaktiv markierter M67-Sonde, die über einen Zeitraum von $15 \mathrm{~min}$ zu Gesamtzellextrakten aus STAT1-exprimierenden U3AZellen zugefügt wurde. STAT1-defiziente U3A-Zellen wurden zuvor mit pcDNA3.1-Plasmiden transfiziert und nach der Rekonstitution der STAT1-Expresion für 45 min mit IFN $\gamma$ stimuliert. Durch Zugabe von Staurosporin über größer werdende Zeiträume wurde die Abnahme der Tyrosin-Phosphorylierung autoradiographisch bestimmt. Die Mutante K278A zeigt keine Unterschiede im Vergleich zum Wildtyp-Protein. Für Supershift-Experimente wurden die Antikörper $\alpha$ STAT1 und $\alpha$ STAT3 den Reaktionsansätzen hinzugefügt. 


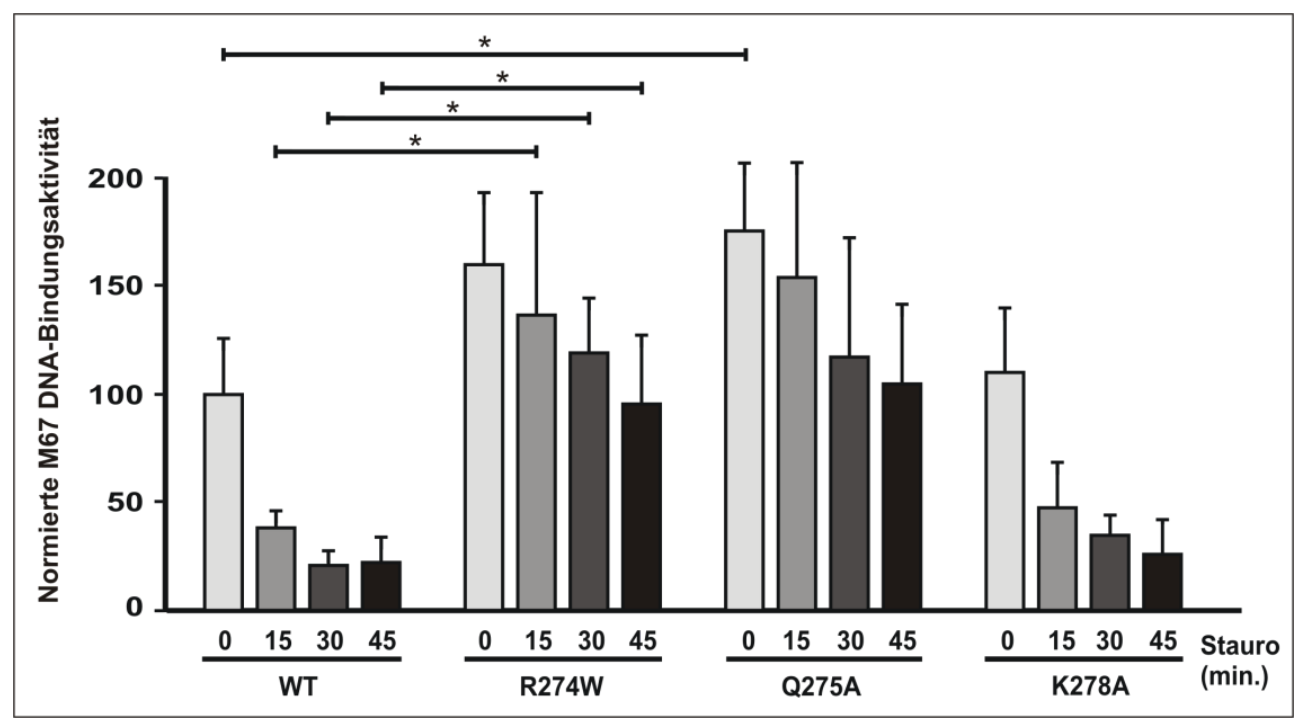

Abb. 12: Säulendiagramm zur Darstellung der signifikant prolongierten DNA-Bindung der STAT1-Mutanten R274W und Q275A. Für die Quantifizierung wurden drei unabhängige EMSA-Experimente wie in Abb. 11 durchgeführt und statistisch ausgewertet.

Zur weiteren Charakterisierung der drei STAT1-Punktmutationen R274W, Q275A und K278A wurde das sequenzspezifische DNA-Bindungsverhalten untersucht. Hierfür wurden U3A-Zellen mit einem der drei pcDNA3.1-Konstrukte oder dem Wildtyp-Molekül transfiziert. Nach 45-minütiger Stimulation mit 50 $\mathrm{ng} / \mathrm{ml}$ IFN $\gamma$ wurden Proteinextrakte hergestellt und mit verschiedenen doppelsträngigen Oligonukleotiden inkubiert, wobei diese entweder zwei (2xGAS), eine (GAS-nonGAS) oder keine (2xnonGAS) GAS-Stellen enthielten. Die DNASonden wurden zuvor mit dem radioaktiven Isotop $\left[\mathrm{P}^{33}\right]$ markiert.

Die Ergebnisse zeigen, dass die STAT1-Varianten verglichen mit STAT1-WT keinen Unterscheid bezüglich der Bindung an DNA-Sequenzen in TandemOrientierung aufweisen. Auch das Verhältnis von tetrameren zu dimeren STAT1-Komplexen unterscheidet sich nicht zwischen dem STAT1-WT-Protein und den drei Punktmutanten. Die Anzahl der Bindungen von STAT1Tetrameren an 2xGAS ist in allen gezeigten STAT1-Varianten autoradiographisch deutlich und an 2xnonGAS nahezu nicht mehr detektierbar. 


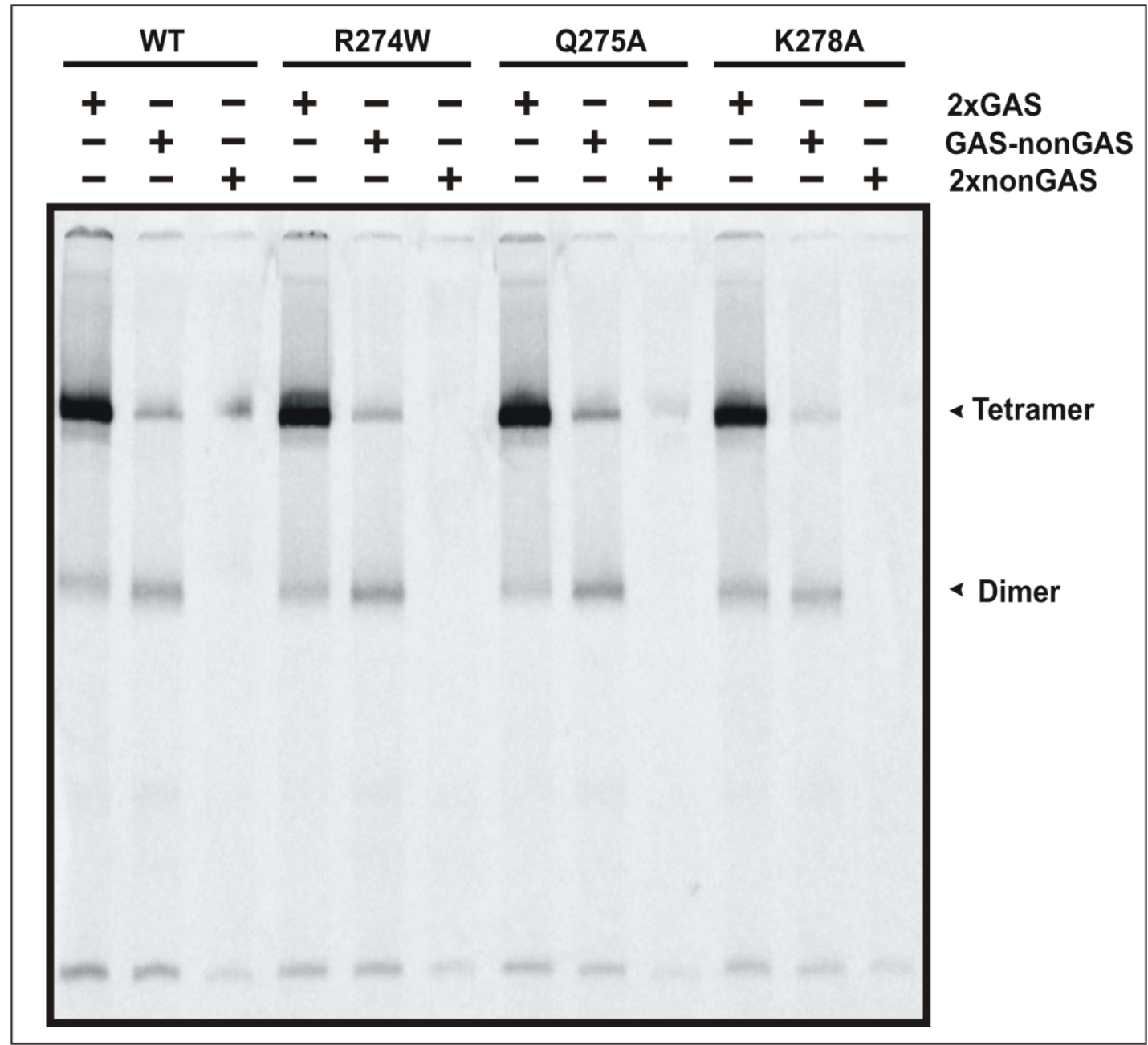

Abb. 13: Typisches sequenzspezifisches DNA-Bindungsverhalten der drei generierten STAT1-Punktmutanten R274W, Q275A und K278A. Zellysate von STAT1-WT-, STAT1R274W- , STAT1-Q275A- und STAT1-K278A-exprimierenden U3A-Zellen wurden mit $50 \mathrm{ng} / \mathrm{ml}$ IFN $\gamma$ für 45 min stimuliert und am nächsten Tag mit [ $\left.{ }^{33}\right]$-markierten 2xGAS, GASnonGAS oder 2xnonGAS-Sonden inkubiert. Nach gelektrophoretischer Auftrennung konnten tetramere und dimere Komplexe autoradiographisch dargestellt werden; sie sind in der Abbildung durch Pfeile gekennzeichnet. Es bestehen keine Unterschiede zwischen den STAT1-Punktmutanten und dem Wildtyp-Molekül im sequenzspezifischen DNA-Bindungsverhalten. 


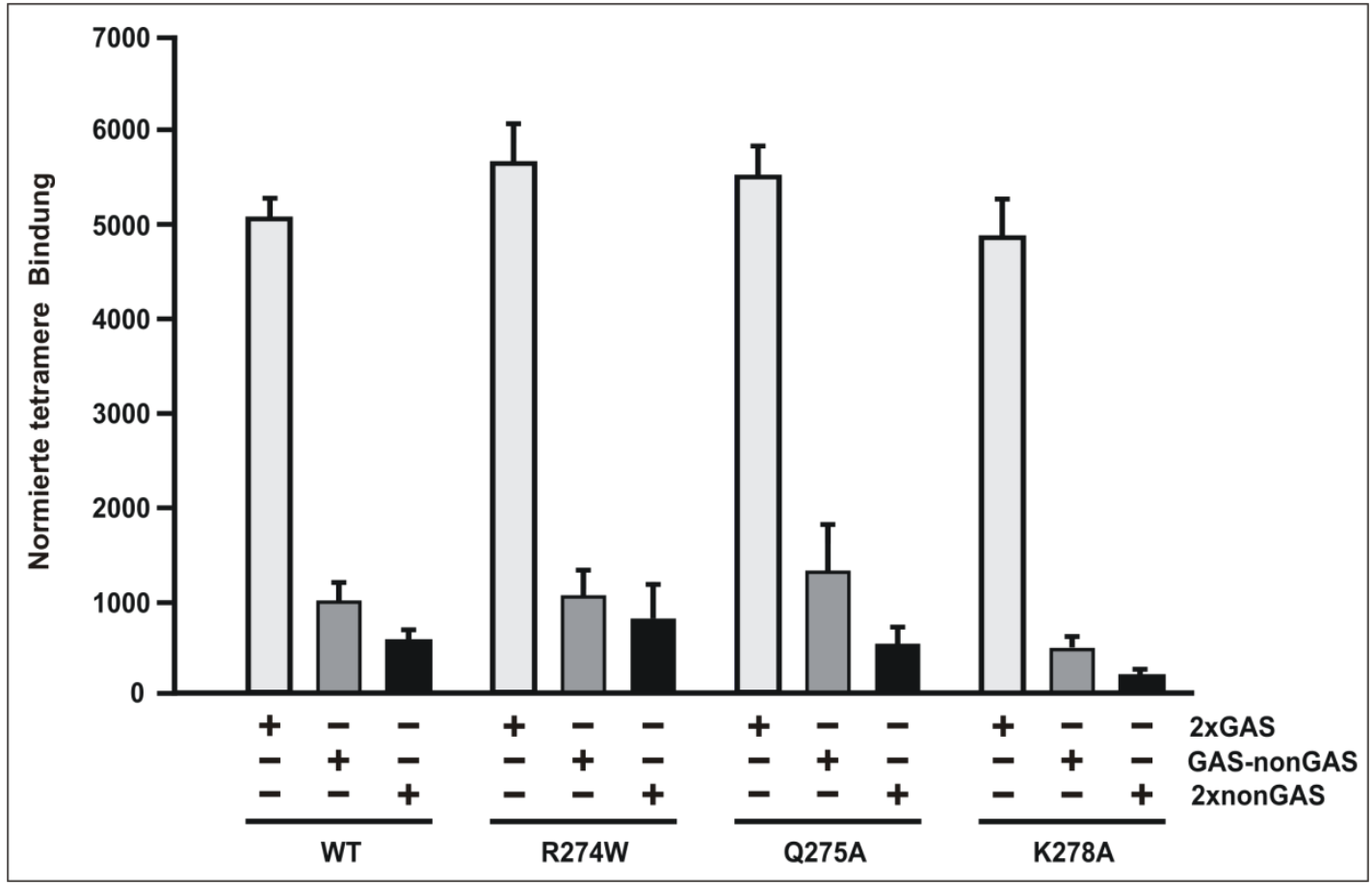

Abb. 14: Die Quantifizierung zeigt keine signifikanten Unterschiede in der Kinetik der Bindung an verschiedene GAS-Sonden zwischen den STAT1-Punktmutanten und dem Wildtyp-Molekül. Das Verhältnis von tetrameren zu dimeren STAT1-Komplexen in den untersuchten STAT1-Varianten entspricht dem des Wildtyp-Moleküls, wie in drei unabhängigen Gelretardierungsexperimenten gezeigt werden konnte.

In einem weiteren Gelretardierungs-Assay wurde das Tetramerisierungsverhalten und somit die Fähigkeit zur kooperativen DNA-Bindung der STAT1Punktmutanten in einem Kompetitionsexperiment untersucht. U3A-Zellen wurden hierfür mit pcDNA3.1-STAT1-WT oder den entsprechend mutierten Plasmiden transfiziert und am folgenden Tag für $45 \mathrm{~min}$ mit $50 \mathrm{ng} / \mathrm{ml} \mathrm{IFN} \gamma$ stimuliert. Daraufhin erfolgte die Herstellung von Proteinextrakten, die für das Experiment 30 min mit einer radioaktiv markierten 2xGAS-Sonde inkubiert wurden. Zur Kompetition kam eine unmarkierte Sonde mit einfacher GAS-Bindestelle in 750fachem molarem Überschuss zum Einsatz. Die Ergebnisse zeigen, dass alle STAT1-Varianten bei Inkubation mit einer zweifachen GAS-Bindestelle die Fähigkeit besitzen Tetramere und Dimere zu bilden, wobei die Ausbildung tetramerer Komplexe bei den gewählten Konzentrationen bevorzugt wird. Aufgrund inrer Instabilität zerfielen die dimeren STAT1-Komplexe nach Kompetition mit der unmarkierten GAS-Sonde. Die Auftrennung erfolgte im nicht-denatu-rierten Polyacrylamidgel, wobei die größeren tetrameren Molekülkomplexe sich langsamer im Laufverhalten präsentierten und somit autoradiographisch von den 
dimeren Komplexen abgrenzbar waren. Einem Reaktionsansatz wurde vor Beladung des Gels radioaktiv markierte M67-Sonde hinzugefügt, um im Anschluss die Position dimerer STAT1-Komplexe zu detektieren. Die Fähigkeit zur kooperativen DNA-Bindung war sowohl für die STAT1-GOF-Mutationen als auch für das Wildtyp-Molekül gegeben. Im Vergleich ließen sich keine Unterschiede erkennen.

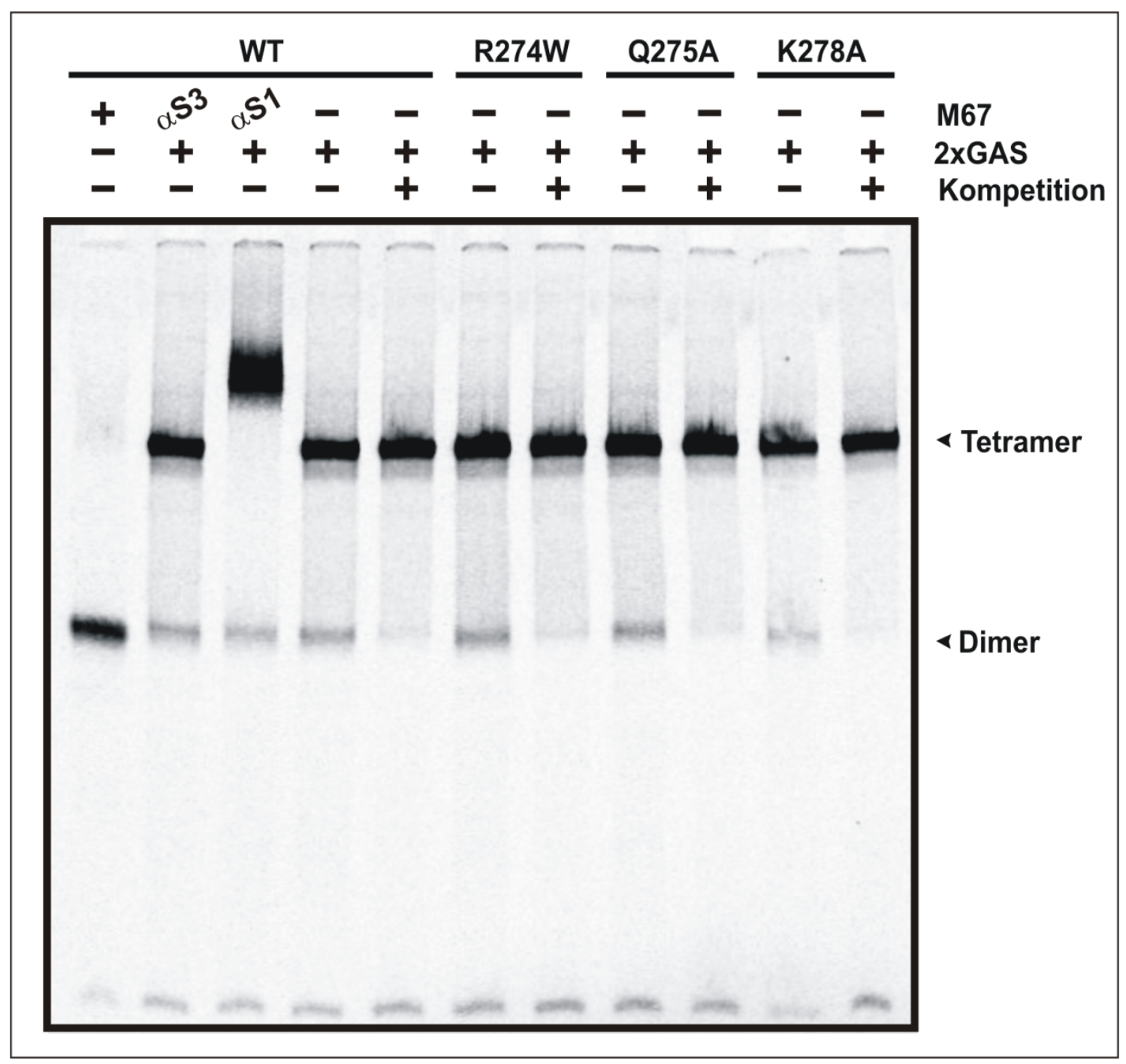

Abb. 15: Das Tetrameriserungsverhalten der STAT1-Mutanten entspricht dem des Wildtyp-Moleküls. U3A-Zellen wurden mit pcDNA3.1-WT-, R274W, Q275A oder K278A-Plasmid transfiziert und anschließend mit IFN $\gamma$ stimuliert. Für den dargestellten Gelshift-Assay wurden aus den Zellen gewonnene Lysate mit einer $\left[\mathrm{P}^{33}\right]$-markierten 2xGAS-Sonde inkubiert und anschließend zur gelelektrophoretischen Auftrennung auf ein Polyacrylamidgel geladen. Jeder zweite Reaktionsansatz wurde zuvor mit einer unmarkierten, einfachen GAS-Probe in 750fachem molarem Überschuss versetzt. Supershift-Experimente mit STAT1-spezifischem E-23und STAT3-spezifischem H-190-Antikörper verifizieren die STAT1-spezifische DNA-Bindung in der hier gezeigten autoradiographischen Darstellung. 


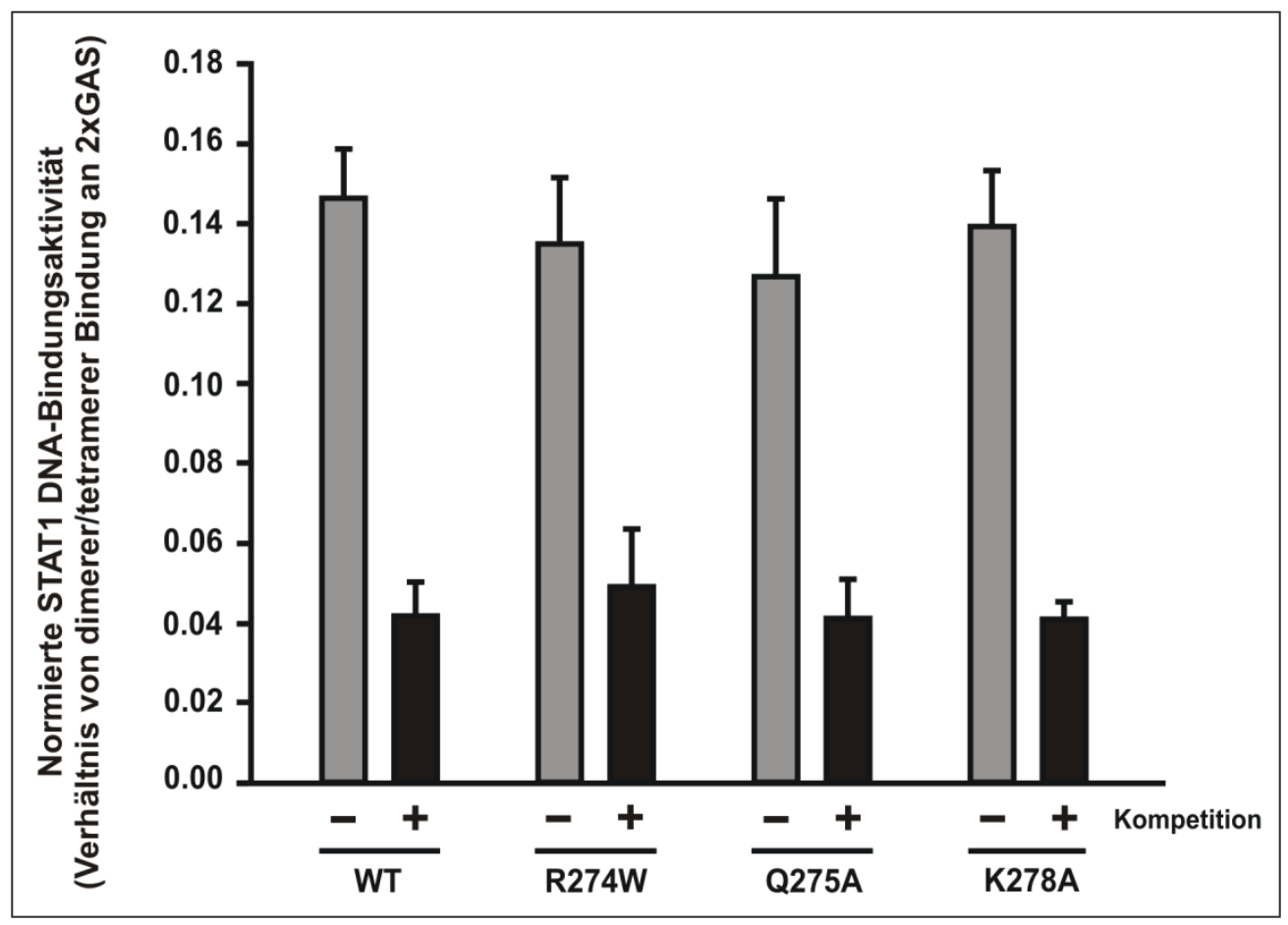

Abb. 16: Statistische Auswertung und Darstellung als Säulendiagramm des Tetrameriserungsverhaltens der verschiedenen STAT1-Derivate. Zur Berechnung wurde der Quotient aus dimeren/tetrameren STAT1-Komplexen herangezogen. Die Abbildung verdeutlicht, dass der Prozentsatz an 2xGAS gebundener Komplexe in den verschiedenen STAT1-Varianten aus drei unabhängigen Experimenten keinen Unterschied zum Wildtyp-Molekül aufweist.

In einem letzten Versuch zur DNA-Bindungsanalyse wurde die Dissoziationskinetik von GAS-Bindestellen der STAT1-GOF-Mutationen untersucht. Hierfür wurden Kompetitionsversuche durchgeführt mit Proteinextrakten von Zellen, die zuvor $45 \mathrm{~min}$ mit $50 \mathrm{ng} / \mathrm{ml}$ IFN $\gamma$ stimuliert worden waren. In In-vitro-Reaktionen wurden die Gesamtzellextrakte 10 min mit einer radioaktiv markierten M67Sonde inkubiert und nachfolgend eine unmarkierte M67-Sonde in 750-fachen molaren Überschuss hinzugefügt. Die Inkubation der Lysaten aus STAT1-WT-, STAT1-R274W-, STAT1-Q275A- und STAT1-K278A-exprimierenden U3AZellen mit unmarkierter, singulärer M67-Bindestelle erfolgte für 0,5 oder 10 min. Die fertigen Reaktionsansätze wurden auf ein natives Polyacrylamidgel geladen und nach Vakuumtrocknung der Gele die radioaktiven Signale mit Hilfe einer Phosphor-Imager-Platte detektiert. 


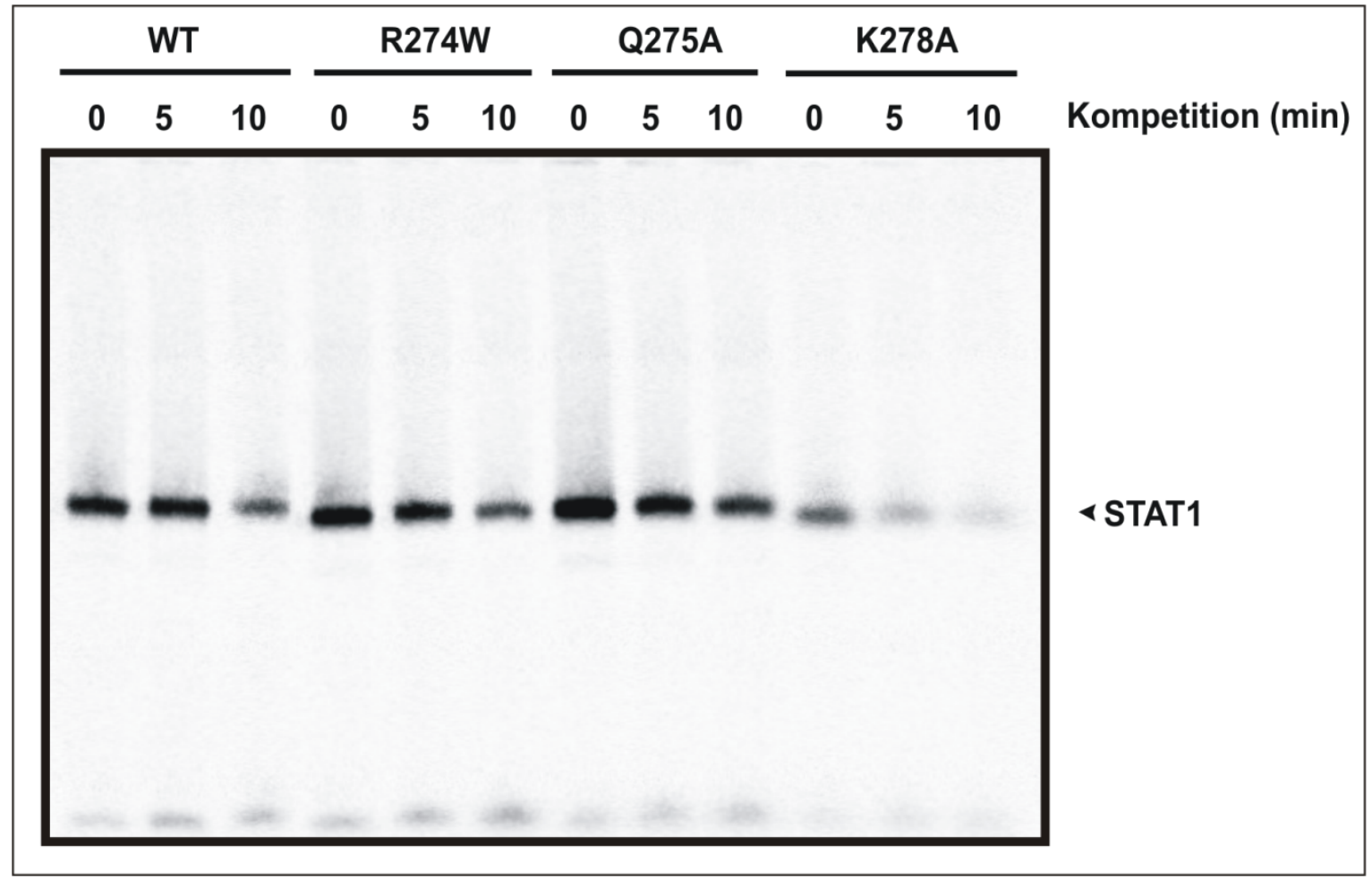

Abb. 17: Die DNA-Bindungsaffinität an eine singuläre GAS-Sonde des STAT1-WTMoleküls ist vergleichbar mit denen der drei STAT1-GOF-Mutanten. Dargestellt ist das Ergebnis eines repräsentativen Gelretardierungs-Experiments. Ganzzell-Proteinextrakte aus IFN $\gamma$-vorbehandelten, STAT1-rekonstituierten U3A-Zellen wurden mit radioaktiv markierter M67DNA für 10 min inkubiert. Anschließend wurde zur Kompetition eine unmarkierte M67-Sonde im hohen molaren Überschuss für die angegebenen Zeitintervalle hinzugefügt. Native Polyacrylamidgele dienten zur Auftrennung der DNA-Protein-Komplexe, und nach deren Vakuumtrocknung erfolgte die autoradiographische Darstellung der an M67 gebundenen STAT1Moleküle. 


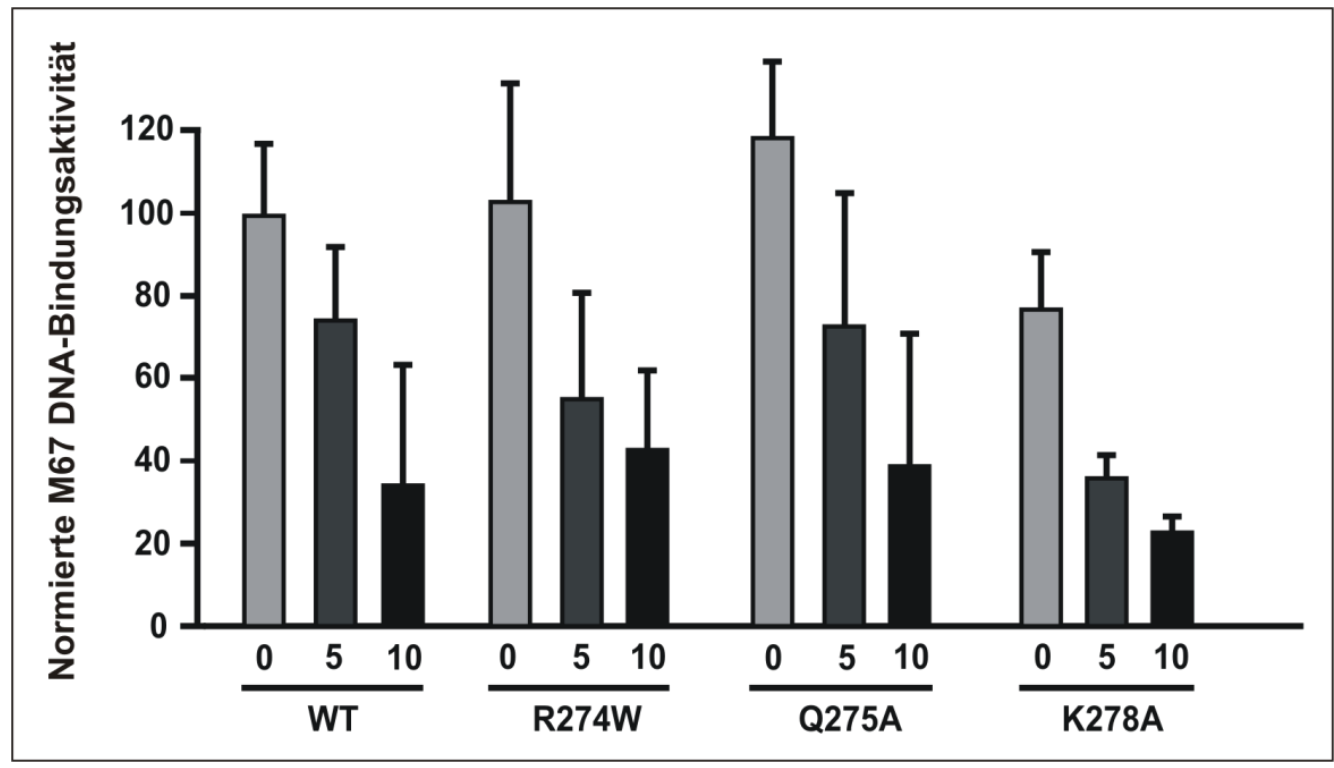

Abb. 18: Vergleichbares IFN $\gamma$-induziertes DNA-Dissoziationsverhalten im kompetitiven Gelshift-Experiment. Die in der Coiled-coil-Domäne lokalisierten Mutanten R274W, Q275A und K278A zeigen keine Unterschiede zu STAT1-WT in der DNA-Bindungsaffinität an eine mit $\left[\mathrm{P}^{33}\right]$-markierte, einfache GAS-Sequenz nach Kompetition mit unmarkierter M67-Sonde. Das Balkendiagramm repräsentiert die Ergebnisse der kinetischen Messungen aus drei stattgefundenen EMSA-Experimenten.

Die Ergebnisse verdeutlichen, dass die Dissoziationsrate der STAT1-GOFMutanten von einer hoch-affinen singulären GAS-Bindestelle nach Kompetition mit unmarkierter M67-Probe in 750-fachem molarem Überschuss der des Wildtyp-Moleküls entspricht.

\subsection{Verlängerte Kernakkumulation nach IFN $\gamma$-Stimulation der beiden Punktmutanten in der Coiled-coil-Domäne}

Nachdem gezeigt worden war, dass die STAT1-Mutationen R274W und Q275A mit einer erhöhten Tyrosin-Phosphorylierung und verstärkten Bindung an eine einfache GAS-Bindestelle assoziiert sind, wurde als nächstes die Kinetik der Kernakkumulation nach Stimulation mit IFN $\gamma$ genauer untersucht. Fluoreszenzmikroskopisch aufgenommene Bilder gaben Aufschluss über das zytoplasmatische und nukleären Verteilungsmusters der drei generierten STAT1-Mutanten und dem Wildtyp-Molekül. Zwecks immunzytochemischer Färbung wurden STAT1-negative U3A-Zellen mit STAT1-exprimierenden pcDNA3.1-Konstukten

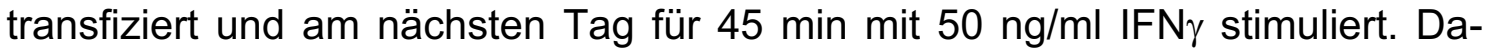
raufhin folgte die Inkubation mit $1 \mu \mathrm{M}$ Staurosporin für die angegebenen Zeitin- 
tervalle. Um Aussagen zur Anfangsdistribution der STAT-Moleküle treffen zu können, blieben Zellen in Kontrollexperimenten unstimuliert. Die Fixierung der Zellen vor der sich anschließenden Immunfärbung erfolgte für 15 min bei $-20{ }^{\circ} \mathrm{C}$ mit Methanol. Nach Permeabilisation der Zellen und Blockierung freier Bindungen mit FCS erfolgte die Inkubation mit dem STAT1-spezifischem Antikörper E-23, gefolgt von einem Cy3-gekoppelten Sekundärantikörper. Somit konnte das intrazelluläre Verteilungsmuster von STAT1 durch indirekte Fluoreszenzmikroskopie sichtbar gemacht werden. Um die Lage der Zellkerne in den verwendeten U3A-Zellen zu visualisieren, wurde zusätzlich eine Färbung mit Hoechst-Farbstoff durchgeführt.

Durch die Expression von STAT1-GFP-Fusionsproteinen in HeLa-Zellen konnte die oben genannte Fragestellung zur Kinetik der zytokininduzierten Kernakkumulation in zwei verschiedenen Versuchsreihen verifiziert werden. Auch hierfür wurden die Zellen entweder unbehandelt gelassen oder die Kernakkumulation durch Zugabe von IFN $\gamma$ herbeigeführt und anschließend eine nukleozytoplasmatische Umverteilung durch die inhibitorische Wirkung von Staurosporin eingeleitet. Nach Fixierung der GFP-markierten HeLa-Zellen mit Paraformaldehyd wurden die Zellkerne mit blau-fluoreszierendem Hoechst-Farbstoff angefärbt und unter dem Fluoreszenz-Mikroskop unter Hinzunahme verschiedener Fluoreszenz-Filter detektiert. Um nicht nur Aussagen bezüglich des Kernzerfalls, sondern auch spezifisch Unterschiede im nukleären Aufnahmeverhalten zu erhalten, wurden des Weiteren fluoreszenzmikroskopische Aufnahmen nach 10- , 20- , und 30-minütiger IFN $\gamma$-Stimulation angefertigt. 


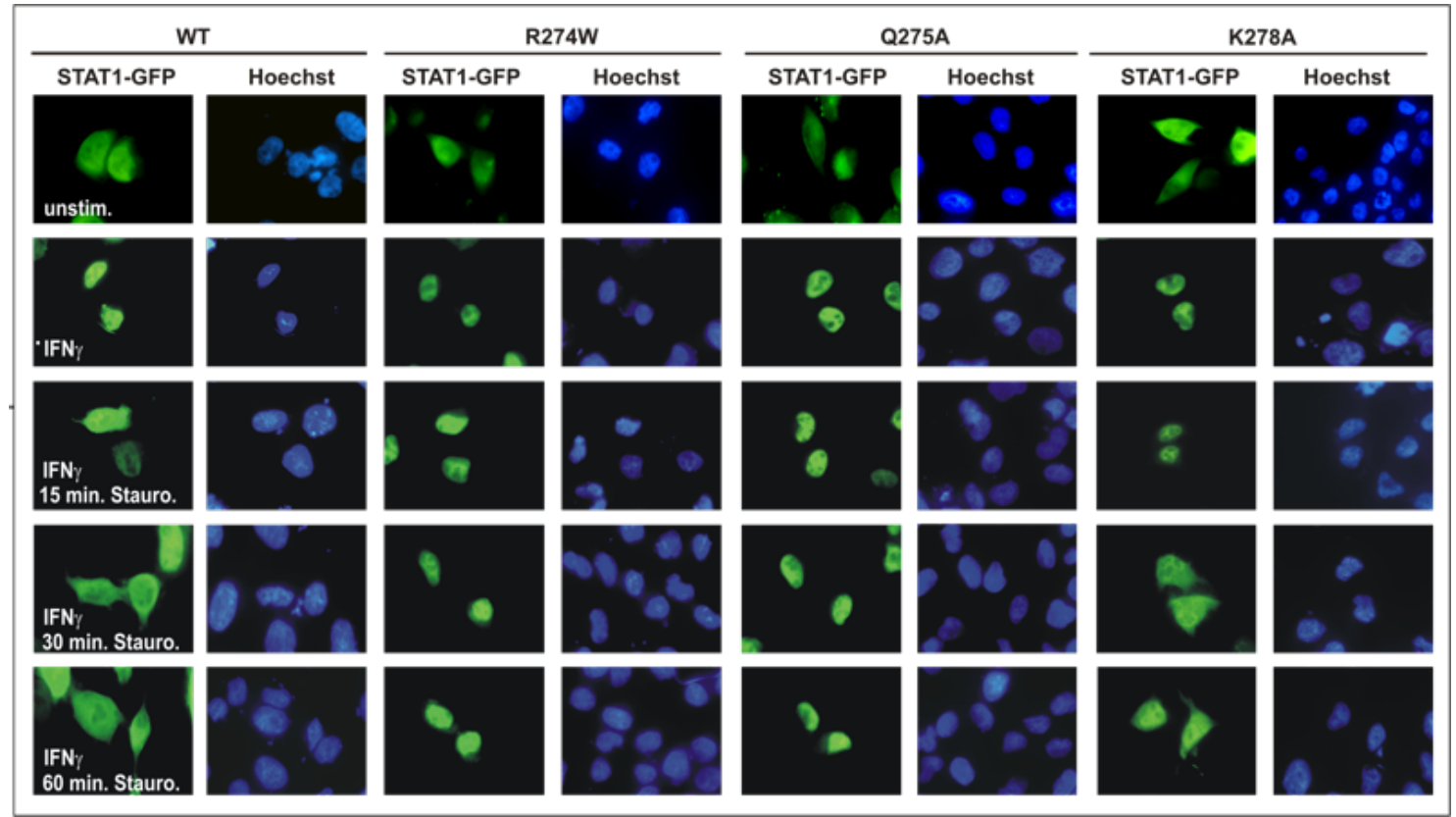

Abb. 19: Kernakkumuliertes STAT1-R274W oder STAT1-Q275A zeigt sich unempfindlich gegenüber Staurosporin-Exposition. STAT1-WT-GFP, STAT1-R274W, STAT1-Q275A und STAT1-K278A exprimierende HeLa-S3-Zellen wurden nach 45-minütiger IFN $\gamma$-Stimulation mit 1 $\mu \mathrm{M}$ Staurosporin inhibiert. Für die fluoreszenzmikroskopischen Aufnahmen erfolgte die Fixierung mit Formaldehyd und die Zellkernanfärbung mit Hoechst 33258. Die Abbildung zeigt Aufnahmen der Zellen im unstimulierten und stimulierten Zustand.

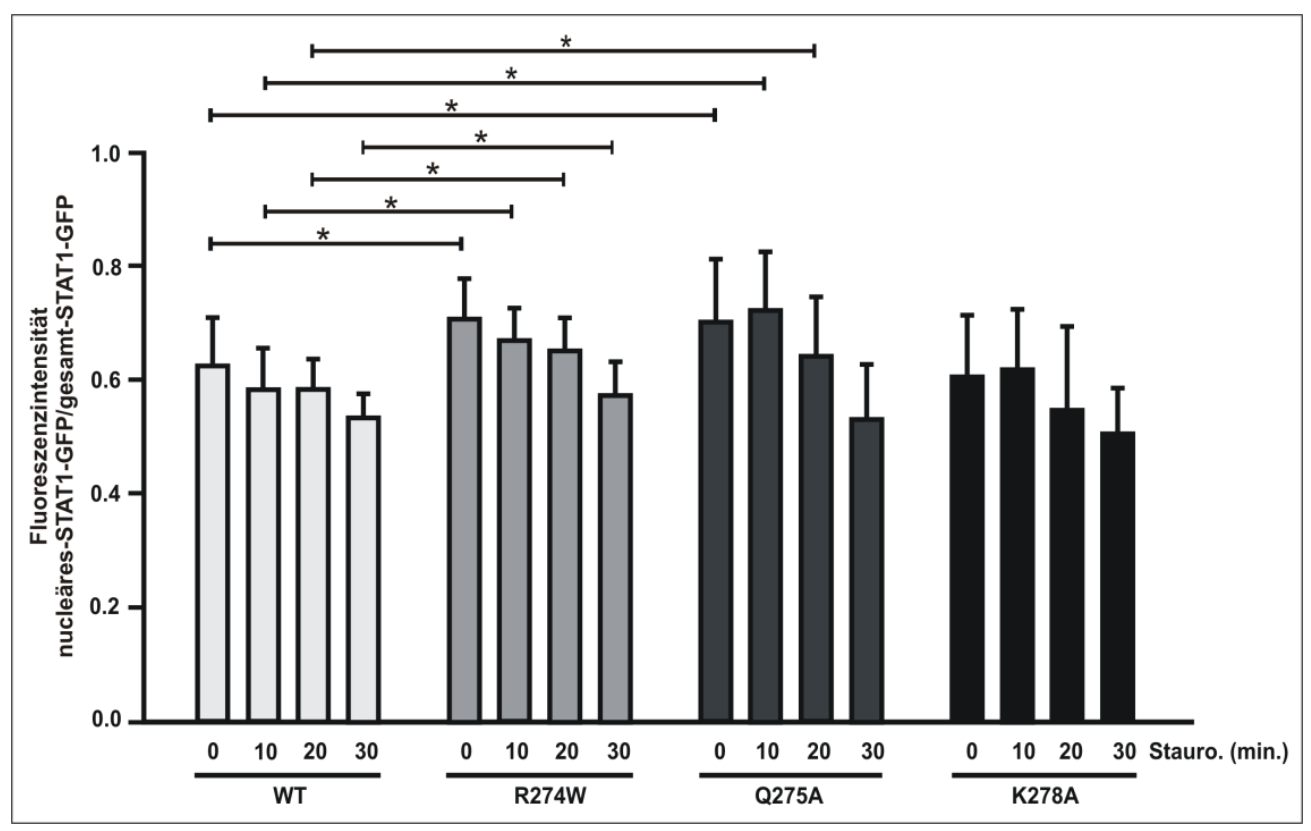

Abb. 20: Statistisch signifikante Unterschiede in der nukleären Retentionszeit der zwei generierten Punktmutanten nach Inkubation mit Staurosporin gegenüber dem WTMolekül. HeLa-Zellen wurden entsprechend den Angaben in Abb. 19 behandelt. Die Messungen der STAT1-Redistribution erfolgten in drei verschiedenen Transfektionsansätzen, wobei 
Aufnahmen der Zellen nach 0-, 10-, 20- und 30-minütiger Stimulation mit Staurosporin angefertigt wurden.

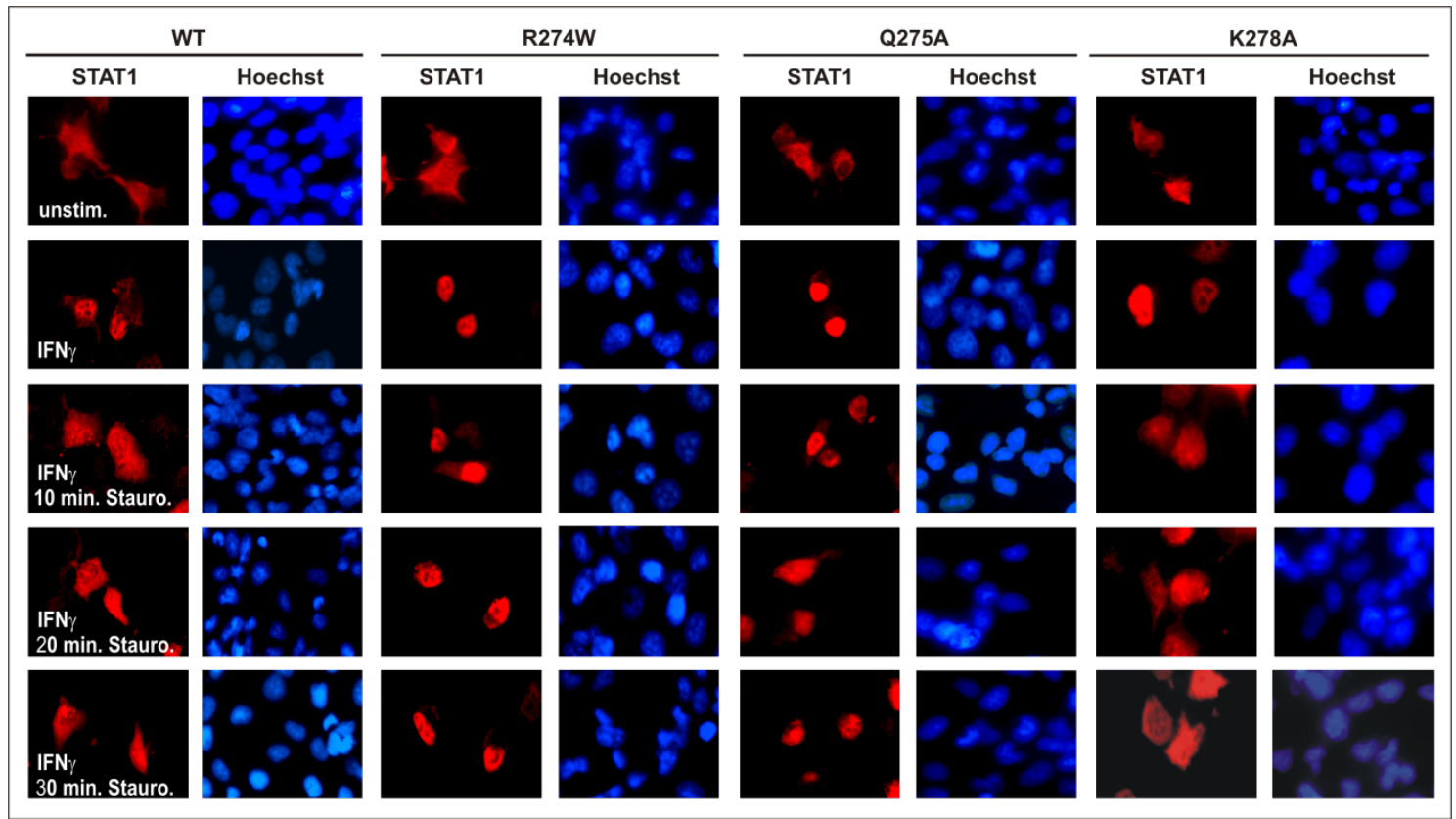

Abb. 21: Prolongierte nukleäre Akkumulationsdauer der STAT1-Varianten R274W und Q275A nach Stimulation mit IFN $\gamma$ und anschließender Zugabe von Staurosporin. STAT1negative U3A-Zellen wurden mit entsprechendem pcDNA3.1-Plasmid transfiziert und am Folgetag mit $50 \mathrm{ng} / \mathrm{ml}$ IFN $\gamma$ stimuliert. Es erfolgte anschließend eine Exposition mit dem KinaseInhibitor Staurosporin für 10, 20 oder 30 min. Für die Immunfärbung wurden die Zellen mit $\alpha$ STAT1-Primärantikörper und mit Cy3-konjugiertem Sekundärantikörper inkubiert und darauffolgend durch indirekte Fluoreszenzmikroskopie visualisiert. 


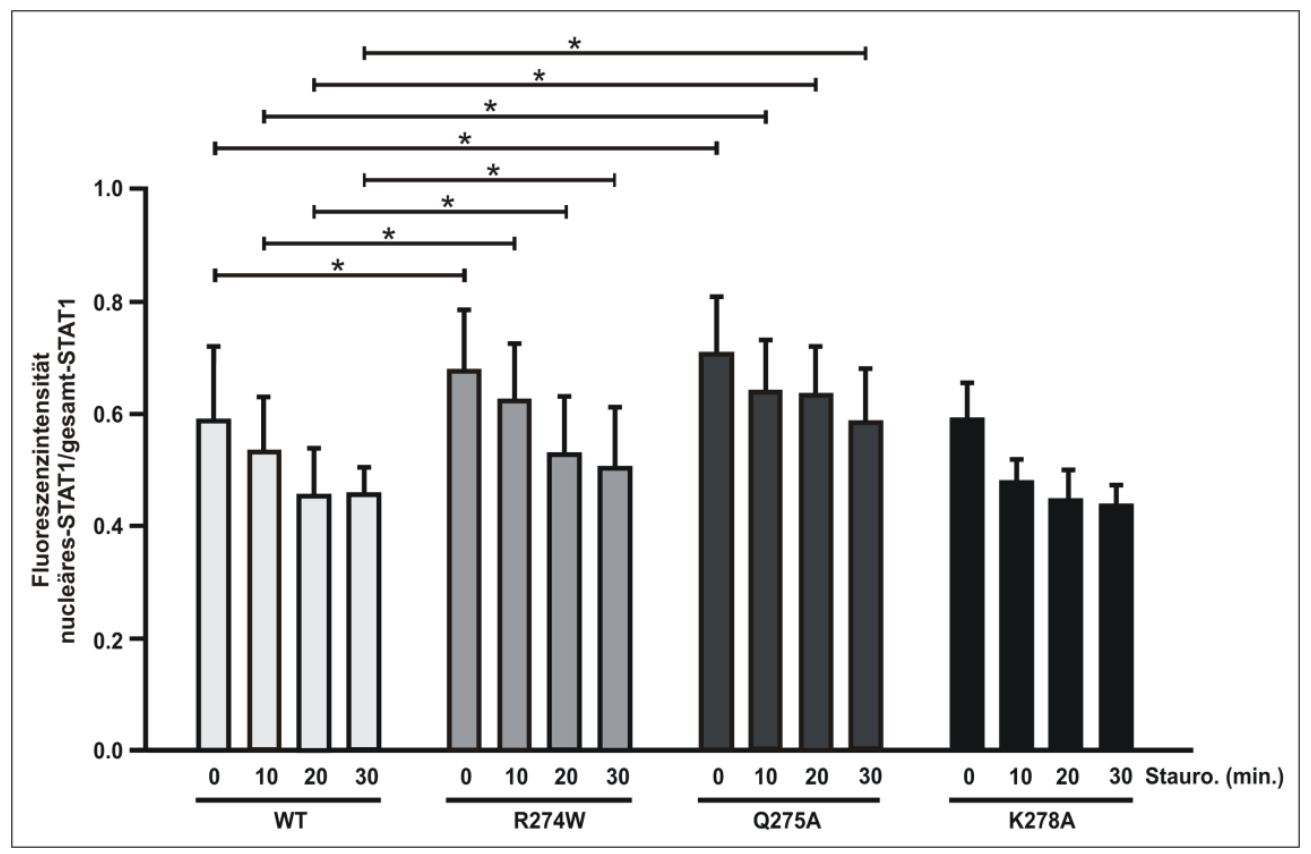

Abb. 22: Säulendiagramm zur Darstellung signifikanter Unterscheide im Abbau der IFN $\gamma$ induzierten Kernakkumulation nach anschließender Inkubation mit Staurosporin bei zwei Mutanten in der STAT1-Coiled-coil-Domäne. Dargestellt ist das Verhältnis von nukleärem zu Gesamt-STAT1 nach Inkubation der mit IFN $\gamma$-vorbehandelten (45 min) und unmittelbar nachfolgend Staurosporin-exponierten Zellen zu den angegebenen Zeitpunkten. Signifikante Ergebnisse sind mit schwarzem Balken und Sternchen $\left({ }^{*}\right)$ gekennzeichnet.

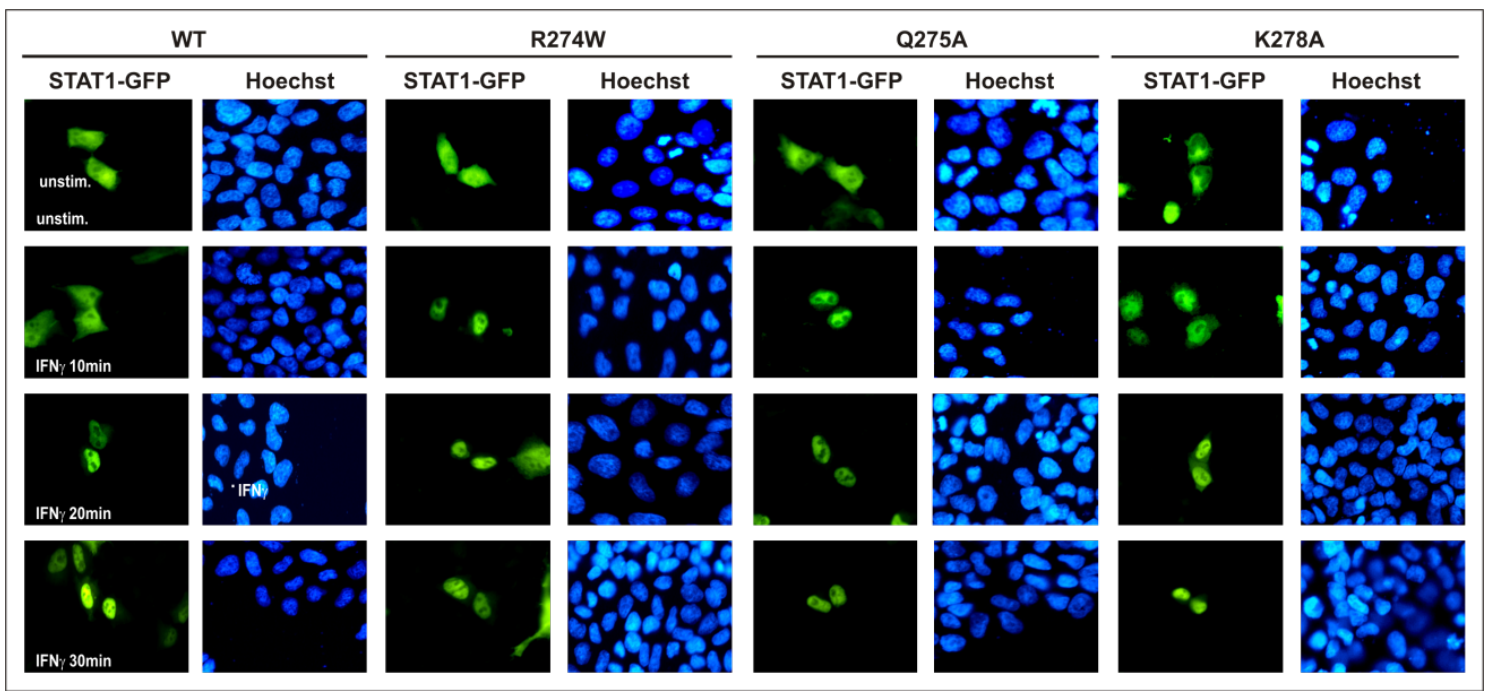

Abb. 23: Vorzeitige Kernakkumulation der Punktmutanten R274W und Q275A in IFN $\gamma$ stimulierten Zellen verglichen mit STAT1-WT. pSTAT1-GFP-WT und die entsprechend mutierten Plasmide, die für GFP-Fusionsproteine von STAT1-R274W, -Q275A bzW. -K278A kodieren, wurden in HeLa-Zellen transfiziert. Nach Inkubation der Zellen mit IFN $\gamma$ erfolgten fluoreszenzmikroskopische Aufnahmen zu dem jeweiligen Stimulationszeitpunkt. Die Zellen wurden zuvor mit 4\% Formalin fixiert und mit Hoechst-Färbstoff angefärbt. 


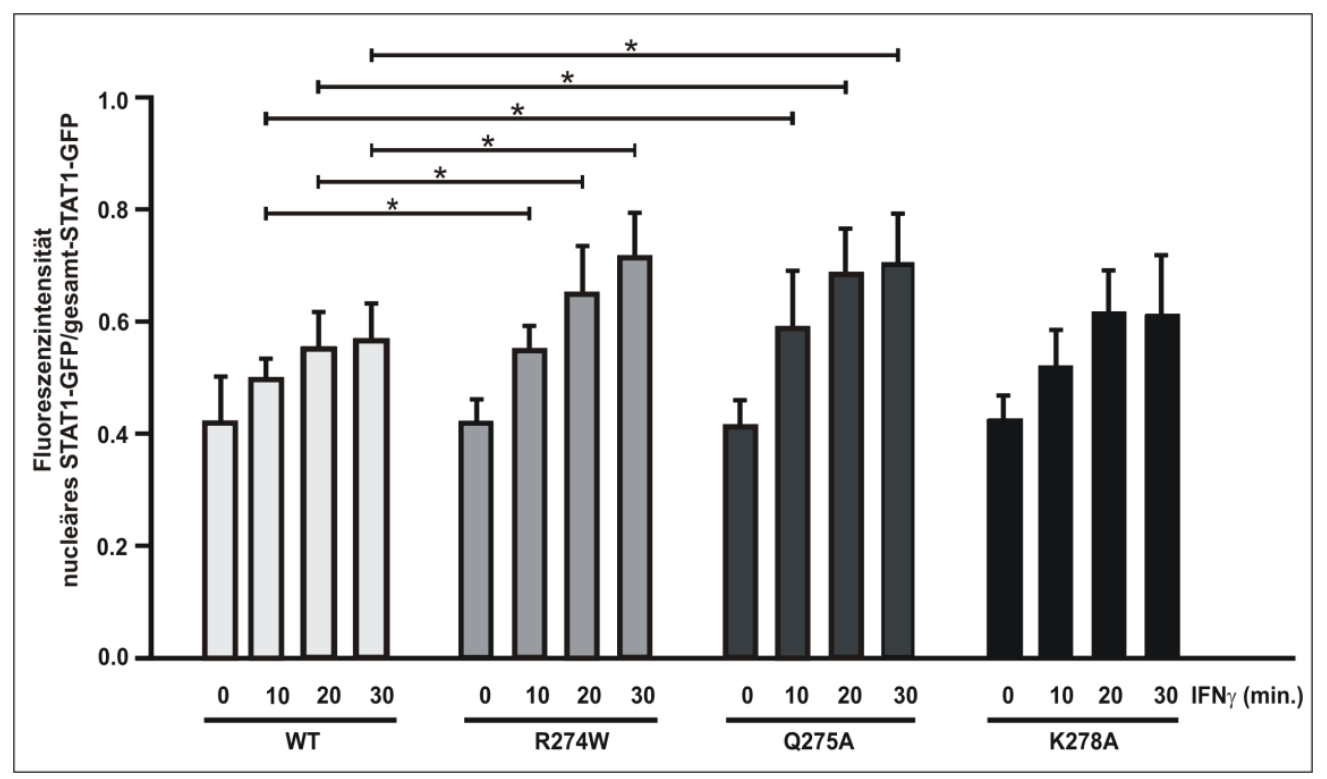

Abb. 24: Quantifizierung der nukleozytoplasmatischen Distribution der GFP-markierten STAT1-Moleküle nach Zytokinstimulation. Die Histodiagramme demonstrieren die signifikant schnellere Kernakkumulation der GOF-Mutationen R274W und Q275A gegenüber dem WildtypMolekül, ermittelt aus drei voneinander unabhängigen Transfektionsansätzen.

Der Austausch von Tryptophan für Arginin an Position 274 und Austausch eines Glycinrests gegen Alanin an Position 275 führt sowohl zu einem schnelleren Kernimport nach Stimulation mit IFN $\gamma$ als auch zu einer verlängerten Akkumulation des STAT1-Dimers im Zellkern, wie Experimente mit dem potenten KinaseInhibitor Staurosporin zeigen. Nach 30-minütiger Inkubation mit Staurosporin erfolgte bereits der vollständige Export der STAT1-Mutante K278A und des Wildtyp-Moleküls zurück ins Zytoplasma; STAT1-R274W und Q275A zeigten sich dagegen zu diesem Zeitpunkt noch unempfindlich gegenüber dem inhibitorischen Effekt des Kinase-Inhibitors und auch nach 60 min war noch eine, wenn auch geringere Akkumulation dieser zwei Mutanten zu erkennen. Diese Staurosporin-Unempfindlichkeit galt sowohl nach Transfektion unmarkierter STAT1Plasmide in U3A-Zellen (Abb. 21) als auch nach Expression von GFPFusionsproteine in HeLa-Zellen (Abb. 19). Die Mutation an Position 274 und 275 durch die hier verwendeten Aminosäuren beeinflusst nicht nur die Dauer der nukleären Akkumulation des STAT1-Moleküls, sondern auch den Kernimport, wie in Abb. 23 deutlich wird. Nach nur 10-minütiger Stimulation mit IFN $\gamma$ erfolgte der vollständige Kernimport von R274W und Q275A. Die beiden Varianten STAT1-WT und K278A benötigten dagegen zusätzliche, weitere $10 \mathrm{~min}$, 
um einen gleichen Effekt in Bezug auf die Erreichung eines nahezu komplett kernakkumulierten Zustandes zu erzielen.

\subsection{Erhöhte Aktivität im Reportergen-Assay von STAT1- R274W, Q275A und K278A}

Zur differentiellen Untersuchung der transkriptionellen Aktivität der generierten STAT1-Punktmutanten fanden in einem ersten Versuch Reportergen-Assays statt. Verwendet wurden zwei verschiedene Reportergenkonstrukte, wobei einmal ein Luciferase-Reporter mit dreifacher GAS-Bindestelle (3xLy6E) eingesetzt wurde und in anderen Experimenten der Reporter pIC-339 Verwendung fand. Letzterer enthielt ein 339 Basenpaar langes, trunkiertes Fragment aus dem Promotor des ICAM1-Gens mit einfacher GAS-Bindestelle. Die zwei erwähnten Konstrukte wurden in unabhängigen Versuchen gemeinsam mit pSTAT1-WT bzw. dem entsprechend mutiertem Expressionsplasmid in U3A-Zellen transfiziert. Da dem Transfektionsansatz noch ein ß-Galaktosidase-kodierendes Plasmid hinzugefügt wurde, konnten die spektrometrischen Messungen am Ende über die Bestimmung des Quotienten Luciferaseaktivität/Galaktosidaseaktivität normiert werden. Nach erfolgreicher Transfektion wurden die Zellen ungefähr 24 h später 6 h mit 50 ng/ml IFN $\gamma$ stimuliert und anschließend im Luciferase-Reportergen-Assay eingesetzt. 


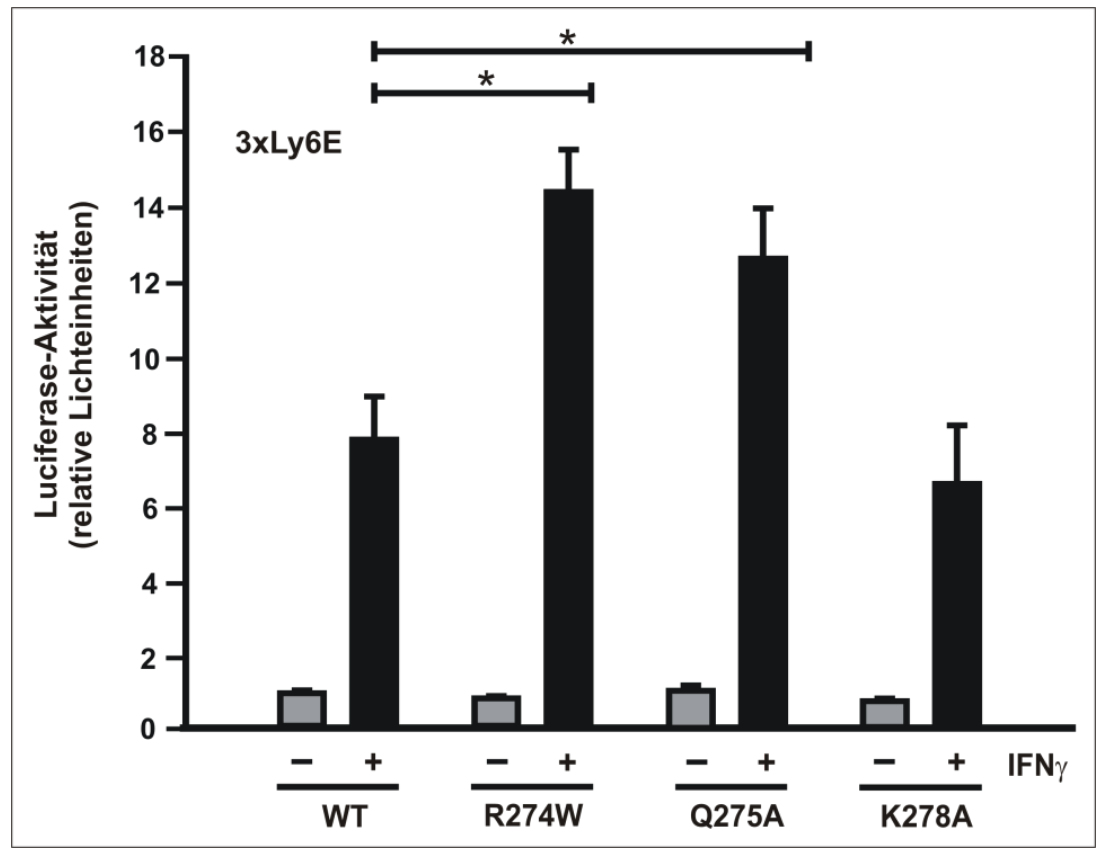

Abb. 25: Die in der Coiled-coil-Domäne lokalisierten STAT1-Punktmutanten R274W und Q275A zeigen eine erhöhte transkriptionelle Aktivität im Reportergen-Assay. U3A-Zellen wurden gemeinsam mit dem Reportergen 3xLy6E und pcDNA3.1-STAT1-Plasmid transfiziert, das entweder das Wildtyp-Protein oder die an Position 274, 275 bzw. 278 mutierte Variante kodiert. Anschließend wurden die rekonstituierten Zellen entweder $6 \mathrm{~h}$ mit IFN $\gamma$ stimuliert (schwarze Balken) oder unbehandelt gelassen (graue Balken). Nach der Herstellung von Zelllysaten erfolgte die spektrometrische Bestimmung der Luciferaseaktivität und die enzymatische Aktivitätsbestimmung der konstitutiv kotransfizierten ß-Galaktosidase. Pro Versuch wurden Sechsfachmessungen durchgeführt und diese dreimalig in unabhängigen Experimenten wiederholt. Statistisch signifikante Ergebnisse sind mit schwarzem Balken und Sternchen $\left({ }^{*}\right)$ gekennzeichnet. 


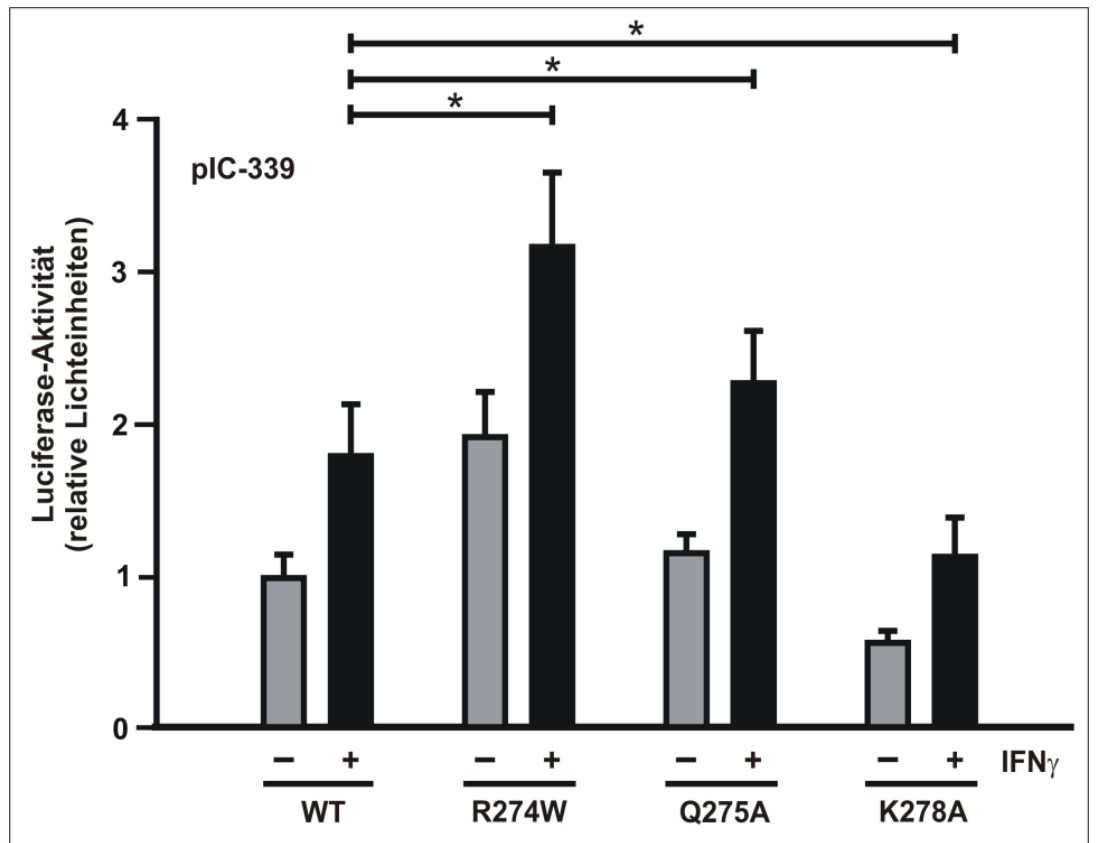

Abb. 26: Austausch des Argininrestes gegen Tryptophan an Position 274 und des Glycinrestes gegen Alanin an Position 275 führt zu einer erhöhten Genexpression des Reportergens pIC-339 nach IFN $\gamma$-Stimulation. Luciferase-Assay mit Gesamtzellextrakten aus rekonstituierten U3A-Zellen, welche $6 \mathrm{~h}$ mit IFN $\gamma$ stimuliert wurden. Nach Bestimmung der Luciferase-Aktivität aus den Zelllysaten wurden diese Werte auf die Aktivität der kotransfizierten $\beta$ Galaktosidase bezogen.

Wie Abb. 31 und 32 zu entnehmen, wiesen zwei von den drei generierten STAT1-Mutationen eine erhöhte transkriptionelle Aktivierung der Reportergene pIC-339 und 3xLy6E nach Stimulation mit IFN $\gamma$ auf. Im Gegensatz zu den Punktmutanten R274W und Q275A fand sich bei der Mutante K278A kein signifikanter Unterschied in der Genexpression verglichen mit dem Wildtyp-Molekül.

\subsection{STAT1-Punktmutanten im Vier-Helix-Bündel zeigen erhöhte Genexpression von IFN $\gamma$-induzierten Zielgenen}

Anhand von Real-time PCR-Analysen wurde die Aktivierung bekannter endogener STAT1-Zielgene in vivo nach Stimulation mit IFN $\gamma$ getestet. Dabei wurde auf Unterschiede im Expressionslevel zwischen dem STAT1-Wildtyp-Molekül gegenüber den generierten STAT1-Punktmutanten geachtet. Die STAT1-WT-, STAT1-R274W-, STAT1-Q275A- oder STAT1-K278A-exprimierenden Zellen wurden zwei Tage vor Beginn des Experiments transfiziert, nach $24 \mathrm{~h}$ in Nährmedium mit $1 \%$ fetalem Kälberserum kultiviert und nach $48 \mathrm{~h}$ für $6 \mathrm{~h}$ mit IFN $\gamma$ stimuliert oder unbehandelt gelassen. Der Extrahierung von RNA aus den trans- 
fizierten U3A-Zellen folgte die reverse Transkription in cDNA. In der daran anschließenden Real-time PCR wurden verschiedene STAT1-Zielgene in Doppelbestimmung untersucht, darunter $c c / 2$, mig1, cxcl10, mcp1 und irf1. Weiterhin wurde zur Überprüfung einer erfolgreichen Transfektion die Induktion des stat1und gapdh-Gens als Referenz gewählt.
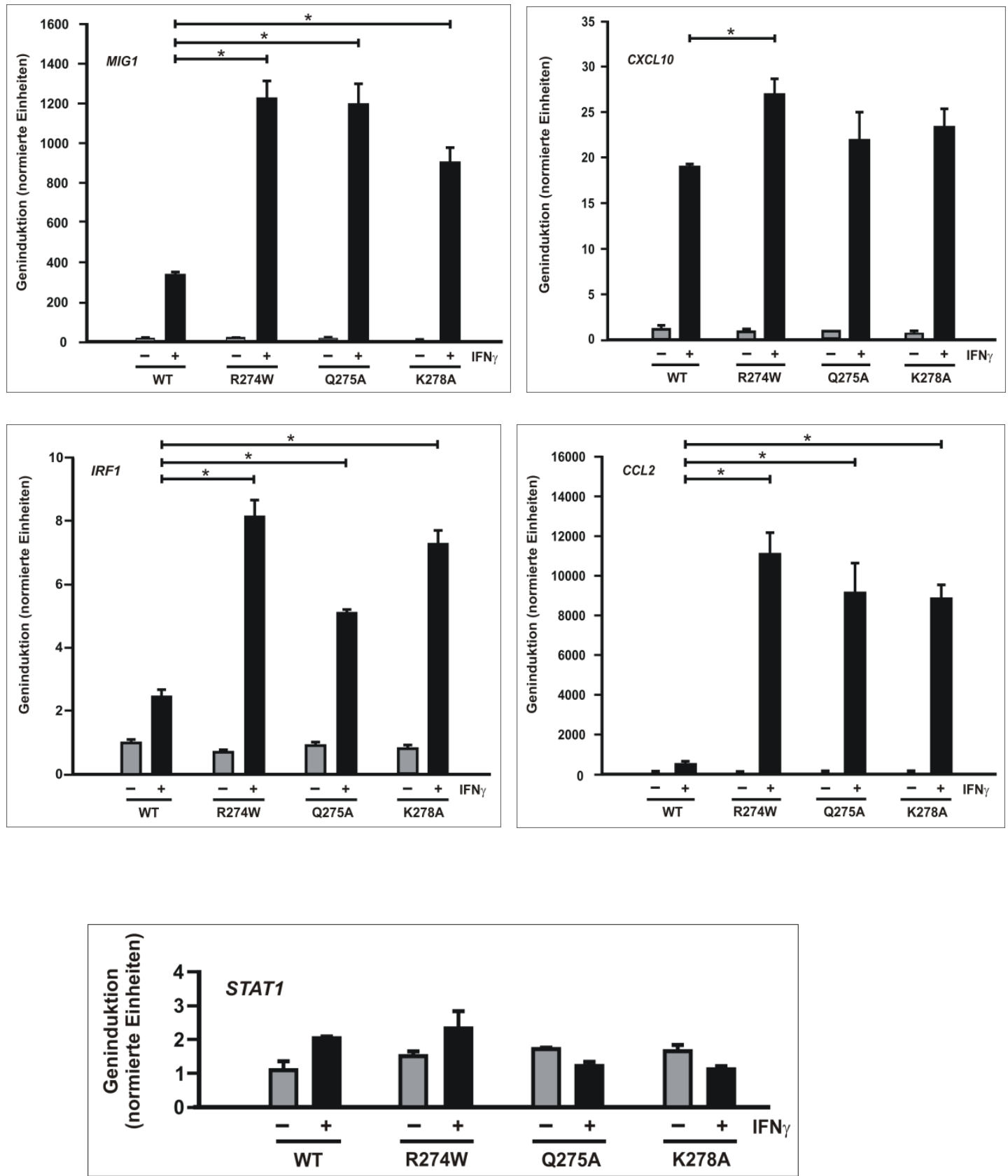

Abb. 27: Die STAT1-Gain-of-Function-Mutationen R274W, Q275A und K278A zeigen eine erhöhte Geninduktion in Real-time PCR-Experimenten. Die schwarzen Balken der Abbildung demonstrieren das Expressionslevel der STAT1-Zielgene mig1, cc/2, irf1, cxcl10 und stat1 nach Stimulation mit $50 \mathrm{ng} / \mathrm{ml}$ IFN $\gamma$. Zusätzlich erfolgte die Bestimmung von gapdh, wodurch die Genaktivierung der getesteten Gene auf das Induktionsniveau dieses konstitutiv exprimierten 
Gens normiert werden konnte. Statistisch signifikante Unterschiede zwischen den STAT1Punktmutanten gegenüber dem STAT1-WT-Molekül sind mit Balken und Sternchen (*) gekennzeichnet. Vor Durchführung der Real-time PCR wurde RNA aus den transfizierten U3A-Zellen (mit pcDNA3.1-STAT1-WT bzw. den davon mutierten Plasmiden) extrahiert und in die komplementäre DNA umgeschrieben. Aus drei unabhängigen Messungen wurden Mittelwerte und Standardabweichungen berechnet.

Die Resultate der Real-time PCR zeigen statistisch signifikante Unterschiede im Expressionsniveau STAT1-induzierter endogener Zielgene der generierten Mutanten R274W, Q275A und K278A gegenüber dem STAT1-WT-Protein. Die Substitution von Arginin gegen Tryptophan an Position 274 und Glutamin gegen Alanin an Position 275 führte verglichen mit dem Wildtyp-Molekül bereits zu einem Unterschied im Verhalten der Tyrosin-Phosphorylierung, der Kernakkumulation und der Bindung an eine einfache GAS-Sonde. Überraschenderweise kommt es bei dem Austausch eines Lysinrests gegen Alanin an Position 278 im STAT1-Molekül auch zu einer vermehrten Induktion der Gene mig1, irf1 und cc/2, jedoch nicht $c x c / 10$. In vorherigen Experimenten ließen sich für diese Lysin-Austauschmutante bis dahin keine Unterschiede gegenüber dem WildtypProtein erkennen. Für alle STAT1-Varianten lagen verglichen mit STAT1-WT ähnliche mRNA-Ausgangskonzentrationen vor, wie das Säulendiagramm zur stat1-Genexpression verdeutlicht. Die Unterschiede im Genaktivierungsprofil lassen sich somit nicht auf eine erhöhte Ausgangskonzentration der Punktmutanten zurückführen.

\subsection{In-vitro-Phosphorylierungs- und Dephosphorylierungskinetik aller generierten STAT1- Varianten entspricht der des WT-Proteins}

Die vorherigen Ergebnisse zeigten, dass die STAT1-Substitutionsmutanten R274W und Q275A nach Stimulation mit IFN $\gamma$ eine Hyperphosphorylierung und verlängerte Kernakkumulation aufweisen. In Versuchen zur DNA-Bindungskinetik ergaben sich keine Unterschiede der Mutanten hinsichtlich der Dissoziationsrate gegenüber dem WT-Molekül. Um die Ursache der Hyperphosphorylierung genauer zu ermitteln, folgten diesbezüglich weitere Experimente. Zum einen könnte das erhöhte Tyrosin-Phosphorylierungsniveau eine gesteigerte JAK-Kinase-Aktivität als Ursache haben, zum anderen könnten die IFN $\gamma$ - 
stimulierten Zellen einer verminderten Dephosphorylierungsrate unterliegen bzw. es könnten beide Erklärungsmöglichkeiten zugleich zutreffend sein.

Für die Untersuchungen wurden Zelllysate aus den STAT1-WT exprimierenden oder den die STAT1-Punktmutanten exprimierenden U3A-Zellen gewonnen und je nach Versuch unterschiedlich stimuliert. In einem ersten Experiment erfolgte die Inkubation der Proteinextrakte in vitro mit rekombinanter JAK2-Kinase für 0, 30 oder 60 min. Das Phosphorylierungsniveau wurde anschließend mit Hilfe eines Phospho-STAT1-Antikörpers in Western-Blot-Analysen ermittelt. Eine Kontrolle der aufgetragenen STAT1-Gesamtmenge erfolgte nach Entfernen der ersten Antikörperkomplexe und Reexposition der gewaschenen Membranen mit einem STAT1-spezifischen Primär- und nachfolgender Inkubation mit Sekundärantikörper.

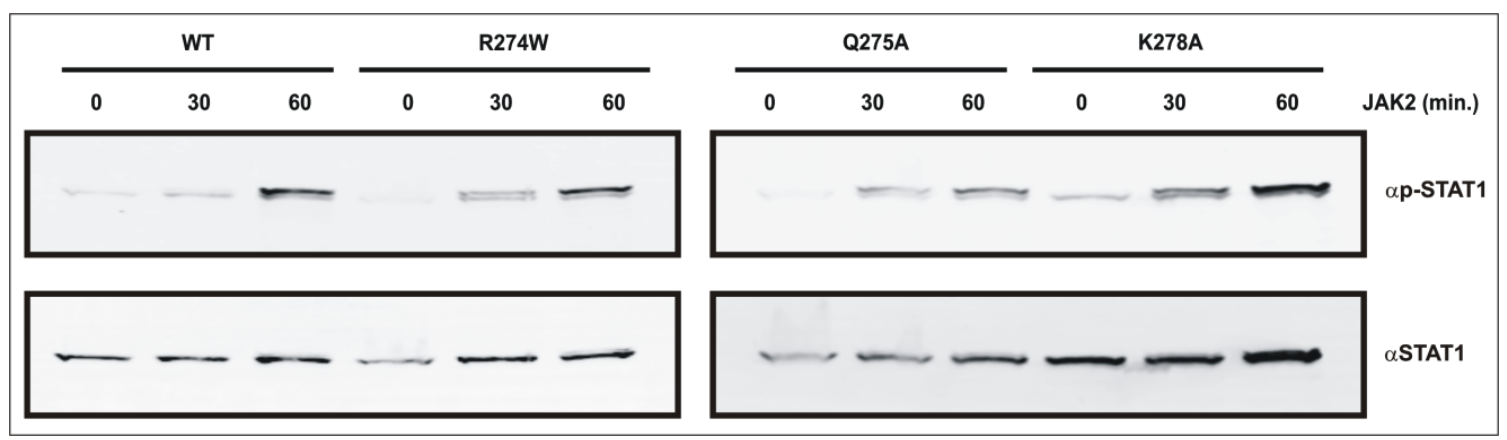

Abb. 28: STAT1-GOF-Mutationen zeigen im Tyrosin-Phosphorylierungs-Assay keine Unterschiede in der In-vitro-Phosphorylierungsrate nach Inkubation mit rekombinanter JAK2. STAT1-negative U3A-Zellen wurden mit pSTAT1-WT oder dem entsprechend mutierten Plasmid transfiziert und die daraus gewonnenen Gesamtzellextrakte mit $40 \mathrm{ng}$ JAK2-Kinase für die angegebenen Zeitintervalle stimuliert. Die Phosphorylierungsbanden wurden in WesternBlot-Analysen ermittelt, wobei durch Inkubation mit einem Phospho-STAT1-spezifischem Antikörper zunächst die Tyrosin-Phosphorylierung (obere Reihe) und anschließend die aufgetragene Gesamt-STAT1-Menge mit Hilfe eines spezifischen Antikörpers erfasst wurde (untere Reihe). 


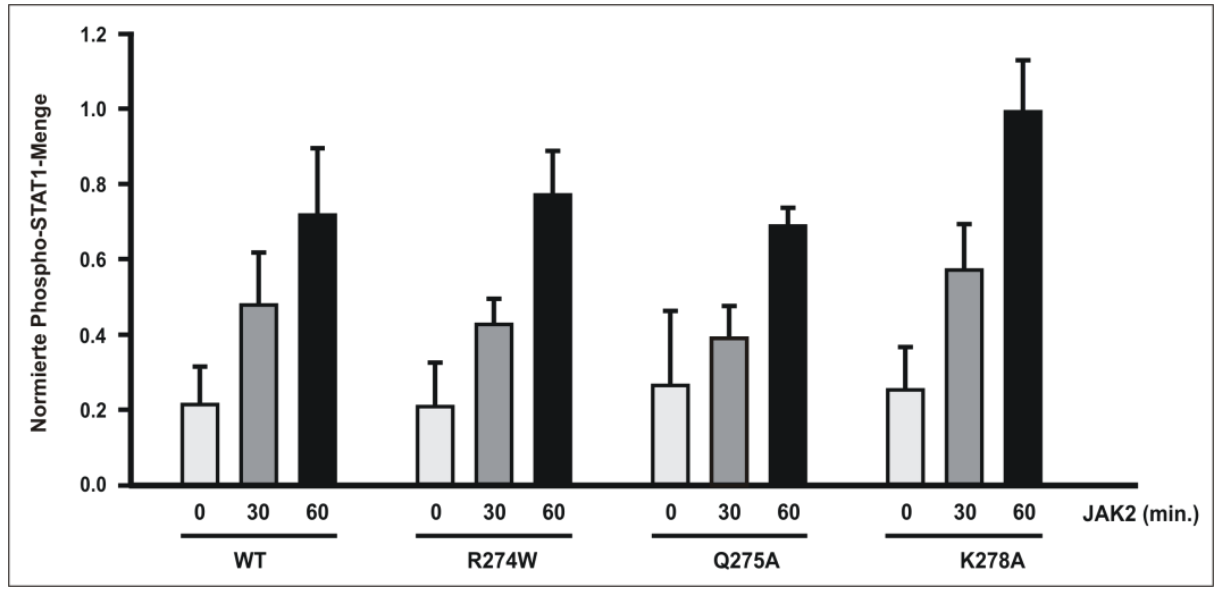

Abb. 29: Histogramm zur Darstellung des In-vitro-Phosphorylierungsniveaus nach Stimulation mit JAK2. Die Auswertung von drei unabhängigen Phosphorylierungs-Assays zeigte keine Unterschiede in der Tyrosin-Phosphorylierungskinetik zwischen STAT1-R274W, Q275A, K278A und dem unveränderten STAT1-Protein. Es wurde in drei unabhängigen Versuchen das Verhältnis von Phospho-STAT1 zu Gesamt-STAT1 berechnet.

Abb. 25 demonstriert, dass das Phosphorylierungssignal bereits nach 30minütiger Stimulation mit IFN $\gamma$ in allen Substitutionsmutanten detektierbar und nach 60 min besonders deutlich ausgeprägt war. Hierbei bestanden zu den angegebenen Zeitpunkten keine statistisch signifikanten Unterschiede gegenüber dem Wildtyp-Protein.

Im nächsten Versuch wurde die Dephosphorylierungsrate der STAT1Punktmutanten R274W und Q275A überprüft. U3A-Zellen wurden hierfür mit STAT1-WT-Plasmid oder dem für STAT1- R274W-, Q275A- und K278Akodierenden Plasmid transfiziert. Am Folgetag erfolgte eine 45-minütige Stimulation der Zellen mit $50 \mathrm{ng} / \mathrm{ml}$ IFN $\gamma$ und die Herstellung von Gesamtzellextrakten, die anschließend im Dephosphorylierungs-Assay verwendet wurden. Die Zelllysate wurden mit T-Zell-Protein-Tyrosin-Phosphatase R (2 U pro Reaktionsansatz) bei $30^{\circ} \mathrm{C}$ inkubiert, wobei die gewählten Zeitpunkte denen des JAKKinase-Versuchs (Abb. 25) entsprachen. Anschließend konnte die Dephosphorylierungskinetik der einzelnen STAT1-Punktmutanten in Western-BlotAnalysen mit der des Wildtyp-Moleküls verglichen werden. 


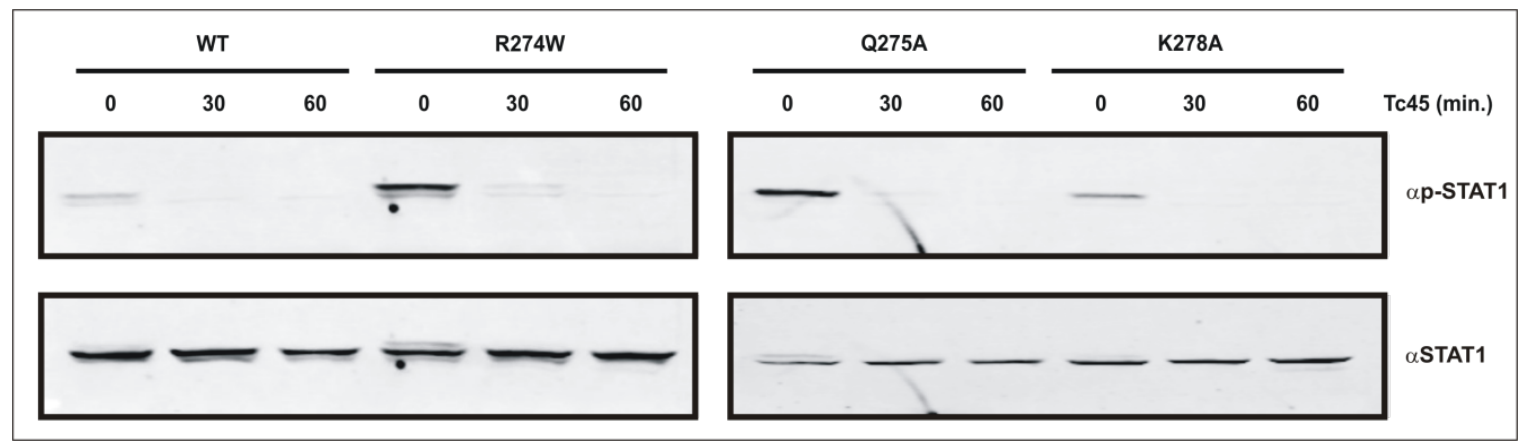

Abb. 30: Punktmutanten in der STAT1-Coiled-coil-Domäne zeigen eine normale Dephosphorylierungsrate. Für den Dephosphorylierungs-Assay wurden U3A-Zellen mit pcDNA3.1Plasmiden, die STAT1-WT oder einen der drei generierten Substitutionsmutanten exprimierten, transfiziert und anschließend mit $50 \mathrm{ng} / \mathrm{ml}$ IFN $\gamma$ stimuliert. Nach der Herstellung von Gesamtzellextrakten wurden $10 \mu \mathrm{l}$ Proteinextrakt mit 2 U STAT1-spezifischer TC45-Phosphatase für 30oder 60 min stimuliert oder unbehandelt gelassen. Nach Beladung eines Polyacrylamidgels mit dem entsprechenden Reaktionsvolumen erfolgte im Westen-Blot-Verfahren die Exposition der Blotmembran mit Phospho-STAT1-Antikörper und deren Detektion mit Fluorochrom-markiertem Sekundärantikörper. Der Antikörper wurde anschließend entfernt und die PVDF-Membranen erneut, nur diesmal mit einem STAT1-spezifischen Antikörper, inkubiert.

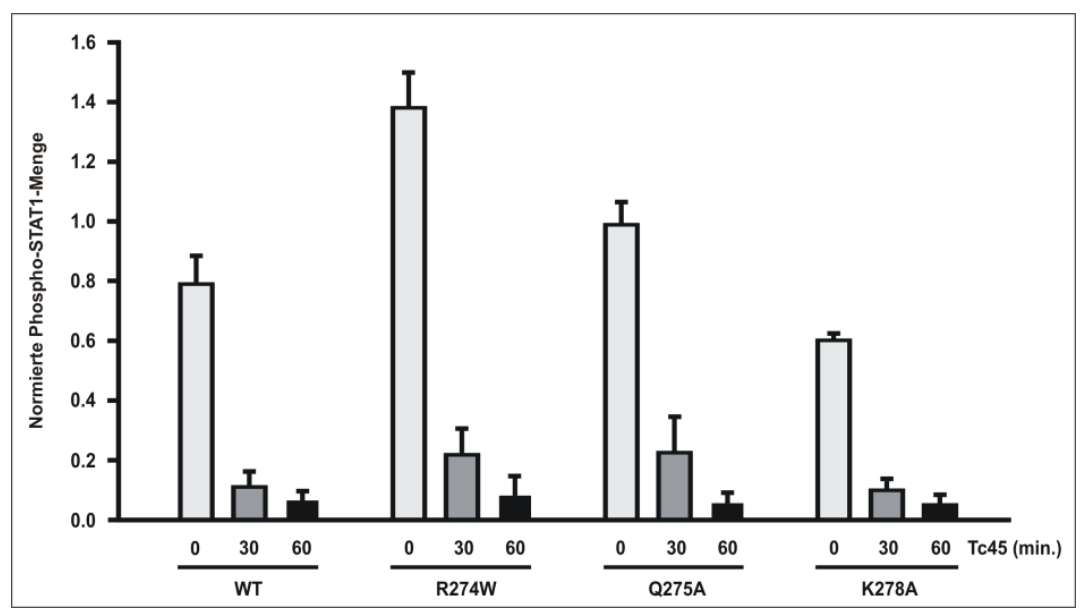

Abb. 31: Säulendiagramm zur Darstellung der Abnahme des Phosphorylierungssignals der STAT1-Punktmutanten und STAT1-WT nach Zugabe von TC45-Phosphatase. Für die statistische Auswertung dreier unabhängiger In-vitro-Dephosphorylierungs-Assays mit STAT1spezifischer TC-PTP wurden Phosphotyrosin-Signale in Western-Blot-Experimenten ermittelt und anschließend durch die Gesamt-STAT1-Menge geteilt.

Die STAT1-Varianten R274W, Q275A und K278A wiesen die gleiche Dephosphorylierungs-Kinetik wie das Wildtyp-Molekül auf, wie die Abb. 27 demonstriert. 
In einem letzten Experiment wurde abschließend ein DephosphorylierungsAssay durchgeführt, der um die Zugabe verschiedener GAS-Elemente in den Reaktionsansätzen erweitert wurde. Da bereits bekannt ist, dass STAT1 nach Bindung an hoch-affine GAS-Bindestellen vor Inaktivierung geschützt ist, wurden Reaktionsansätze unter Zunahme oder Weglassen der DNA-Sonden hergestellt. STAT1-WT-, STAT1-R274W-, STAT1-Q275A- und STAT-K278A-exprimierende U3A-Zellen wurden mit $50 \mathrm{ng} / \mathrm{ml}$ IFN $\gamma$ stimuliert und davon Proteinextrakte gewonnen. Nach Zugabe einer Gas-nonGAS- oder 2xnonGAS-Bindestelle erfolgte die Inkubation von $10 \mu$ Zellextrakt mit $2 U$ der STAT1-spezifischen Protein-Phosphatase. Anschließend wurde die Abnahme des Phosphorylierungs-Signals mit Hilfe eines Immuno-Blots unter Inkubation der verwendeten PVDF-Membranen mit Antikörpern, spezifisch für phosphoryliertes und totales STAT1, detektiert.

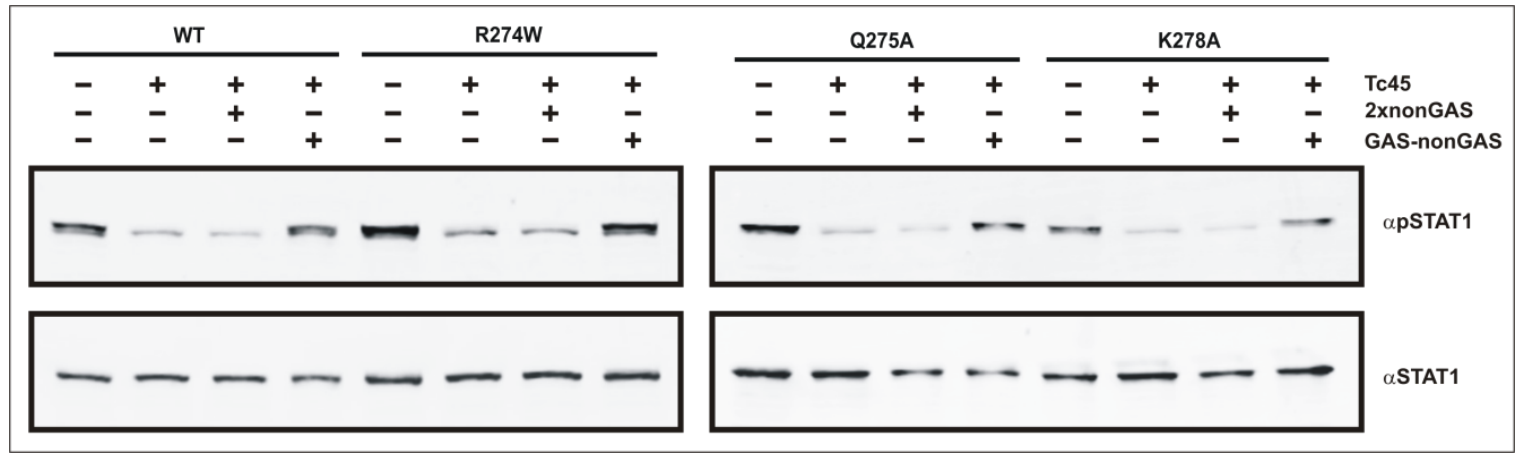

Abb. 32: Bindung an hoch-affine GAS-Elemente schützt STAT1-Punktmutanten im gleichen Maße vor Dephosphorylierung wie das Wildtyp-Molekül. Nach der Transfektion von U3A-Zellen mit dem entsprechenden STAT1-Plasmid und der Stimulation mit $50 \mathrm{ng} / \mathrm{ml} \mathrm{IFN} \gamma$ am Folgetag wurden Geamtzellextrakte hergestellt und diese mit TC45-Phosphatase für 30 min bei $30{ }^{\circ} \mathrm{C}$ inkubiert. Zeitgleich erfolgte die Zugabe einer hoch-affinen GAS-nonGAS-Sonde, einer 2xnonGAS-Sonde oder keiner DNA-Sonde. Die obere Reihe des Western-Blots zeigt, dass der Reaktionsansatz, der mit einer singuläre GAS-Sonde versetzt wurde, ein erhöhtes Phosphorylierungssignal in allen STAT1-Varianten sowie dem WT-Molekül aufweist und somit vor Inaktivierung im Zellkern geschützt ist. Die untere Reihe demonstriert die STAT1-Gesamtmenge detektiert mit spezifischem Antikörper ( $\alpha$ STAT1). 


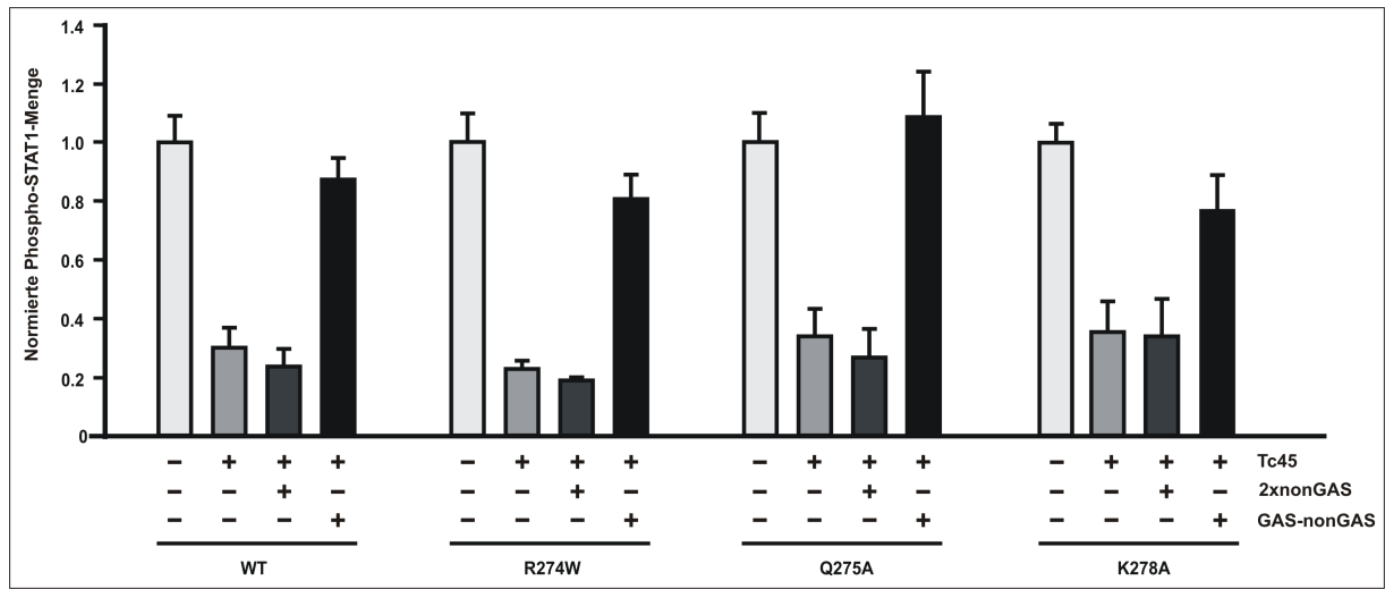

Abb. 33: Die Mutanten R274W und Q275A weisen keinen Dephosphorylierungsdefekt auf. Die Zugabe einer hoch-affinen GAS-Sonde schützt die STAT1-Punktmutanten im gleichen Maße vor Dephosphorylierung mit STAT1-WT. Das Balkendiagramm zeigt die Ergebnisse einschließlich der statistischen Auswertung der densitometrischen Messungen der Signalintensitäten aus den Western-Blot-Membranen von drei unabhängigen Versuchen.

Das Dephosphorylierungs-Assay in Abb. 29 zeigt, dass bei Koinkubation mit einer DNA-Sonde ohne GAS-Bindestelle (2xnonGAS) nahezu kein Phosphorylierungssignal mehr detektierbar war, da die STAT1-spezifische Phosphatase ungehindert zu einer Dephosphorylierung in allen STAT1-Varianten geführt hat. Wird dem Reaktionsansatz allerdings eine hoch-affine singuläre GASBindestelle hinzugefügt, so sind sowohl das Wildtyp-Molekül als auch die in im alpha-Helix-Bündel gelegenen STAT1-Mutationen vor der TC45-katalysierten Inaktivierung geschützt. Das Dephosphorylierungsmuster der STAT1-Derivate unterscheidet sich somit nicht vom Wildtyp-Molekül.

Die Abbildungen 25, 27 und 29 verdeutlichen, dass die Hyperphosphorylierung von STAT1-R274W und -Q275A weder durch eine erhöhte Aktivität der im Zytoplasma lokalisierten JAK2-Kinase noch einer veränderten Dephosphorylierungskinetik nach Inkubation mit STAT1-spezifischer T-Zell-ProteinPhosphatase - mit oder ohne Koinkubation einer singulären GAS-Bindestelle zu Stande kommt. Die zuvor getroffenen Hypothesen können somit nicht als Erklärung für den hyperphosphorylierten Phänotyp der beiden Substitutionsmutanten dienen. 


\section{Diskussion}

Krankheitsassoziierte Gain-of-Function-Mutationen im Transkriptionsfaktor STAT1 sind präferentiell in der Coiled-coil- oder der DNA-Bindedomäne des Moleküls lokalisiert und führen zu einer erhöhten Genexpression von IFN $\gamma$ stimulierten Zielgenen (Liu et al. 2011; van de Veerdonk et al. 2011; Takezaki et al. 2012; Soltész et al. 2013; Depner et al. 2016; Toubiana et al. 2016). Über den genauen molekularen Mechanismus, der dieser transkriptionellen Überaktivität zugrunde liegt, ist bislang wenig bekannt. Es wurde gezeigt, dass die in der Coiled-coil-Domäne lokalisierte GOF-Mutation F172W und die zwei weiteren Substitutionsmutationen F364A und T385A in der DNA-Bindedomäne hyperphosphoryliert sind (Zhong et al. 2005; Staab et al. 2013a; Staab et al. 2013b). Für die Letztgenannten wurde überdies eine partielle Resistenz gegenüber der Inaktivierung durch die STAT1-spezifische TC45-Phosphatase nachgewiesen (Staab et al. 2013a; Staab et al. 2013b). Die antiparallele Kon-formation eines unphosphorylierten STAT1-Dimers wird durch reziproke Interaktionen zwischen der STAT1-Coiled-coil-Domäne des einen Protomers unter Beteiligung der Position F172 und der DNA-Bindedomäne des Partner-protomers stabilisiert, wobei die Aminosäurereste F364 und T385 hierbei entscheidende Bindungen zur Dimerstabilisierung beisteuern. Der Austausch von Threonin gegen Alanin an Position 385 sowie der von Phenylalanin gegen Tryptophan an Position 172 oder die Substitution von Phenylalanin zu Alanin an Position 364 führt zu einer Destabilisierung der antiparallelen Ausrichtung zweier STAT1-Dimere (Mao et al. 2005; Zhong et al. 2005; Mertens et al. 2006; Staab et al. 2013a). Die hyperphosphorylierten Substitutionsmutanten T385A und F172W zeigen neben dem Dephosphorylierungsdefekt eine erhöhte transkriptionelle Aktivität in Reportergen-Assays und eine erhöhte Aktivierung von bestimmten IFN $\gamma$-induzierten Zielgenen. Darüber hinaus konnte bei der STAT1-Mutante T385A eine verlängerte Kernakkumulation nach Stimulation mit IFN $\gamma$ beobachtet werden (Staab et al. 2013b).

In der kristallographischen Darstellung des STAT1-Dimers in antiparalleler Konformation fiel auf, dass die funktionellen Gruppen der drei Aminosäurereste an den Positionen 172, 364 und 385 am äußeren Rand der intradimerischen Inter- 
aktionsfläche zwischen den beiden Protomeren lokalisiert sind (Abb. 4). In der vorliegenden Arbeit wurden deshalb STAT1-Mutationen zur genaueren Charakterisierung gewählt, die genau im Zentrum dieser Interaktionsfläche gelegen sind. Hierfür wurden durch sequenzspezifische Mutagenese Punktmutationen an den Positionen 274, 275 und 278 eingeführt und Experimente zu den gleichen Bedingungen, die bei den hyperphosphorylierten Mutanten F172W, F364A und T385A herrschten, durchgeführt. Untersuchungen zum Verhalten hinsichtlich Phosphorylierungsniveau, DNA-Bindung, Kernakkumulation, Dephosphorylierungsverhalten und Genexpression nach Zytokinstimulation lagen im Fokus dieser Arbeit. Die hier gewonnenen Ergebnisse wurden anschließend mit denen von Staab und Kollegen verglichen, mit dem Ziel das Wissen über den molekularen Mechanismus von Gain-of-Function-Mutationen im Transkriptionsfaktor STAT1 zu erweitern.

Die hier generierten Substitutionsmutanten R274W und Q275A zeigen in Western-Blot-Analysen nach Stimulation mit IFN $\gamma$ und anschließender Inhibition mit der Tyrosin-Kinase Staurosporin ein erhöhtes Phosphorylierungsniveau verglichen mit dem Wildtyp-Molekül (Abb. 7 bis Abb. 10). Die Hyperphosphorylierung der beiden Mutanten konnte ebenfalls autoradiographisch in EMSA-Experimenten demonstriert werden (Abb. 11, Abb. 12). Das Phosphorylierungslevel der Punktmutante K278A wies sowohl in Western-Blot-Experimenten auch als im Gelretardierungs-Assay keinen Unterschied zum Wildtyp-Molekül auf.

In einem weiteren Gelretardierungs-Experiment erfolgte der Nachweis, dass die Mutanten R274W und Q275A trotz der Hyperphosphorylierung ein normales sequenzspezifisches DNA-Bindeverhalten an verschiedene GAS-Sequenzen in Tandem-Orientierung aufwiesen (Abb. 13, Abb. 14). Darüber hinaus ergaben sich weder Unterschiede in der Stabilität tetramerer Komplexe aufgrund erhaltener kooperativer DNA-Bindung (Abb. 15, Abb. 16), noch wiesen die STAT1Derivate verglichen mit dem Wildtyp-Protein ein verändertes Dissoziationsverhalten von einer hoch-affinen, singulären DNA-Bindestelle auf. Dies wurde im Kompetitionsexperiment mit Zusatz einer kalten M67-DNA-Probe in hohem molaren Überschuss gezeigt (Abb. 17, Abb. 18). Der hyperphosphorylierte Phänotyp der STAT1-Derivate R274W und Q275A lässt sich somit weder durch ein verändertes DNA-Dissoziationsverhalten, ein abweichendes Tetramerisierungs- 
verhalten noch ein alteriertes, sequenz-spezifisches Bindungsverhalten erklären.

In einem weiteren Versuch konnte festgestellt werden, dass der Austausch von Arginin gegen Tryptophan an Position 274 und die Substitution von Glutamin gegen Alanin an Position 275 zu einer verlängerten Kernakkumulation nach Stimulation der Zellen mit IFN $\gamma$ führte. Nicht nur die Verweildauer im Zellkern dieser zwei Mutanten war verlängert (Abb. 19, Abb. 20, Abb. 21, Abb. 22), sondern auch die Geschwindigkeit der Kernakkumulation war verglichen mit dem nicht-mutierten STAT1-Protein erhöht (Abb. 23, Abb. 24).

Die transkriptionelle Aktivität der STAT1-Punktmutanten R274W und Q275A zeigte sich sowohl im Reportergen-Assay mit dem künstlich hergestellten Promoter 3xLy6E und pIC-339 (Abb. 25 und 26) als auch in Real-time PCRExperimenten erhöht (Abb. 27). Die getesteten Gene der Real-time PCR enthielten entweder eine singuläres GAS-Element (irf1, mig1) oder zusätzlich ein halbes palindromisches GAS-Element wenige Basenpaare entfernt von der klassischen GAS-Bindestelle (cxc/10, cc/2). Diese Ergebnisse stehen in Übereinstimmung mit den Resultaten aus der Untersuchung von Fujiki und Kollegen, in denen gezeigt wurde, dass die erhöhte transkriptionelle Aktivität der hyperphosphorylierten Mutante R274W nicht mit einer Änderung des Repertoires an STAT1-Zielgenen einhergeht (Fujiki et al. 2017).

Für die Phosphatase-resistenten Mutanten T385A und F172W konnten Staab et al. im Unterschied zu den hier beschriebenen Substitutionsmutanten zeigen, dass diese ein inhomogenes Muster der Genaktivierung aufweisen und im erhöhten Maße nur die Gene aktivieren, die zusätzlich zu einer einfachen GASBindestelle ein TCC/GAA-Motiv ( $c x c / 10$ und mcp1) enthalten. Mit Hilfe dieses zusätzlichen halben GAS-Elementes wird eine kooperative DNA-Bindung sehr wahrscheinlich erleichtert, da es die Ausbildung von STAT1-Tetrameren begünstigt (Staab et al. 2013b).

Die eigenen Versuche ergaben, dass weder die Aktivierung am Rezeptor signifikant erhöht noch die Deaktivierung der beiden Punktmutanten gestört war. Hierfür wurde sowohl ein In-vitro-Kinase-Assay mit rekombinanter JAK2-Kinase (Abb. 28, Abb. 29) wie auch ein In-vitro-Dephosphorylierungs-Assay mit STAT1-spezifischer TC45-Phosphatase, mit oder ohne Zugabe von verschiedenen GAS-Bindestellen, durchgeführt (Abb. 30, Abb. 31, Abb. 32, Abb. 33). 
Die bisherigen Ergebnisse liefern keine eindeutige Erklärung für die Hyperphosphorylierung der STAT1-GOF-Mutationen R274W und Q275A. Zu den wichtigsten Erkenntnissen dieser Arbeit zählen jedoch die Resultate aus dem Phosphorylierungs- und Dephosphorylierungs-Assay. Nach Stimulation mit JAK2Kinase unterscheiden sich die hyperphosphorylierten Mutanten R274W und Q275A im Phosphorylierungsverhalten nicht von dem Wildtyp-Molekül und auch im Dephosphorylierungs-Assay zeigten sich keine Unterschiede. Dies unterscheidet die zwei Substitutionsmutanten dieser Arbeit eindeutig von den Phosphatase-resistenten STAT1-GOF-Mutanten F172W, F364A und T385A. Die Vermutung liegt nahe, dass es zwei verschiedene Mechanismen geben muss, die in der vermehrten Expression von STAT1-Zielgenen resultieren.

Die in der kristallographischen Darstellung eines antiparallelen Dimers im äußeren Bereich lokalisierte, reziproke Interaktion zwischen F172 und T385 könnte eine entscheidende Rolle für die Formierung eines isolierten Dimers in antiparalleler Konformation spielen, worüber die Rekrutierung der TC45-Phosphatase erfolgt und die Inaktivierung des Dimers gewährleistet wird. Das antiparallele Dimer wird über Interaktionen zwischen Aminosäureresten der DBD eines Protomers und der CCD des Partnerprotomers stabilisiert. Hierbei interagieren zwei Glutaminreste an Position 340 und 384 und ein Glycin- und Threoninrest an Position 384 und 385, die gemeinsam in einer Tasche der DBD-Domäne des einen STAT1-Monomers lokalisiert sind, mit dem kritischen Phenylalaninrest F172 der CCD des anderen Protomers (Mao et al. 2005; Zhong et al. 2005; Mertens et al. 2006). Wie Arbeiten aus dem Darnell-Labor ein Jahr später zeigen konnten, führen Mutationen an den oben genannten Positionen zu einem erhöhten Phosphorylierungsniveau im STAT1-Molekül (Mao et al. 2005; Mertens et al. 2006). Normalerweise unterliegt endogenes STAT1 einem kontinuierlichen Wechsel zwischen paralleler und antiparalleler Ausrichtung (Wenta et al. 2008). Durch mutationsbedingte, strukturelle Alterationen an den Oberflächen der CCD oder DBD kann das Gleichgewicht der beiden Konformere mutmaßlich zugunsten des parallelen Dimers verschoben sein. Wenn das antiparallele Dimer das bevorzugte Substrat der TC45-Phosphatase darstellt, könnte insbesondere für die STAT1-Mutationen F172, T385A und F364A der Inaktivierungsprozess maßgeblich beeinträchtigt sein (Zhong et al. 2005; Staab et al. 2013a; Staab et al. 2013b). 
Die im inneren Teil der Interaktionsflächen gelegenen Mutanten R274W und Q275A bilden aufgrund der Ergebnisse dieser Arbeit eine zweite Kategorie von STAT1-GOF-Mutationen.

Die hyperphosphorylierten Punktmutanten R274W und Q275A weisen gegenüber dem Wildtyp-Molekül keine Unterschiede im Dephosphorylierungsverhalten auf. Sie werden von der TC45-Phosphatase regelrecht erkannt und scheinen auf andere Art und Weise die Stabilität des antiparallelen Dimers zu beeinflussen. Eine mögliche Erklärung für dieses Phänomen könnte die folgende Annahme liefern: Wie bereits in der kristallographischen Darstellung eines antiparallelen STAT1-Dimers in Abb. 4 ersichtlich, bildet der nicht-mutierte Argininrest an Position 274 und der Glutaminrest an Position 275 in der CCD des einen Protomers eine fingerartige Brücke mit der DBD des interagierenden Partnerproteins, deren Ausbildung durch die Punktmutationen beeinträchtigt wird. Diese im Zentrum der intradimerischen Interaktionsfläche gelegenen Aminosäureresten könnten der Bindung eines einzelnen STAT1-Monomers in antiparalleler Konfiguration an ein phosphoryliertes Dimer mit paralleler Orientierung dienen. Wie die Abb. 34 demonstriert, käme es hierbei zur Ausbildung eines trimeren Komplexes, der verhindern würde, dass Importin- $\alpha 5$ an das Dimerspezifische, nukleäre Lokalisationssignal binden kann.

Nach Mutation an den Positionen 274 und 275 käme es gemäß der oben genannten Hypothese zu einer Unterbrechung der brückenartigen Verbindung dieser zwei Aminosäuren. Dies würde die Ausbildung eines stabilen trimeren Komplexes verhindern. Das nukleäre Lokalisationssignal befindet sich im STAT1-Molekül in der DNA-Bindedomäne und ist bei einem phosphorylierten Dimer in paralleler Konformation demaskiert und somit zugänglich (Fagerlund et al. 2002; Meyer et al. 2002). Wird dieses nukleäre Lokalisationssignal durch ein unphosphoryliertes oder phosphoryliertes STAT1-Protomer (oder möglicherweise auch einem parallelen Dimer) in antiparalleler Konfiguration verdeckt, ist der Kernimport gestört (Abb.34). Die Seitenkette des Glutaminrests an Position 275 liegt nahe dem aromatischen Ring des Tyrosinrests an Position Y356 in der DBD des Partnerprotomers, so dass dieser Aminosäurerest sehr wahrscheinlich ebenfalls zur Bindung des trimeren Komplexes beiträgt. 
Gemäß dieser Annahme entsteht ein Modell, indem die Verbindung von R274 und Q275 an der Bildung eines trimeren Komplexes beteiligt ist, bestehend aus einem unphosphorylierten oder phosphorylierten STAT1-Monomer in antiparalleler Konformation und einem parallel ausgerichteten STAT1-Dimer. Wenta und Kollegen konnten anhand analytischer Ultrazentrifugation und EMSA-Experimenten demonstrieren, dass STAT1 in der Zelle ständig zwischen den beiden Konformationen oszilliert, wobei die Tyrosin-Phosphorylierung hierbei die Häufigkeit der Entstehung paralleler Dimer-Konformere bestimmt (Wenta et al. 2008). Die gezielte Anlagerung eines STAT1-Protomers (oder Dimers unabhängig von seinem Phosphorylierungsstatus) in antiparalleler Konfiguration an eines der phosphorylierten STAT1-Protomere in paralleler Dimer-Konfiguration, führt nach dieser Hypothese zu der Blockierung des in der DBD lokalisierten NLS und verhindert somit die Translokation in den Zellkern mit konsekutiver Aktivierung von zytokinabhängigen Zielgenen. Mutiert man, wie in der vorliegenden Arbeit geschehen, die daran beteiligten Aminosäurereste, kommt es zu einer überschießenden Genaktivierung (Abb. 27). 


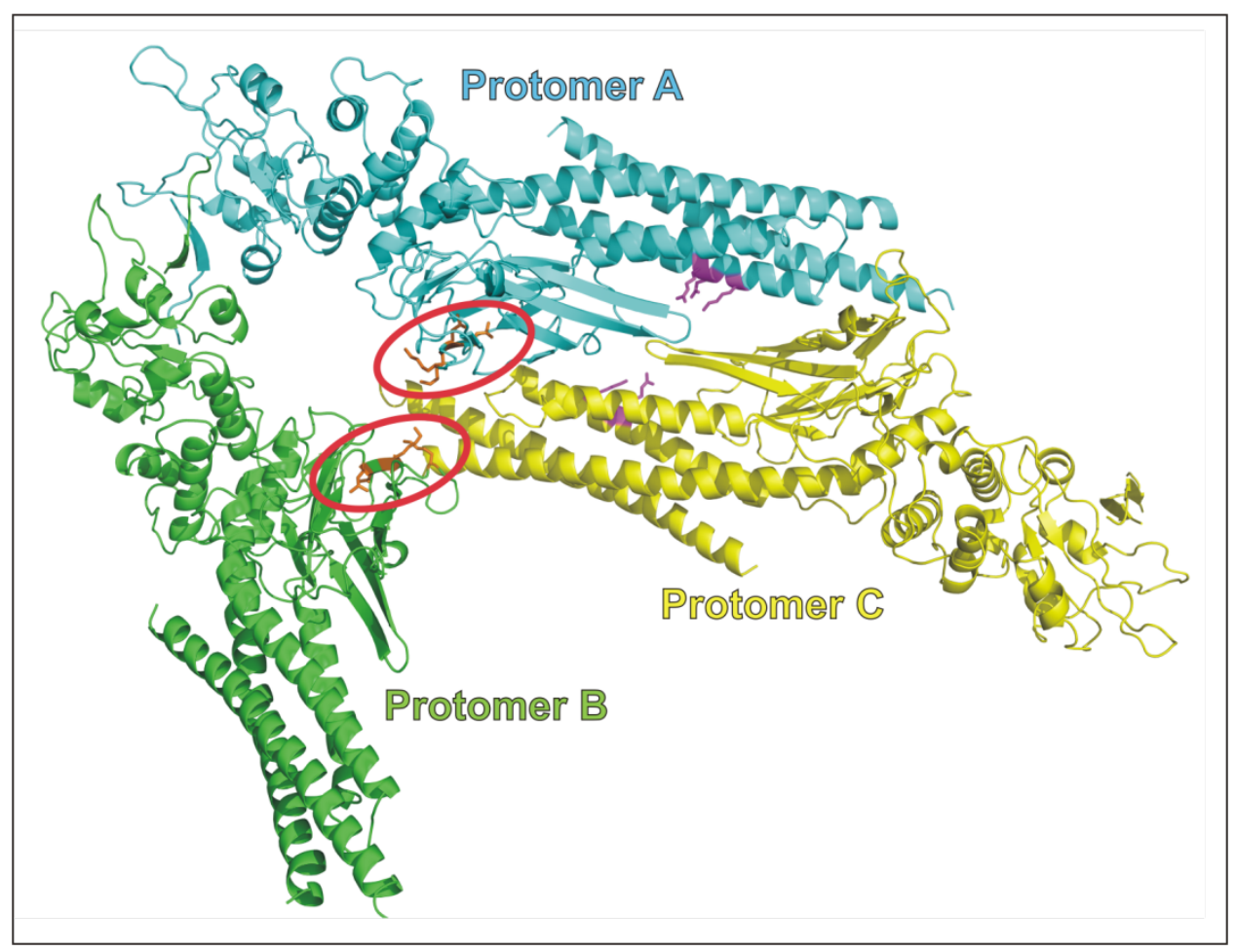

Abb. 34: Strukturelles Modell des inhibitorischen trimeren Komplexes von STAT1. Ein antiparalleles Dimer (gelb markiert) überlagert das nukleäre Lokalisationssignal eines Tyrosinphosphorylierten STAT1-Dimers bestehend aus einem hier hellblau markierten Protomer und einem in Grün markierten zweiten Protomer. In Magenta sind die Aminosäurereste der Protomere markiert, die eine brückenartige-Bindung in antiparalleler Dimer-Orientierung eingehen und in dieser Arbeit mutiert wurden. Darüber hinaus sind mit zwei roten Kreisen die am nukleären Lokalisationssignal beteiligten Aminosäurereste in dem parallelen Dimer, geformt aus den Protomeren A und B, markiert. 
Die Abb. 35 zeigt ein überarbeitetes Modell des Aktivierungs- und Inaktivierungszyklus eines STAT1-Moleküls unter Einbeziehung der oben genannten Vermutungen.

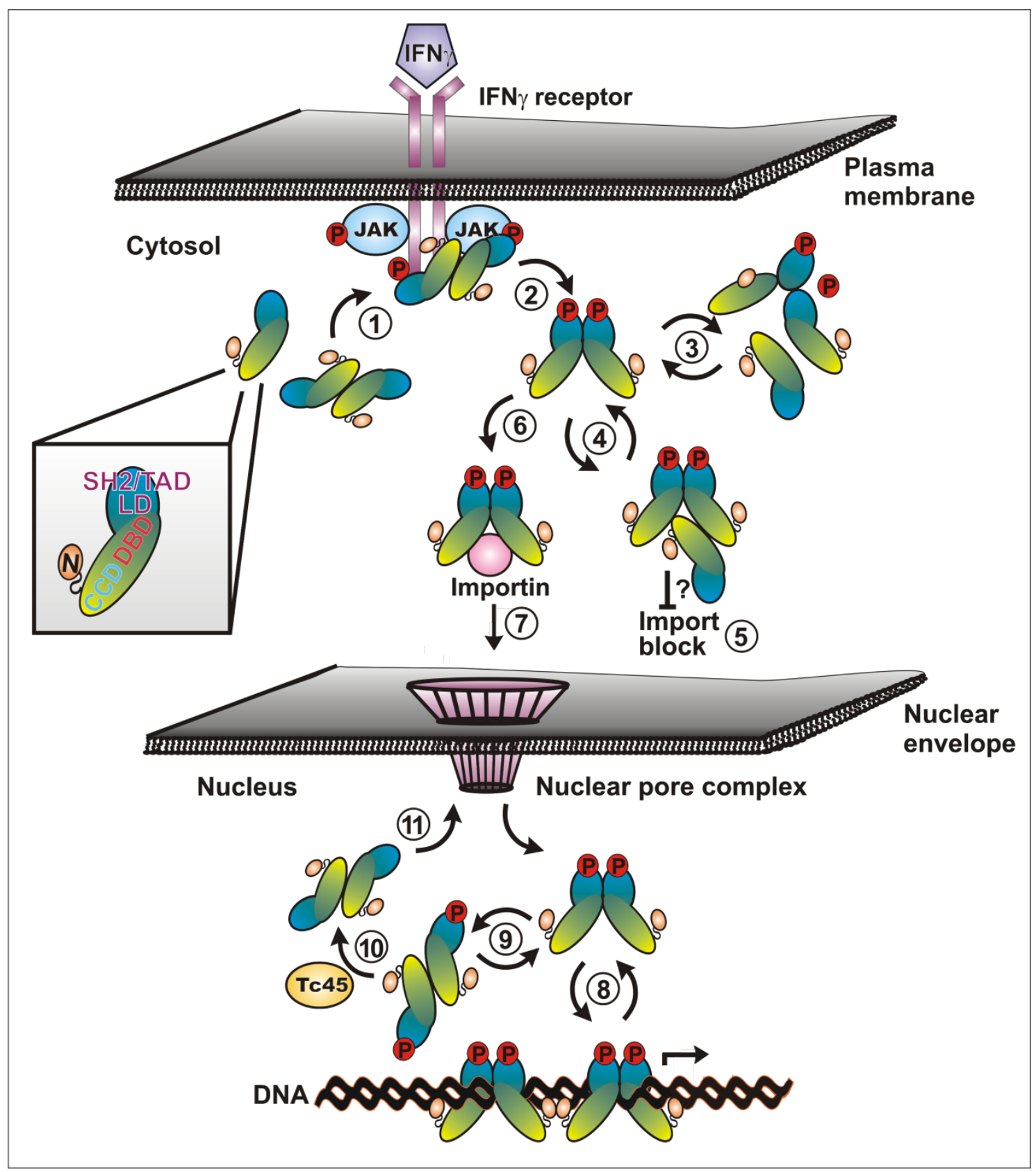

Abb. 35: Weiterentwickeltes Modell des Aktivierungs- und Inaktivierungszyklus von STAT1. Darstellung des JAK-STAT-Signalwegs mit hypothetischem Importblock aufgrund der Ausbildung eines inhibitorisch wirkenden, trimeren Komplexes. JAK-induzierte Tyrosin-Phosphorylierung (1) und Bildung eines parallelen Phospho-STAT1-Dimers (2), Dissoziation (3) und Reassoziation der Dimere (4), Bindung eines phosphorylierten oder unphosphorylierten STAT1Monomers in antiparalleler Konformation an eines der beiden Partner-Protomere des parallelen Phospho-Dimers (5), wodurch das Dimer-spezifische NLS für Importin- $\alpha 5$ maskiert wird, For- 
mierung eines Import-geeigneten Komplexes (6) mit Translokation des Komplexes in den Zellkern (7), DNA-Bindung unter Ausbildung von Tetrameren mit Aktivierung der Genexpression bzw. Dissoziation von DNA (8), Konformationsshift von parallelem zu antiparallelem Dimer nach DNA-Dissoziation (9), TC45-katalysierte Dephosphorylierung (10) und anschließender Export des dephosphorylierten STAT1 aus dem Zellkern (11).

Die physiologische Konsequenz dieses hypothetischen Modells liegt in der inhibitorischen Funktion des monomeren STAT1, welches den Import eines Phospho-STAT1-Dimers verhindert, womit eine hohe Schwelle für das intrazelluläre phosphorylierte STAT1 entsteht, in den Zellkern zu transloziert und dort als Aktivator der Transkription zu fungieren.

IFN $\gamma$ übernimmt im Organismus eine antiproliferative, eine antivirale und proapoptotische Funktion und führt durch Priming zu einer erhöhten STAT1Expression in präexponierten Zellen (Boehm et al. 1997). Die inhibitorische Funktion von monomerem STAT1 würde sicherstellen, dass die nukleäre Akkumulation in Zellen nur dann begünstigt wird, wenn diese einer hohen Konzentration von extrazellulären Zytokinen ausgesetzt sind.

Bei ausgeprägter Ligandenbesetzung der IFN $\gamma$-Rezeptoren resultiert die Zytokinstimulation in hohen intrazellulären Konzentrationen von phosphory-ierten STAT1-Dimeren und gleichzeitig nimmt die Anzahl an STAT1-Mono-meren im Zytoplasma ab. Bei ausreichender Rezeptorstimulation verringert sich die molare Konzentration von unphosphoryliertem STAT1 zugunsten der von PhosphoDimeren, da nun vermehrt parallele STAT1-Dimere gebildet werden. Der antagonisierende Effekt des STAT1-Protomers würde damit vielleicht weniger wirksam sein und damit die Wahrscheinlichkeit erhöht, dass das nukleäre Lokalisationssignal nun für das Importmolekül Importin- $\alpha 5$ frei zugänglich wäre. Letzten Endes wird bei Überschreiten einer bestimmten Schwelle alles phosphorylierte und aktivierte, dimere STAT1 vom Zytoplasma in den Zellkern transloziert, und es kommt über die Bindung an palindrome DNA-Sequenzen zur Aktivierung von STAT1-Zielgenen. Die transkriptionelle Wirkung wird erst bei hoher Zytokinstimulation am Rezeptor eingeleitet, dann jedoch in einem hohen Maße zu einer STAT1-Aktivierung beitragen. Die Aktivierung von STAT1-Zielgenen wird in diesem Modell durch ein ,Alles oder Nichts'-Prinzip erreicht, wobei unphosphoryliertes STAT1 als sein eigener Inhibitor des Kernimports fungiert. 
Die hier getroffenen Annahmen werden durch die fluoreszenzmikroskopischen Aufnahmen der hyperphosphorylierten R274W- und Q275A-Mutanten unterstützt, da in diesen der rasche Kernimport der zwei GOF-Mutationen nach Zytokinstimulation ersichtlich wird. Die in dieser Arbeit gewonnenen Erkenntnisse könnten unser Wissen über den Aktivierungs- und Inaktivierungsprozess der STAT1-Moleküle erweitert haben. Dennoch sind weitere Experimente nötig, um den molekularen Mechanismus dieser klinisch relevanten und interessanten STAT1-GOF-Mutationen weiter zu entschlüsseln. Die beschriebenen Resultate könnten für unser Verständnis der STAT1-vermittelten Genexpression eine wichtige Grundlage für weitere Foschungsanstrengungen geliefert haben. Doch zusätzliche Experimente werden für die Verifizierung benötigt, dass in der Tat unphosphoryliertes, monomeres STAT1 über die Maskierung des nukleären Lokalisationssignals den Kernimport und somit die vollständige Geninduktion von transkriptionell aktivem dimerem STAT1 verhindert. 


\section{$5 \quad$ Zusammenfassung}

Heterozygote Gain-of-Function(GOF)-Mutationen im Transkriptionsfaktor STAT1 (Signaltransduktor und Aktivator der Transkription 1) resultieren in einer vermehrten Expression von zytokinregulierten Zielgenen. Durch diese transkriptionelle Überaktivität und die damit verbundene fehlgeleitete Immunantwort kann es zum Ausbruch einer chronischen mukokutanen Candidiasis kommen (CMC). Über die zu Grunde liegende molekularen Mechanismen dieser pathogenen Missense-Mutationen ist bisher wenig bekannt. Die als CMC-Auslöser bekannte STAT1-GOF-Mutation R274W und ein nach Alanin mutierter benachbarter Glutaminrest an Position 275 wurden in dieser Arbeit genauer charakterisiert. Beide hier generierten Substitutionsmutanten zeigten ein erhöhtes Tyrosin-Phosphorylierungsniveau, eine verlängerte nukleäre Akkumulationsdauer und eine gesteigerte transkriptionelle Aktivität nach Stimulation der Zellen mit Interferon- $\gamma$ (IFN $\gamma)$. In Versuchen zur DNA-Dissoziationskinetik und sequenzspezifischem Bindungsverhalten mit hoch-affinen STAT1-Bindestellen, sogenannten gamma-activated-sites (GAS), ergaben sich zwischen den STAT1Mutanten und dem Wildtyp-Molekül keine Unterschiede. Weiterhin zeigten die in der Coiled-coil-Domäne lokalisierten Punktmutanten ein normales Tetramerisierungsverhalten. Unvorhergesehenerweise haben sich keine Unterschiede im Dephosphorylierungs-Assay mit STAT1-spezifischer TC45-Phosphatase zwischen den mutierten Varianten und dem Wildtyp-Protein aufgetan. Die STAT1-GOF-Mutanten R274W und Q275A ließen sich im Gegensatz zu anderen, bereits näher charakterisierten GOF-Mutationen, einwandfrei durch die TC45-Phosphatase dephosphorylieren. In Anwesenheit von doppel-strängigen GAS-Proben waren die STAT1-Mutanten sowie das Wildtyp-Protein vor Inaktivierung geschützt. Darüber hinaus ließen sich auch in einem Phosphorylierungs-Assay mit Janus-Kinase 2 (JAK2) keine Unterschiede in kinetischen Messungen dokumentieren, so dass der Phänotyp dieser Mutanten weder aus einem TC45-katalysierten Dephosphorylierungsdefekt noch aus einer gesteigerten JAK-induzierten Aktivierung am Rezeptor resultiert. Die Ergebnisse aus einem Experiment zum nukleären Akkumulationsverhalten unterstützen die Annahme, dass die beiden hyperphosphorylierten Mutanten R274W und Q275A 
als Systemmutationen anzusehen sind. Nach nur 10-minütiger Stimulation mit IFN $\gamma$ war eine vollständige Kernakkumulation dieser zwei Mutanten fluoreszenzmikroskopisch ersichtlich, wohingegen das Wildtyp-Molekül zu diesem frühen Zeitpunkt noch vorwiegend im Zytoplasma lokalisiert war. Die kritischen Aminosäurereste an Position 274 und 275 liegen im Zentrum der Interaktionsfläche zweier STAT1-Protomere in antiparalleler Konformation. Basierend auf den Ergebnissen dieser Arbeit wird ein hypothetisches Modell vorgestellt, in dem ein (unphosphoryliertes) STAT1-Molekül einen trimeren Komplex mit einem parallelen Phospho-STAT1-Dimer bildet, der den Kernimport inhibiert. Kommt es durch eine GOF-Mutation an dieser interdimerischen Interaktionsfläche zur Instabilität der hypothetischen trimeren Komplexes, resultiert dies in einer vorzeitigen Kernakkumulation und führt durch DNA-Bindung zu einem Schutz vor enzymatischer Dephosphorylierung durch die STAT1-spezifische TC45-Phosphatase. 


\section{Summary}

Heterozygous gain-of-function (GOF) mutations in the transcription factor STAT1 (signal transductor and activator of transcription 1) result in increased expression of cytokine-regulated target genes. The abnormally high transcriptional activation mediated by these mutants usually results in misdirected immune responses and the development of chronic mucocutaneous candidiasis (CMC). However, little is known about the underlying molecular mechanisms mediated by these pathogenic missense mutations. The CMC-associated GOF mutation R274W and a substitution mutation of the neighboring glutamine residue at position 275 were further characterized in this study. Upon stimulation of cells with interferon- $\gamma$ (IFN $\gamma$ ), the two substitution mutants displayed an increased tyrosine phosphorylation level, a prolonged nuclear accumulation and an increased transcriptional response. Kinetic studies on DNA dissociation from high-affinity binding elements, known as gamma-activated sites (GAS), and sequence-specific binding to DNA revealed no differences between the mutant and wild-type molecules. Furthermore, the two point mutants localized in the coiled-coil domain showed normal tetramer stability on DNA. Unexpectedly, there were no differences in an in vitro dephosphorylation assay using the STAT1-specific TC45 phosphatase between the STAT1 variants. In contrast to other previously characterized GOF mutations, the STAT1 GOF mutants R274W and Q275A were normally dephosphorylated by the phosphatase, and, in the presence of double-stranded GAS sites, all STAT1 variants were protected from TC45-catalyzed enzymatic inactivation. In addition, no differences were found in a phosphorylation assay with Janus kinase 2 (JAK2), excluding that the phenotype of these mutants results either from a TC45-catalyzed dephosphorylation defect or from increased JAK-induced activation. Results from a nuclear accumulation experiment support the assumption that the two hyperphosphorylated mutants R274W and Q275A must be regarded as system mutants. Already 10 minutes after stimulation of the cells with IFN $\gamma$, complete nuclear accumulation of the two GOF mutants was achieved, whereas at this early time point, the wild-type molecule was still predominantly located in the cytoplasm. The two critical amino acid residues 274 and 275 are located in the center of the binding interface between two STAT1 protomers aligned in antiparallel conformation. Based on the results from this study, a hypothetical model is pre- 
sented in which an unphosphorylated STAT1 molecule forms a trimeric complex with a parallel phospho-dimer, which inhibits its own nuclear import by masking a dimer-specific nuclear localization signal in the two DNA-binding domains. A GOF mutation localized at the interdimeric interaction surface may destabilize the hypothetical trimeric complex, resulting in premature nuclear accumulation and DNA binding of dimeric STAT1, which is then protected against enzymatic dephosphorylation by the inactivating TC45 phosphatase. 


\section{$6 \quad$ Literaturverzeichnis}

Bach EA, Aguet M, Schreiber RD (1997): The IFNy receptor: a paradigm for cytokine receptor signaling. Annu. Rev. Immunol. 15, 563-591

Baran-Marszak F (2004): Differential roles of STAT1 and STAT1 in fludarabineinduced cell cycle arrest and apoptosis in human B cells. Blood 104, 2475-2483 Barillas-Mury C, Han YS, Seeley D, Kafatos FC (1999): Anopheles gambiae AgSTAT, a new insect member of the STAT family, is activated in response to bacterial infection. EMBO J 18, 959-967

de Beaucoudrey L, Puel A, Filipe-Santos O, Cobat A, Ghandil P, Chrabieh M, Feinberg J, von Bernuth $\mathrm{H}$, Samarina $A$, Jannière $L$, et al. (2008): Mutations in STAT3 and IL12RB1 impair the development of human IL-17-producing T cells. J. Exp. Med. Sci. 205, 1543-1550

Begitt A, Meyer T, van Rossum M, Vinkemeier U (2000): Nucleocytoplasmic translocation of Stat1 is regulated by a leucine-rich export signal in the coiledcoil domain. Proc. Natl. Acad. Sci. $\underline{97}$, 10418-10423

Begitt A, Droescher M, Meyer T, Schmid CD, Baker M, Antunes F, Knobeloch KP, Owen MR, Naumann R, Decker T, Vinkemeier U (2008): STAT1cooperative DNA binding distinguishes type 1 from type 2 interferon signaling. Nat. Immunol. 15 168-176.

Boehm U, Klamp T, Groot M, Howard JC (1997): Cellular responses to interferon-y. Annu. Rev. Immunol. 15, 749-795

Boisson-Dupuis S, Kong X-F, Okada S, Cypowyj S, Puel A, Abel L, Casanova $J-L$ (2012): Inborn errors of human STAT1: allelic heterogeneity governs the diversity of immunological and infectious phenotypes. Curr. Opin. Immunol. $\underline{24}$, 364-378

Bork P, Holm L, Sander C (1994): The immunoglobulin fold: structural classification, sequence patterns and common core. J. Mol. Biol. 242, 309-320

Casanova J-L, Abel L (2002): Genetic dissection of immunity to mycobacteria: the human model. Annu. Rev. Immunol. 20, 581-620 
Chang CH, Hammer J, Loh JE, Fodor WL, Flavell RA (1992): The activation of major histocompatibility complex class I genes by interferon regulatory factor-1 (IRF-1). Immunogenetics $\underline{35}$, 378-384

Chapgier A, Wynn RF, Jouanguy E, Filipe-Santos O, Zhang S, Feinberg J, Hawkins K, Casanova JL, Arkwright PD (2006a): Human complete stat-1 deficiency is associated with defective type I and II IFN responses in vitro but immunity to some low virulence viruses in vivo. J. Immunol. 176 , 5078-5083

Chapgier A, Boisson-Dupuis S, Jouanguy E, Vogt G, Feinberg J, ProchnickaChalufour A, Casrouge A, Yang K, Soudais C, Fieschi C, et al. (2006b): Novel stat1 alleles in otherwise healthy patients with mycobacterial disease. PLoS Genetics 2, e131

Chapgier A, Kong X-F, Boisson-Dupuis S, Jouanguy E, Averbuch D, Feinberg J, Zhang S-Y, Bustamante J, Vogt G, Lejeune J, et al. (2009): A partial form of recessive STAT1 deficiency in humans. J. Clin. Invest. 119, 1502-1514

Chen X, Vinkemeier U, Zhao Y, Jeruzalmi D, Darnell JE, Kuriyan J (1998): Crystal structure of a tyrosine phosphorylated Stat-1 dimer bound to DNA. Cell $\underline{93}, 827-839$

Chen X, Bhandari R, Vinkemeier U, Van Den Akker F, Darnell JE, Kuriyan J (2003): A reinterpretation of the dimerization interface of the $\mathrm{N}$-terminal domains of STATs. Prot. Sci. 12, 361-365.

Darnell JE (1997): Stats and gene regulation. Science 277, 1630-1635

Darnell JE, Kerr IM, Stark GR (1994): Jak-stat pathways and transcriptional activation in response to IFNs and other extracellular signaling proteins. Science $\underline{264}, 1415-1421$

Decker T, Kovarik P, Meinke A (1997): GAS elements: a few nucleotides with a major impact on cytokine-induced gene expression. J. Interf. Cytok. Res. 17, $121-134$

Depner M, Fuchs S, Raabe J, Frede N, Glocker C, Doffinger R, Gkrania-Klotsas E, Kumararatne D, Atkinson TP, Schroeder HW, et al. (2016): The extended clinical phenotype of 26 patients with chronic mucocutaneous candidiasis due to gain-of-function mutations in stat1. J. Clin. Immunol. $\underline{36}$, 73-84 
Dupuis S (2001): Impairment of mycobacterial but not viral immunity by a germline human stat1 mutation. Science $\underline{293}, 300-303$

Dupuis S, Jouanguy E, Al-Hajjar S, Fieschi C, Al-Mohsen IZ, Al-Jumaah S, Yang K, Chapgier A, Eidenschenk C, Eid P, et al. (2003): Impaired response to interferon- $\alpha / \beta$ and lethal viral disease in human STAT1 deficiency. Nat. Genet. 33, 388-391

Fagerlund R, Melén K, Kinnunen L, Julkunen I (2002): Arginine/lysine-rich nuclear localization signals mediate interactions between dimeric stats and importin a5. J. Biol. Chem. 277, 30072-30078

Fornerod M, Ohno M, Yoshida M, Mattaj IW (1997): CRM1 is an export receptor for leucine-rich nuclear export signals. Cell $\underline{90}, 1051-1060$

Fujiki R, Hijikata A, Shirai T, Okada S, Kobayashi M, Ohara O (2017): Molecular mechanism and structural basis of gain-of-function of STAT1 caused by pathogenic R274Q mutation. J. Biol. Chem. 292, 6240-6254

Görlich D, Kutay U (1999): Transport between the cell nucleus and the cytoplasm. Annu. Rev. Cell Dev. Biol. 15, 607-660

Greenlund AC, Morales MO, Viviano BL, Yan H, Krolewski J, Schreiber RD (1995): Stat recruitment by tyrosine-phosphorylated cytokine receptors: an ordered reversible affinity-driven process. Immunity $\underline{2}$, 677-687

Haspel RL, Darnell JE (1999): A nuclear protein tyrosine phosphatase is required for the inactivation of Stat1. Proc. Natl. Acad. $\underline{96}, 10188-10193$

Haspel RL, Salditt-Georgieff M, Darnell JE (1996): The rapid inactivation of nuclear tyrosine phosphorylated Stat1 depends upon a protein tyrosine phosphatase. EMBO J. $\underline{15}, 6262-6268$

Hiller J, Hagl B, Effner R, Puel A, Schaller M, Mascher B, Eyerich S, Eyerich K, Jansson AF, Ring J, et al. (2018): STAT1 gain-of-function and dominant negative stat3 mutations impair il-17 and il-22 immunity associated with CMC. J. Invest. Dermatol. $\underline{138}, 711-714$

Horvath CM (2000): STAT proteins and transcriptional responses to extracellular signals. Trends in Biochem. Sci. 25, 496-502

Horvath CM, Wen Z, Darnell JE (1995): A STAT protein domain that determines 
DNA sequence recognition suggests a novel DNA-binding domain. Genes Dev. $\underline{9}, 984-994$

Hüntelmann B, Staab J, Herrmann-Lingen C, Meyer T (2014): A conserved motif in the linker domain of STAT1 transcription factor is required for both recognition and release from high-affinity DNA-binding sites, Plos One $\underline{9}$, e97633

John S, Vinkemeier U, Soldaini E, Darnell JE, Leonard WJ (1999): The significance of tetramerization in promoter recruitment by stat5. Mol. Cell. Biol. 19, 1910-1918

Kawata T, Shevchenko A, Fukuzawa M, Jermyn KA, Totty NF, Zhukovskaya NV, Sterling AE, Mann M, Williams JG (1997): SH2 signaling in a lower eukaryote: a stat protein that regulates stalk cell differentiation in dictyostelium. Cell $\underline{89}, 909-916$

Kisand K, Bøe Wolff AS, Podkrajšek KT, Tserel L, Link M, Kisand KV, Ersvaer E, Perheentupa J, Erichsen MM, Bratanic N, et al. (2010): Chronic mucocutaneous candidiasis in APECED or thymoma patients correlates with autoimmunity to Th17-associated cytokines. J. Exp. Med. 207, 299-308

Kong X-F, Ciancanelli M, Al-Hajjar S, Alsina L, Zumwalt T, Bustamante J, Feinberg J, Audry M, Prando C, Bryant V, et al. (2010): A novel form of human STAT1 deficiency impairing early but not late responses to interferons. Blood $\underline{116}, 5895-5906$

Krebs DL, Hilton DJ (2001): SOCS Proteins: negative regulators of cytokine signaling. Stem Cells $\underline{19}, 378-387$

Kristensen IA, Veirum JE, Møller BK, Christiansen M (2011): Novel STAT1 alleles in a patient with impaired resistance to mycobacteria. J. Clin. Immunol. $\underline{31}$, 265-271

Kudo N, Matsumori N, Taoka H, Fujiwara D, Schreiner EP, Wolff B, Yoshida M, Horinouchi S (1999): Leptomycin B inactivates CRM1/exportin 1 by covalent modification at a cysteine residue in the central conserved region. Proc. Natl. Acad. 96, 9112-9117

Langer JA, Pestka S (1988): Interferon receptors. Immunol. Today $\underline{9}$, 393-400 Levy DE, Darnell JE (2002): STATs: transcriptional control and biological im- 
pact: Signalling. Nat. Rev. Mol. Cell Biol. $\underline{3}, 651-662$

Litterst CM, Pfitzner E (2001): Transcriptional activation by stat6 requires the direct interaction with ncoa-1. J. Biol. Chem. 276, 45713-45721

Liu L, Okada S, Kong X-F, Kreins AY, Cypowyj S, Abhyankar A, Toubiana J, Itan Y, Audry M, Nitschke P, et al. (2011): Gain-of-function human STAT1 mutations impair IL-17 immunity and underlie chronic mucocutaneous candidiasis. J. Exp. Med. 208, 1635-1648

Liu X, Quinn A, E. Chin Y, Fu X-Y (1999): STAT genes found in C. elegans. Science $\underline{285}, 167$

Ma CS, Chew GYJ, Simpson N, Priyadarshi A, Wong M, Grimbacher B, Fulcher DA, Tangye SG, Cook MC (2008): Deficiency of Th17 cells in hyper IgE syndrome due to mutations in STAT3. J. Exp. Med. 205, 1551-1557

Mao X, Ren Z, Parker GN, Sondermann H, Pastorello MA, Wang W, McMurray JS, Demeler B, Darnell JE, Chen X (2005): Structural bases of unphosphorylated stat1 association and receptor binding. Mol. Cell $\underline{17}, 761-771$

Marg A, Shan Y, Meyer T, Meissner T, Brandenburg M, Vinkemeier U (2004): Nucleocytoplasmic shuttling by nucleoporins Nup153 and Nup214 and CRM1dependent nuclear export control the subcellular distribution of latent Stat1. J. Cell Biol. 165, 823-833

Mattaj IW, Englmeier L (1998): Nucleocytoplasmic transport: the soluble phase. Annu. Rev. Biochem. 67, 265-306

McBride KM, Banninger G, McDonald C, Reich NC (2002): Regulated nuclear import of the STAT1 transcription factor by direct binding of importin- $\alpha$. EMBO J. $\underline{21}, 1754-1763$

Mertens C, Zhong M, Krishnaraj R, Zou W, Chen X, Darnell JE (2006): Dephosphorylation of phosphotyrosine on STAT1 dimers requires extensive spatial reorientation of the monomers facilitated by the $\mathrm{N}$-terminal domain. Genes Dev. 20, 3372-3381

Meyer T, Vinkemeier U (2004): Nucleocytoplasmic shuttling of STAT transcription factors. Euro. J. Bio. $\underline{271}, 4606-4612$

Meyer T, Begitt A, Lödige I, Rossum M van, Vinkemeier U (2002): Constitutive 
and IFN- $y$-induced nuclear import of STAT1 proceed through independent pathways. EMBO J. 21, 344-354

Meyer T, Marg A, Lemke P, Wiesner B, Vinkemeier U (2003): DNA binding controls inactivation and nuclear accumulation of the transcription factor Stat1. Gen. Dev. 17, 1992-2005

Meyer T, Hendry L, Begitt A, John S, Vinkemeier U (2004): A single residue modulates tyrosine dephosphorylation, oligomerization, and nuclear accumulation of stat transcription factors. J. Biol. Chem. $\underline{279}, 18998-19007$

Milner JD, Brenchley JM, Laurence A, Freeman AF, Hill BJ, Elias KM, Kanno Y, Spalding C, Elloumi HZ, Paulson ML, et al. (2008): Impaired TH17 cell differentiation in subjects with autosomal dominant hyper-lgE syndrome. Nature $\underline{452}$, $773-776$

Minegishi Y, Saito M, Tsuchiya S, Tsuge I, Takada H, Hara T, Kawamura N, Ariga T, Pasic S, Stojkovic O, et al. (2007): Dominant-negative mutations in the DNA-binding domain of STAT3 cause hyper-IgE syndrome. Nature $\underline{448}, 1058-$ 1062

Mössner R, Diering N, Bader O, Forkel S, Overbeck T, Gross U, Grimbacher B, Schön MP, Buhl T (2016): Ruxolitinib induces interleukin 17 and ameliorates chronic mucocutaneous candidiasis caused by stat1 gain-of-function mutation. Clin. Infect. Dis. $\underline{62}, 951-953$

Nardozzi J, Wenta N, Yasuhara N, Vinkemeier U, Cingolani G (2010): Molecular basis for the recognition of phosphorylated stat1 by importin a5. J. Mol. Biol. $\underline{402}, 83-100$

Oates AC, Wollberg P, Pratt SJ, Paw BH, Johnson SL, Ho RK, Postlethwait JH, Zon LI, Wilks AF (1999): Zebrafishstat3 is expressed in restricted tissues during embryogenesis andstat1 rescues cytokine signaling in aSTAT1-deficient human cell line. Dev. Dyn. 215, 352-370

Ouchi T, Lee SW, Ouchi M, Aaronson SA, Horvath CM (2000): Collaboration of signal transducer and activator of transcription 1 (STAT1) and BRCA1 in differential regulation of IFN-y target genes. Proc. Natl. Acad. $\underline{97}, 5208-5213$

Pascal A, Riou J-F, Carron C, Boucaut J-C, Umbhauer M (2001): Cloning and developmental expression of STAT5 in Xenopus laevis. Mech. Develop. 106, 
$171-174$

Platanias LC (2005): Mechanisms of type-I- and type-II-interferon-mediated signalling. Nat. Rev. Immunol. $\underline{5}, 375-386$

Puel A, Döffinger R, Natividad A, Chrabieh M, Barcenas-Morales G, Picard C, Cobat A, Ouachée-Chardin M, Toulon A, Bustamante J, et al. (2010a): Autoantibodies against IL-17A, IL-17F, and IL-22 in patients with chronic mucocutaneous candidiasis and autoimmune polyendocrine syndrome type I. J. Exp. Med. $\underline{207}, 291-297$

Puel A, Picard C, Cypowyj S, Lilic D, Abel L, Casanova J-L (2010b): Inborn errors of mucocutaneous immunity to Candida albicans in humans: a role for IL17 cytokines? Curr. Opin. Immunol. 22, 467-474

Puel A, Cypowyj S, Maródi L, Abel L, Picard C, Casanova J-L (2012): Inborn errors of human IL-17 immunity underlie chronic mucocutaneous candidiasis: Current Opinion in Allergy and Clinical Immunology 12, 616-622 Rawlings JS, Rosler KM, Harrison DA (2004): The JAK/STAT signaling pathway. J. Cell Sci. $\underline{117}, 1281-1283$

Renner ED, Rylaarsdam S, Aňover-Sombke S, Rack AL, Reichenbach J, Carey JC, Zhu Q, Jansson AF, Barboza J, Schimke LF, et al. (2008): Novel signal transducer and activator of transcription 3 (STAT3) mutations, reduced TH17 cell numbers, and variably defective STAT3 phosphorylation in hyper-lgE syndrome. J. Allergy Clin. Immunol. 122, 181-187

Schindler C, Darnell J (1995): Transcriptional responses to polypeptide ligands: the jak-stat pathway. Annu. Rev. of Biochem. 64, 621-652 Schindler C, Shuai K, Prezioso VR, Darnell JE (1992a): Interferon-dependent tyrosine phosphorylation of a latent cytoplasmic transcription factor. Science $\underline{257}, 809-813$

Schindler C, Fu XY, Improta T, Aebersold R, Darnell J, Jr (1992b): Proteins of transcription factor ISGF-3: one gene encodes the 91-and 84-kDa ISGF-3 proteins that are activated by interferon alpha. Proc. Natl. Acad. $\underline{89}$, 7836-7839

Schooltink H, Rose-John S (2002): Cytokines as therapeutic drugs. J. Interf. Cytok. Res. 22, 505-516 
Sekimoto T, Imamoto N, Nakajima K, Hirano T, Yoneda Y (1997): Extracellular signal-dependent nuclear import of Stat1 is mediated by nuclear pore-targeting complex formation with NPI-1, but not Rch1. EMBO J. 16, 7067-7077

Shuai K, Schindler C, Prezioso VR, Darnell JE (1992): Activation of transcription by IFN-gamma: tyrosine phosphorylation of a $91-k D$ DNA binding protein. Science $\underline{258}, 1808-1812$

Shuai K, Stark GR, Kerr IM, Darnell JE (1993a): A single phosphotyrosine residue of Stat91 required for gene activation by interferon-gamma. Science $\underline{261}$, 1744-1746

Shuai K, Ziemiecki A, Wilks AF, Harpur AG, Sadowski HB, Gilman MZ, Darnell JE (1993b): Polypeptide signalling to the nucleus through tyrosine phosphorylation of Jak and Stat proteins. Nature $\underline{366}, 580-583$

Shuai K, Horvath CM, Huang LHT, Qureshi SA, Cowburn D, Darnell JE (1994): Interferon activation of the transcription factor Stat91 involves dimerization through SH2-phosphotyrosyl peptide interactions. Cell $\underline{76}, 821-828$

Soltész B, Tóth B, Shabashova N, Bondarenko A, Okada S, Cypowyj S, Abhyankar A, Csorba G, Taskó S, Sarkadi AK, et al. (2013): New and recurrent gain-of-function STAT1 mutations in patients with chronic mucocutaneous candidiasis from Eastern and Central Europe. J. Med. Gen. $\underline{50}, 567-578$

Spellberg BJ, Filler SG, Edwards JE (2006): Current treatment strategies for disseminated candidiasis. Clin. Infect. Dis. 42, 244-251

Staab J, Herrmann-Lingen C, Meyer T (2013a): A rapid conformational rearrangement of STAT1 dimers is required for termination rather than for amplification of interferon- $y$ signaling. JAK-STAT $\underline{2}$, e23576

Staab J, Herrmann-Lingen C, Meyer T (2013b): Clinically Relevant Dimer Interface Mutants of STAT1 Transcription Factor Exhibit Differential Gene Expression. Plos One $\underline{8}$, e69903

Starr R, Hilton DJ (1999): Negative regulation of the JAK/STAT pathway. BioEssays $\underline{21}, 47-52$

Sung S-C, Fan T-J, Chou C-M, Leu J-H, Hsu Y-L, Chen S-T, Hsieh Y-C, Huang C-J (2003): Genomic structure, expression and characterization of a STAT5 
homologue from pufferfish (Tetraodon fluviatilis). Euro. J. Biochem. 270, 239252

Takezaki S, Yamada M, Kato M, Park M, Maruyama K, Yamazaki Y, Chida N, Ohara O, Kobayashi I, Ariga T (2012): Chronic mucocutaneous candidiasis caused by a gain-of-function mutation in the stat1 DNA-binding domain. J. Immunol. $\underline{189}, 1521-1526$

Ten Hoeve J, de Jesus Ibarra-Sanchez M, Fu Y, Zhu W, Tremblay M, David M, Shuai K (2002): Identification of a Nuclear Stat1 Protein Tyrosine Phosphatase. Mol. Cell. Biol. 22, 5662-5668

Toubiana J, Okada S, Hiller J, Oleastro M, Lagos Gomez M, Aldave Becerra JC, Ouachee-Chardin M, Fouyssac F, Girisha KM, Etzioni A, et al. (2016): Heterozygous STAT1 gain-of-function mutations underlie an unexpectedly broad clinical phenotype. Blood 127, 3154-3164

van de Veerdonk FL, Plantinga TS, Hoischen A, Smeekens SP, Joosten LAB, Gilissen C, Arts P, Rosentul DC, Carmichael AJ, Smits-van der Graaf CAA, et al. (2011): STAT1 mutations in autosomal dominant chronic mucocutaneous candidiasis. N. Engl. J. Med. $\underline{365}, 54-61$

Vinkemeier U, Cohen SL, Moarefi I, Chait BT, Kuriyan J, Darnell JE (1996): DNA binding of in vitro activated Stat1 alpha, Stat1 beta and truncated Stat1: interaction between $\mathrm{NH}$-terminal domains stabilizes binding of two dimers to tandem DNA sites. EMBO J. $\underline{15}, 5616-5626$

Walter MJ, Look DC, Tidwell RM, Roswit WT, Holtzman MJ (1997): Targeted inhibition of interferon-y-dependent intercellular adhesion molecule-1 (icam-1) expression using dominant-negative stat1. J. Biol. Chem. 272, 28582-28589

Weis K (1998): Importins and exportins: how to get in and out of the nucleus. Trends Biochem. Sci. 23, 185-189

Wen Z, Zhong Z, Darnell JE (1995): Maximal activation of transcription by stat1 and stat 3 requires both tyrosine and serine phosphorylation. Cell $\underline{82}, 241-250$

Wenta N, Strauss H, Meyer S, Vinkemeier U (2008): Tyrosine phosphorylation regulates the partitioning of STAT1 between different dimer conformations. Proc. Natl. Acad. 105, 9238-9243 
Williams JG (1999): Serpentine receptors and STAT activation: more than one way to twin a STAT. Trends Biochem. Sci. 24, 333-334

Yan R, Small S, Desplan C, Dearolf CR, Darnell JE (1996): Identification of a stat gene that functions in drosophila development. Cell $\underline{84}, 421-430$

Yang E, Wen Z, Haspel RL, Zhang JJ, Darnell JE (1999): The linker domain of stat1 is required for gamma interferon-driven transcription. Mol. Cellular Biol. $\underline{19}, 5106-5112$

Yang E, Henriksen MA, Schaefer O, Zakharova N, Darnell JE (2002): Dissociation time from DNA determines transcriptional function in a STAT1 linker mutant. J. Biol. Chem. 277, 13455-13462

Zhang JJ, Vinkemeier U, Gu W, Chakravarti D, Horvath CM, Darnell JE (1996): Two contact regions between Stat1 and CBP/p300 in interferon y signaling. Proc. Natl. Acad. 93, 15092-15096

Zhang JJ, Zhao Y, Chait BT, Lathem WW, Ritzi M, Knippers R, Darnell JE (1998): Ser727-dependent recruitment of MCM5 by Stat1 alpha in IFN-gammainduced transcriptional activation. EMBO J. 17, 6963-6971

Zhong M, Henriksen MA, Takeuchi K, Schaefer O, Liu B, Hoeve J ten, Ren Z, Mao X, Chen X, Shuai K, Darnell JE (2005): Implications of an antiparallel dimeric structure of nonphosphorylated STAT1 for the activation-inactivation cycle. Proc. Natl. Acad. 102, 3966-3971 


\section{Danksagung}

Die Danksagung möchte ich nutzen, um mich im besonderen Maße bei meinem überaus engagierten Doktorvater Prof. Dr. mult. Thomas Meyer zu bedanken. Es hat mir sehr viel Freude bereitet, einen Einblick in das wissenschaftliche Arbeiten zu erlangen, die Möglichkeit zu bekommen, selbständig all die verschiedenen Experimente im Labor durchzuführen und dabei stets Hilfestellung, Rückmeldung und Unterstützung zu erhalten. Die experimentelle Dissertation hat mein Medizinstudium sehr bereichert, da ich sonst nicht die Möglichkeit bekommen hätte, einen solch detaillierten Einblick in die Grundlagenforschung zu erlangen und wissenschaftliche Diskussionen zu führen. Für die Bereitstellung des interessanten Themas, die Übernahme des Erstgutachtens und all die motivierenden und fachlich belebenden Gespräche möchte ich mich herzlich bedanken.

Darüber hinaus möchte ich im besonderen Maße Prof. Dr. rer. nat. Susanne Lutz für die Übernahme des Zweitgutachtens und die vielfältigen Anregungen und Vorschläge während meiner Thesis-Komitee-Treffen danken.

Frau Prof. Dr. med. Dörthe Katschinski als Sprecherin und Initiatorin der International Research Training Group (IRTG) 1618 danke ich für die Aufnahme als Stipendiatin. Das IRTG mit dem Forschungsschwerpunkt ,Herzerkrankungen“ wird durch die Deutsche Forschungsgemeinschaft finanziert und stellt eine Kooperation zwischen dem Herzzentrum der Universitätsmedizin Göttingen und der Kardiovaskulären Abteilung des King's College in London dar. Als Graduiertenschule bietet das IRTG neben einem strukturierten internationalen DreiJahres-Plan für naturwissenschaftliche Doktoranden auch Medizinstudenten die Möglichkeit einer exzellenten Betreuung während des wissenschaftlichen Dissertationsprojekts. Ich erhielt eine hervorragende Supervision, die Möglichkeit zur Teilnahme an interessanten wissenschaftlichen Vorträgen und das Privileg, mit anderen erfahrenen naturwissenschaftlichen Doktoranden in Kontakt zu treten, um sich über deren und das eigene Projekt auszutauschen. Im Rahmen der Zusammenarbeit erhielt ich die großartige Möglichkeit für zwei Wochen nach London zu reisen, wo ich unter der Leitung von Dr. Alexander Ivetic in den 
Laboratorien des King's College in der Abteilung Cardiovascular Science im James Black Centre Fluoreszenzaufnahmen anfertigen durfte. Vielen Dank, Alexander Ivetic, für die tolle Betreuung während dieser Zeit.

Ohne diese vielfältige Unterstützung und enge Einbindung in die Graduiertenschule hätte ich mein anspruchsvolles Dissertationsprojekt nicht gemeistert.

Darüber hinaus bedanke ich mich herzlich bei den medizinisch-technischen Assistentinnen Anke Gregus und Heike Hühn, ohne deren Unterstützung weder das wissenschaftliche Experimentieren möglich noch die Freude daran so groß gewesen wäre.

Weiterhin haben zur Freude am Arbeiten im Labor viele meiner tollen Kollegen beigetragen; ganz besonders bedanken möchte ich mich bei Julian Sachs, Asma Doudin und Julia Staab für die Unterstützung und all die wissenschaftlichen und nicht-wissenschaftlichen Gespräche, die zu einer motivierenden Stimmung und einer erfolgreichen Dissertation beigetragen haben. 


\section{Lebenslauf}

Mein Name ist Jana Petersen, geboren als zweites Kind am 10.06.1992 in Wolfenbüttel. Meine Eltern sind die Eheleute Ulrike Petersen (Apothekerin) und Dirk Petersen (Dipl.-Ing.). Ich habe zwei Geschwister. Das Abitur absolvierte ich 2011 an der Ricarda-Huch-Schule in Braunschweig.

Im Oktober 2011 begann mein Studium an der Georg-August-Universität Göttingen als Lehramtsstudentin für die Fächer Chemie und Biologie. Nach einem Semester fiel die Entscheidung, mich um einen Studienplatz in Humanmedizin zu bewerben.

Im April 2012 nahm ich das Studium der Humanmedizin an der Georg-AugustUniversität Göttingen auf. Während des Studiums sammelte ich erste Erfahrungen und Einblicke in die ärztlichen Tätigkeiten bei meinen Famulaturen in den Abteilungen Kardiologie (Klinikum Braunschweig), Allgemeinmedizin (Göttingen), Anästhesie (Universitätsklinikum Göttingen) und Psychosomatische Medizin und Psychotherapie (Universitätsklinikum Göttingen).

Nach meiner Vorstellung bei Prof. Dr. mult. Thomas Meyer und seiner Übernahme des Erstgutachtens im September 2016 begann der ein halbes Jahr andauernde experimentelle Teil meiner Promotionstätigkeit im Labor für Molekulare Psychokardiologie in der Klinik für Psychosomatische Medizin und Psychotherapie in Göttingen. Als Stipendiatin der International Research Training Group 1816 (IRTG 1816) verbrachte ich während dieser Zeit zwei Wochen in den Laboratorien des King's College London in der Abteilung Cardiovascular Science unter der Leitung von Dr. Alexander Ivetic.

Das 2. Saatsexamen absolvierte ich im April 2018 und habe anschließend den schriftlichen Teil meiner Promotionsarbeit verfasst.

Den ersten Teil meines praktischen Jahres verbrachte ich von November 2018 bis Mitte März 2019 in Wien auf der kardiologischen und onkologischen Abteilung des Kaiser-Franz-Josef-Spitals. Anschließend habe ich die folgenden vier Monate in München im Klinikum am Biederstein auf der dermatologischen Station absolviert. Den letzten Abschnitt des praktischen Jahres absolvierte ich in der Chirurgie im Sankt Bernward Krankenhaus in Hildesheim. 
Voraussichtlich werde ich das Studium am 4. Dezember 2019 mit dem 3. Staatsexamen beenden. 